\title{
Characterisation of the cell wall protein Pga29p in the human pathogenic fungus Candida albicans
}

\author{
Dissertation \\ zur Erlangung des Doktorgrades \\ der Mathematisch-Naturwissenschaftlichen Fakultäten \\ der Georg-August-Universität zu Göttingen
}

Vorgelegt von

Albert Daniël de Boer

Geboren in Amsterdam, die Niederlande

Göttingen 2008 
Referent: Prof. Dr. Uwe Gross

Korreferent: Dr. Wilfried Kramer

Tag der mündliche Prüfung: 
To my parents

Jan and Marga de Boer 


\section{Table of Contents}

Table of Contents 1

Acknowledgements

$\begin{array}{ll}\text { Abstract } & 6\end{array}$

1. Introduction 9

1.1 C. albicans: classification, growth, morphology and genetics 9

1.1.1 Classification 9

$\begin{array}{lll}1.1 .2 \text { Growth } & 10\end{array}$

$\begin{array}{lll}\text { 1.1.3 Morphology } & 10\end{array}$

1.1.4 Genetics 11

$\begin{array}{lll}1.2 & \text { Medical relevance } & 12\end{array}$

1.2.1 C. albicans infections and predisposing conditions 12

$\begin{array}{ll}\text { 1.2.2 Epidemiology of invasive candidosis } & 12\end{array}$

$\begin{array}{lll}\text { 1.2.3 Medication } & 13\end{array}$

$\begin{array}{lll}\text { 1.2.4 Resistance to antifungal agents } & 14\end{array}$

$\begin{array}{lll}\text { 1.2.5 Fungal vaccines } & 14\end{array}$

1.3 Virulence factors of C. albicans 15

$1.4 \quad$ The cell wall of $C$. albicans 16

$\begin{array}{lll}\text { 1.4.1 Molecular organisation of the cell wall } & 17\end{array}$

1.4.2 Non-conventional cell wall-associated proteins 18

1.4.3 Covalently linked cell wall proteins and glycosylation 19

$\begin{array}{lll}1.5 & \text { Alkali-sensitive linkage proteins }\end{array}$

1.6 Glycosylphosphatidylinositol modified (GPI) proteins 20

1.6.1 The role of GPI-proteins in the virulence of C. albicans 23

1.7 The Predicted GPI-anchored protein 29 (Pga29p) 26

$\begin{array}{lll}1.8 & \text { Aim of the study } & 27\end{array}$

2. Methods 29

2.1 Chemicals 29

2.2 Kits Plasmids and Enzymes 29

2.3 Table 3. Media used in this study 30 
2.4 Table 4. C. albicans strains used in this study 31

Table 5. E. coli strains used in this study

2.5 Primers that were used in this study 32

2.6 Basic Local Alignment Search Tool (BLAST) 34

2.7 Anti-Pga29p polyclonal antibodies 35

2.7.1 Cloning of PGA29 in the pQE30 expression vector 35

2.7.2 PGA29 overexpression and purification 35

2.7.3 Generation of anti-Pga29p polyclonal antibodies 36

2.8 Cell wall extraction, digestion and immuno blot analysis 36

2.8.1 Cell wall isolation 36

2.8.2 Cell wall digestions with enzymes and chemicals 37

2.8.3 Immuno-blot analysis 38

2.9 PGA29 expression in hyphae 39

2.9.1 RNA isolation from C. albicans 39

2.9.2 Northern blot analysis 39

2.10 PGA29 deletion $\quad 40$

2.10.1 Generation of gene disruption cassettes $\quad 40$

2.10.2 Transformation of C. albicans 41

2.10.3 DNA isolation from C. albicans 41

2.10.4 Southern blotting 42

2.11 Cell wall composition analysis 43

2.11.1 Electron microscopy 43

2.11.2 Chitin determination 43

2.11.3 Protein determination 44

2.11.4 Determination of the mannose/glucose ratio 44

2.11.5 Cell wall proteome of the Apga29/4pga29 mutants 44

2.11.5.1 Sample preparation for MS analysis 44

2.11.5.2 MS analysis 45

2.12 Phenotypic analysis $\quad 45$

2.12.1 Growth determination at different $\mathrm{pH}$ values 45

2.12.2 Growth rate determination with microdilution spot assay 46

2.12.3 $\beta$-1,3-glucanase sensitivity assay 46

2.12.4 Determination of antimycotic susceptibility using E-test 46

2.12.5 Yeast-to-hyphae transition 46 
2.12.6 Hyphae-to-yeast-transition 48

2.12.7 Adhesion assays 48

2.13 Phenotypic analysis in infection models 49

2.13.1 Mouse model for systemic candidosis 49

2.13.2 Reconstituted Human Epithelial model based on oral candidosis 49

$\begin{array}{lll}2.13 .3 & \text { Light microscopy } & 50\end{array}$

2.13.4 Epithelial cell damage assay 50

2.13.5 RNA isolation and quantitative RT-PCR 50

2.13.6 Determination of cytokine release 51

2.14 Interaction assays with immune cells

2.14.1 Primary culture myeloid dendritic cells (mDCs) 51

2.14.2 In vitro interaction of mDCs with C. albicans strains. 51

2.14.3 RNA isolation from mDCs and quantitative RT-PCR 52

2.14.4 Determination of oxidative burst in PMNs upon interaction with C. albicans 52

3. Results 53

$\begin{array}{lll}3.1 & \text { Antibody generation against Pga29p } & 53\end{array}$

3.2 Pga29p incorporation into the cell wall 55

3.3 Pga29p is a yeast-specific protein $\quad 56$

3.3.1 PGA29 expression during the yeast-to-hyphal transition 56

3.3.2 PGA29 expression in mutants that are impaired in hyphal development 57

$3.4 \quad$ Functional analysis of Pga29p 59

3.4.1 Expression under different conditions 59

3.5 Generation of PGA29 deletion mutants 60

3.5.1 Verification of PGA29 deletion 60

3.5.2 Verification of URA3 and PGA29 complementation 63

3.6 Cell wall composition of the $\triangle p g a 29 / \triangle p g a 29$ mutants 66

3.7 Phenotypic analysis of PGA29 deletion mutants 69

3.7.1 Growth rate of $\Delta$ pga29/4pga29 mutants 69

$\begin{array}{ll}\text { 3.7.2 CFW and other cell wall stress } & 70\end{array}$

3.7.3 $\beta$-1,3-glucanase sensitivity assay $\quad 71$

$\begin{array}{lll}3.7 .4 & \text { Sensitivity against antimycotics } & 72\end{array}$

3.8 Is Pga29p redundant?

3.8.1 PGA30 and PGA31 expression in Apga29/Apga29 mutants 72 
3.8.2 Cell wall proteome of the Apga29/_pga29 mutants 73

3.9 Pga29p is involved in systemic candidosis $\quad 83$

3.10 PGA29 deletion does not affect morphology or adhesion of C. albicans 83

3.11 Reconstituted Human Epithelial as model for oral candidosis.

3.11.1 PGA29 expression in C. albicans infected RHE 88

$\begin{array}{lll}3.12 & \text { Pga29p is a potential PAMP } & 88\end{array}$

3.13 Immune response against the Apga29/Apga29 strain 89

3.13.1 Immune response of C. albicans infected RHE 89

3.13.2 Interaction of C. albicans with PMNs and primary dendritic cells 93

$\begin{array}{lll}4 . & \text { Discussion } & 95\end{array}$

4.1 Pga29p incorporation into the cell wall 95

4.2 Pga29p is a yeast-specific protein 96

4.2.1 PGA29 expression during the yeast-to-hyphal transition 96

4.2.2 Expression in the $\Delta e f g 1 / \Delta e f g 1$ and $\Delta e f g 1 / \Delta e f g 1 \Delta c p h l / \Delta c p h 1$ mutants $\quad 97$

4.4 Expression under different conditions 98

$\begin{array}{lll}\text { 4.4.1 Expression under cell wall stress } & 98\end{array}$

4.5 Generation of PGA29 deletion mutants 99

4.6 Cell wall composition of the Apga29/4pga29 mutants 99

$\begin{array}{lll}4.7 & \text { Phenotypic analysis of PGA29 deletion mutants } & 101\end{array}$

4.8 Pga29p is involved in the virulence of $C$. albicans 102

$\begin{array}{lll}4.9 & \text { Pga29p is a potential PAMP } & 104\end{array}$

4.10 Immune response against the Apga29/4pga29 strain 105

4.10.1 Immune response of the RHE 105

4.10.2 Immune response of immune cells 106

$\begin{array}{lll}4.11 & \text { Conclusion } & 107\end{array}$

5. References 109

$\begin{array}{ll}\text { Appendix } & 130\end{array}$

$\begin{array}{ll}\text { Curriculum vitae } & 132\end{array}$ 


\section{Acknowledgements}

I am deeply grateful to God, Who gave me the opportunity to study His creation on molecular level.

I would also like to thank my colleagues, friends and family, who supported me during my

Ph.D. period. I want to give special thanks to those who helped me bringing this Ph.D. thesis into existence. 


\section{Abstract}

Candida albicans is an opportunistic fungal pathogen that is responsible for most of the Candida infections in humans. It can cause superficial infections on the mucosa, nails or skin and in severly immunocompromised individuals it is able to disseminate via the bloodstream and infect deep tissues, which can lead to life-threatening situations. In order to improve the treatment against $C$. albicans infections, a thorough understanding of the pathogenesis on a molecular level is needed. The last two decades, the cell wall of C. albicans has been an interesting object of research for investigators around the world, mainly because this structure is not present in mammalian cells and therefore it is a potential drug target. Moreover, the upper layer of the cell wall consists of mannoproteins that play an important role in the infection process of $C$. albicans.

In this study we characterised Pga29p (Predicted GPI-anchored protein 29), a small glycosylphosphatidylinositol modified cell wall protein (GPI-CWP) that is abundantly present in the yeast cell wall of $C$. albicans. In a previous study, Pga29p was among a small group of 14 cell wall proteins (CWPs) that could be identified with liquid chromatography-tandem mass spectrometry (LC/MS/MS) (De Groot et al., 2004). Putative homologs of Pga29p are mainly found in pathogenic Candida species, but their functional roles during human infection are completely unknown so far.

For characterisation of Pga29p, we raised polyclonal antiserum against recombinant Pga29p, which was used for studying the cell wall incorporation of the protein. Immunoblot analysis of different groups of purified cell wall protein (CWP) fractions, showed that Pga29p is linked to the $\beta$-1,3-glucan framework via $\beta$-1,6-glucan.

As the yeast-to-hyphae transition is of major importance for C. albicans to establish an infection, we monitored the transcriptional and translational levels of PGA29 during hyphal development. In addition, Pga29p levels were determined in a deletion mutant that is locked up in the yeast form and lacks the transcription factors Efg1 and Cph1, both of which are known to be key-regulators of hyphae formation. During the yeast-to-hyphae transition $P G A 29$ gene products were strongly downregulated. In agreement with this, Pga29p levels were upregulated in the $E F G 1 / C P H 1$ deletion mutant compared with the wild type strain SC5314. Taken together, these data show that Pga29p is an abundant, yeast-specific protein that is covalently embedded into the cell wall of $C$. albicans.

To elucidate its function, the level of Pga29p incorporation in the cell wall was systematically determined under different growth conditions and cell (wall) stresses . Only 
yeasts that were exposed to the cell wall perturbant Calcofluor White (CFW) incorporated higher levels of Pga29p in their cell wall, which might indicate that $C$. albicans attempts to stabilise its perturbed cell wall by upregulating Pga29p levels under this specific situation. In order to study the function of Pga29p in more detail, Apga29/4pga29 deletion mutants were generated by using a PCR-based transformation method. Possible structural alterations in the cell wall of this deletion strain were examined by transmission electron microscopy and by quantitiative determination of the different cell wall components. These experiments showed that PGA29 deletion had no direct effect on the thickness of the cell wall and the levels of chitin and protein. However, the mannose/glucose ratio in Apga29/4pga29 cell walls was significantly reduced, indicating the absence of Pga29p results in a reduced mannose level in the cell wall. In order to determine whether PGA29 deletion caused phenotypical changes in C. albicans that could be related to decreased cell wall integrity, we performed assays in which growth, sensitivity to cell wall stress and antimycotics were tested. We could show that the Apga29/4pga29 strain did not exhibit significant differences compared to the control strains. Further investigation was conducted to exclude the possibility that the function of Pga29p was compensated by its family members, Pga30p and Pga31p, or other CWPs. Northern analysis showed that $P G A 30$ and $P G A 31$ were not upregulated in the Apga29/4pga29 strain, indicating that the PGA29 gene is not redundant. This result was confirmed on a translational level, by analysing the full cell wall proteome of the Apga29/4pga29 strain making use of a "cell wall shaving” LC/MS/MS-technique. These comprehensive proteomic analyses further showed that an upregulation of other CWPs is not taking place in the mutant, suggesting that Pga29p does not play a singificant role in maintaining the cell wall integrity in $C$. albicans but might have another function for the yeast-form of this human pathogen.

In order to study a possible role of Pga29p in the establishment of $C$. albicans infection, the Apga29/4pga29 strain was tested in two virulence models: a mouse model of systemic infection and the reconsituted human epithelium (RHE) oral model. Both experiments showed that $P G A 29$ deletion results in a reduction of virulence. The conditions in these virulence models promote the formation of hyphae, a growth form in which PGA29 is downregulated. These data suggest that Pga29p is involved in the initial stages of the infection, where $C$. albicans faces the host in the yeast-morphology. Experiments that tested the adherence capacity and abitlity to form hyphae of the Apga29/4pga29 strain showed that the reduction of virulence was not dependent on these two virulence characteristics. As cell wall mannans are known as important pathogen associated molecular patterns (PAMPs), further experiments 
were conducted to investigate whether the reduced mannan in the Apga29/4pga29 strain could be responsible for altered host cell interactions which may lead to the observed reduced virulence. O-mannosylation of Pga29p by protein- $O$-mannosyltransferase 1 (Pmt1p) was proven by analysis of CWP extracts from $C$. albicans mutants that are deficient in Oglycosylation. RHE infected with the $\Delta p g a 29 / \Delta p g a 29$ strain showed a reduced expression of proinflammatory cytokines. This diminished immune response could be related with the decrease of mannan in the cell wall or the reduced tissue damage that was caused by Apga29/_pga29 strain. However, upon stimulation with Apga29/4pga29 mutants, murine primary dendritic cells (mDCs) and human polymorphonuclear leukocytes (PMNs) did not show altered cytokine or oxidative burst levels, respectively. These results indicate that the reduced virulence may not be related to an altered pathogen host cross-talk via the mannans. We propose that Pga29p is involved in the initial stage of infection, prior to hyphae development, which designates this protein as the first yeast-specific CWP of $C$. albicans that directly plays a role in virulence. 


\section{Introduction}

The opportunistic fungus Candida albicans is a major cause of human fungal infections. These infections may be confined superficially to the mucosa, but in immunocompromised hosts they can develop systemically and ultimately lead to life-threatening situations. Although antifungal therapies are available and recent epidemiological studies reveal a stable or a slightly decreasing trend of systemic infections, C. albicans is still a serious medical problem. It is therefore of great importance to unravel the molecular mechanisms that are involved in the infection process of this pathogen, thereby revealing particular virulence factors which might be putative targets for antifungal drugs development. In the last decade, intensive research has led to a significant increase of our knowledge about $C$. albicans. Despite this fact, unfortunately, powerful therapeutic strategies to combat systemic candidosis did not arise yet. Nevertheless, researchers around the world are confident in finding a solution and are steadfastly continuing their exploration.

In this introduction we will shortly discuss the taxonomy, growth, morphology, genetics and medical relevance of $C$. albicans. Furthermore we describe the cell wall with particular emphasis on the role of glycosylphophatidylinositol modified proteins (GPI-proteins) in virulence.

\subsection{C. albicans: classification, growth, morphology and genetics}

\subsubsection{Classification}

The classification of fungi is primarily based on characteristics of spores and fruiting bodies that are produced during sexual reproduction. However, due to the analyses of PCR-amplified ribosomal RNA genes in the early 1990s (White et al., 1990), the fungal taxonomy has been undergoing a molecular revolution.

Candida species are classified as yeasts and are subdivided in the phylum of the Ascomycota. The genus Candida comprises more than a 150 species, of which only a minority is medically significant. For many years, the absence of any sexual form was considered as the main characteristic that was shared between the Candida species (Odds, 1988). However, it has been shown that $C$. albicans is able to mate in-vitro and in-vivo (Hull et al., 2000) 


\subsubsection{Growth}

C. albicans is capable to adapt itself to a wide range of environmental conditions, for example in vivo it can grow on the relatively acidic vaginal mucosa $(\mathrm{pH} 4.5)$ and in the blood ( $\mathrm{pH} 7.4)$, whereas in vitro it is able grow in the $\mathrm{pH}$ range between 2.5 and 10 and at temperatures ranging from $5^{\circ} \mathrm{C}$ to $46^{\circ} \mathrm{C}$ (Odds, 1988; Hubbard et al., 1986). Optimum growth of $C$. albicans is observed under aerobic conditions, but it is able to grow under anaerobic conditions (Eklund and Jarmund, 1983) elevated concentrations of $\mathrm{CO}_{2}$ (Iralu, 1971; Webster and Odds, 1987). The maximal achieved doubling time is just under one hour (Odds, 1988).

\subsubsection{Morphology}

Already in the $19^{\text {th }}$ century it was reported that C. albicans is able to grow as yeast, pseudohyphae, true hyphae and chlamydospores (Audrey, 1887). A yeast cell (also known as blastospore or blastoconidium) is the unicellular form of C. albicans. Cell division of yeast cells is regulated by a process called 'budding'. In this process a parent cell (mother cell) produces near one of its poles a new cellular out-growth which is designated as the 'bud' or 'daughter cell'. During its development, the bud increases in size and at a certain time point mitosis occurs followed by the generation of septum around the bud-neck, which leads ultimately to cell separation (Odds, 1988).

True hyphae are microscopic tubular structures that contain cells that are separated by septa. A hypha originates from a single elongated yeast cell, known as a 'germ tube', that continuously grows by apical extension. From hyphae new buds may develop that bud off laterally just behind the septa (Odds, 1988). Several factors induce hyphal growth such as temperature $\left(37^{\circ} \mathrm{C}\right)$, a neutral $\mathrm{pH}$ value, $\mathrm{CO}_{2}$ concentration, nutrient deprivation and serum (Odds, 1988).

Although pseudohyphae resemble true hyphae, they appear to be an intermediate form between yeast cells and hyphae. The development of pseudohyphae emerges from a yeast cell or hypha by a process that is very similar to the typical blastospore budding. However, in this case each generation of buds remains attached to each other and the cells form an elongated shape (Odds, 1988; reviewed by Sudbery et al., 2004).

Chlamydospores are spherical, thick-walled cells, that can be three to four time larger than yeast cells. $C$. albicans and $C$. dubliniensis are the only species that are able to produce these structures of which the biological function remains to be elucidated (reviewed by Staib and Morschhäuser, 2007). 


\subsubsection{Genetics}

C. albicans is considered to be the most important fungal species that causes infections in humans and therefore it was one of the first eukaryotic pathogens selected for genome sequencing. Due to its widespread and increasing use in molecular analyses, the genome of the clinical isolate SC5314 was sequenced by the Stanford Genome Technology Center in 1998. The complete and annotated sequence was published in 2004 by Jones et al. (2004) who assembled the diploid genome. The release of the genome sequence facilitated the molecular manipulation of $C$. albicans and it enabled to establish transcript and proteomic profiling projects, which resulted in a considerable increase in the amount of biological data. Two main differences distinguish $C$. albicans from other yeast species, such as the bakers yeast Saccharomyces cerevisiae, which frequently was used as model for C. albicans. For instance, $C$. albicans does not follow the universal codon usage, because it translates the CUG codon in a serine instead of a leucine residue (Santos et al., 1993). This unusual codon usage has to be taken into account for recombinant expression of $C$. albicans proteins. Moreover, $C$. albicans is a diploid organism; consequently two rounds of allele disruption have to be performed in order to delete a single gene. During the last decade, several systems have been developed for gene deletion (Alani et al., 1987; Gow et al., 1994; Wilson et al., 1999; Morschhäuser et al., 1999; Wilson et al., 2000; Reuss et al., 2004; Morschhäuser et al., 2005). Most studies that describe gene functions use auxotrophic strains in their gene disruption methods. These strains are impaired in producing a certain compound (mostly an amino acid), due to deletion of genes encoding enzymes that are active in the respective metabolic pathways. The auxotrophy is complemented with a gene disruption cassette that consists of the respective auxotrophic marker and sequences sharing homology with the gene of interest at the 5' and 3' ends. After gene disruption the auxotrophy is restored, enabling selection of transformants on minimal medium. One potential problem that could arise by using this method is that the ectopically inserted auxotrophic marker is not properly expressed from the integration locus, which has been shown in case of the URA3 marker gene. Changing the location of $U R A 3$ results in an altered Ura3p activity (orotidine 5'-monophosphate carboxylase activity) (Lay et al., 1998; Cheng et al., 2003; Brand et al., 2004) and influences the phenotypes of C. albicans mutants in virulence models (Lay et al, 1998; Bain et al.,2001; Sundstrom et al, 2002; Cheng et al., 2003; reviewed by Staab and Sundstrom, 2003). However, directing the URA3 marker to the high-expression RPS10 locus (RPS1) can avoid these problems (Brand et al., 2004). Another technique that has been established by Reuss and Morschhäuser (2004), circumvents all problems with auxotrophy by utilizing a disruption 
cassette containing an antibiotic resistance marker that can be excised out of the genome. In this way, wild type strains can be used and the same disruption cassette can be utilized multiple times in order to delete the second allele or other genes. This method has been successfully applied in several studies; however, gene disruption in auxotrophic strains is still preferred by many scientists.

\subsection{Medical relevance}

\subsubsection{C. albicans infections and predisposing conditions}

C. albicans and other Candida species are part of the normal flora of the skin, mucous membranes and gastrointestinal tract. During or soon after birth the mucosal surfaces of most human beings are colonized and the risk of an endogenous Candida infection is therefore always present. An infection with Candida is referred to the term 'candidiasis' or 'candidosis'. All forms of visible infections that are located at the surface, such as skin, nail, oral and vaginal infections, are defined as 'superficial candidosis'. One of the most wellknown Candida infection that occurs superficially is oral candidosis (also known as oral thrush) which causes lesions on the tongue, lips, gums or palate. All other infections that are located in the respiratory, urinary tract or organs could be classified as 'systemic or invasive candidosis' (proposed by Odds, 1988). Systemic candidosis can occur in a single organ, but the fungus can disseminate via the blood stream and subsequently infect other organs (Odds, 1988). Another form of infection is the development of biofilms on implanted or indwelling devices (for example catheters or prosthetic heart valves), which has become an increasing clinical problem, particularly because of the resistance of biofilms against a wide range of antifungal drugs (reviewed by Douglas, 2002).

The most important factor that contributed to the increase of candidosis over the last two decades is the growing number of immunocompromised individuals, which can be divided in groups who suffer from mucosal or cutaneous barrier disruption, neutrophil dysfunctioning, defects in cell-mediated immunity, metabolic disorders or have an extreme young or old age (reviewed by Segal et al., 2006). Additionally, other risk factors for infections are the increase use of broad-spectrum antibiotics, cytotoxic chemotherapies, and transplantation (reviewed by Nucci and Marr, 2005, Pfaller and Diekema, 2004).

\subsubsection{Epidemiology of invasive candidosis}

Although the list of opportunistic fungi causing serious life-threatening infections is steadily increasing (reviewed by Walsh et al., 2004), Candida species are evidently the number one 
cause of systemic mycoses worldwide (reviewed by Pfaller and Diekema, 2007). More than 17 different Candida species have been reported to be agents of invasive candidosis in humans (reviewed by Hazen, 1995; Pfaller and Diekema, 2004). This number will continue to grow as laboratories are forced to provide identification to the species level, as a facility in optimizing therapy for candidal infections (reviewed by Rex and Pfaller, 2002; Pappas et al., 2004; Pfaller and Diekema, 2004; Spellberg et al., 2006). The five most common species $C$. albicans, C. glabrata, C. parapsilosis, $C$. tropicalis and $C$. krusei are ascribed to more than $90 \%$ of invasive Candida infections. Up to $70 \%$ are related to C. albicans, making it by far the most frequently isolated species from Candida bloodstream infections (Pfaller and Diekema, 2007).

Candida species are the fourth leading cause of nosocomial bloodstream infection in the United States (Pfaller, 1998; Wisplinghofff et al., 2004). The absolute number for Candida bloodstream infections in the US varies approximately between 10,500 to 42,000 per year (Pfaller and Diekema , 2007). These infections are associated with a high mortality rate that ranges from $46 \%$ to $75 \%$, reflecting the severity of this illness (Diekema and Pfaller, 2004; Pfaller and Diekema, 2007). As a result of high mortality rates and prolonged length of hospital stays, Candida infections also have their impact on health care costs, which is estimated at one billion dollar per year in the US alone (Rentz et al., 1998).

\subsubsection{Medication}

Several antifungal agents are used to treat systemic fungal infections. The three major groups of drugs are the polyenes, azoles and the echinocandins.

The first described polyene with specific antifungal activity that could be used against candidosis is nystatin (Hazen and Brown, 1950), but the most well known antifungal polyene is amphotericin B, which has been used for many years as a standard drug to treat lifethreatening Candida infections (Odds, 1988). It binds ergosterol, the main sterol in fungal membranes, causing membrane perturbation which results in leakage of cellular contents. The antifungal selectivity of amphotericin B is relatively low and therefore it is toxic to mammalian cells, often causing nephrotoxicity (reviewed by Odds et al., 2003).

Azoles are the largest class of drugs that are used in antifungal therapies. They can be classified in two groups, the imidazoles and triazoles. Similar to the polyenes, the azoles are causing disorganisation of the fungal membrane by targeting the fungal cytochrome P-450, which inhibts the $14 \alpha$-demethylation of lanosterol in the ergosterol biosynthetic pathway (Vanden Bossche et al., 1995). Depletion of ergosterol causes an accumulation of several 
$14 \alpha$-methyl-sterols thereby altering permeability and fluidity of the fungal membrane with secondary consequences for membrane-bound enzymes (Marichal et al., 1985)

Echinocandins are fungal secondary metabolites that consist of a cyclic hexapeptide core with a lipid side-chain responsible for the antifungal activity. They form a relative new class of antifungal agents, that target a complex of enzymes which are responsible for synthesizing the polysaccharide $\beta$-1,3-glucan for the fungal cell wall. The component to which echinocandins bind is the Fks1p protein, however, whether this protein is the catalytic subunit involved in glucan synthesis and whether the binding site on Fks1p is internal or external to the cell membrane remains to be clarified (Odds et al., 2003). In the late 1990s, the echinocandinclass compounds anidulafungin, caspofungin and micafungin were tested for clinical development (Vanden Bossche, 2002). Several studies recently showed that these three compounds are relatively safe and effective for the treatment of Candida infections (reviewed by Cappelletty and Eiselstein-McKitrick, 2007).

\subsubsection{Resistance to antifungal agents}

The resistance of Candida species to antifungal agents is a notorious fact that needs to be encountered from different angles, such as combination therapies with different drugs and revealing the mechanisms behind resistance. Although clinicians are not in exigencies, Candida infections should not be trivialized and should be acknowledged as a significant medical problem. Therefore the identification of new potential drug targets is essential for maintaining the mortality rates as low as possible.

\subsubsection{Fungal vaccines}

The persistent need for novel approaches to cure Candida infections eventuated in a growing medical interest for fungal vaccine development. The principle of vaccination depends on stimulation of the host immune system by using antigens of the pathogen. Since most of the fungal infections occur in patients with a deficient immune system, the task of finding a proper vaccine is difficult and will be the new challenge for the academic community in the coming years (reviewed by Cassone, 2008).

Theoretically, antibody production against pathogenic fungi can be induced by vaccination in at-risk patients before they become immunocompromised. IgG antibodies might remain in the body with a protective titre for several weeks to months (Cassone, 2008). Data show, that vaccination before immunosuppression could work for many fungal infections (Gigliotti et al., 2003, Zheng et al, 2005). However, vaccines, that exclusively induce protective responses of 
shorter persistence (antifungal T cells, pro-inflammatory cytokines and activation of macrophages or neutrophils), seem less suitable for this purpose.

Passive vaccination with monoclonal recombinant antibodies have shown to be a promising tool to confer efficient protection against fungal infection (Beninati et al., 2000; Matthews et al., 2003, De Bernardis et al., 2006; Selvakumar et al., 2006). As $\beta$-glucan is present in most of the human fungal pathogens, the anti- $\beta$-glucan antibodies are probably one of the best option for therapeutic use (Bromuro et al., 2002; Masuoka, 2004; Torosantucci et al., 2005;

Cassone and Torosantucci, 2006). Nevertheless, antibody-based immunotherapy should carefully be considered with respect to antibody specificity, affinity and isotype. For example, antibodies with identical specificity but of different isotypes may result in a non-protective or even a disease-enhancing effect in patients (Casadevall et al., 2004, Beenhouwer et al., 2007).

\subsection{Virulence factors of C. albicans}

The ability of $C$. albicans to switch from a yeast to a hyphal form is considered as one of the most important virulence factors that cause infection in the host. Hyphae are able to penetrate tissue cells of the host, thereby causing severe damage. As gene expression of other virulence factors are co-regulated with hyphal morphogenesis, it has been difficult to assess the degree of contribution of hyphae in virulence (reviewed by Kumamoto and Vinces, 2005). However, the $h g c l$ deletion mutant generated by Zheng et al. (2004) showed the importance of hyphae in the infection process. Disruption of $H G C 1$ (G1 cyclin gene) results in an impaired hyphal development, but does not effect the expression of the hypha-associated genes HWP1, HYR 1 and $E C E 1$. This indicates that $H G C l$ encodes not a regulator of hyphal gene expression, but a component of the hyphal formation machinery. The $h g c l$ deletion mutants cause decreased lethality in mice, supporting the fact that hyphae are indeed an important virulence factor. Hyphal morphogenesis and co-regulation of virulence factors is regulated by a number of transcription factors, of which TUP1, NRG1, RFG1, EFG1 and CPH1 are the most well characterised (Braun and Johnson, 1997; Murad et al., 2001; Braun et al., 2001; Kadosh and Johnson, 2001; Khalaf and Zitomer, 2001; Stoldt et al., 1997; Liu et al., 1994). Deletion mutants lacking TUP1, NRG1 and RFG1 show filamentous growth under non-filamentous growth conditions, suggesting these transcription factors act as repressors of hyphal growth (Braun and Johnson, 1997; Murad et al., 2001; Braun et al., 2001; Kadosh and Johnson, 2001). In contrast, deletion of $E F G 1$ or $C P H 1$ results in defective hypha formation, indicating that they are positive regulators (Lo et al., 1997). A double null efg $1 / \mathrm{cph} 1$ mutant is unable to cause mortality in mice (Lo et al., 1997), showing that EFG1 and CPH1 play an important 
role in virulence. The disability to generate proper hyphae is probably not the only cause for the avirulent phenotype of this strain. Several studies revealed that Efg1 regulates a large number of genes, including several that are associated with virulence (Lane et al., 2001; Nantel et al, 2002; Sohn et al., 2003; Doedt et al., 2004; Harcus et al., 2004). Virulence factors that are controlled by Efg1 are for example the secreted aspartic proteases (SAPs), which may degrade host proteins in the extracellular matrix (Naglik et al., 2003), and GPImodified adhesins such as Als1p, Als3p and Hwp1 that play a role in adhesion to host tissue (Hoyer et al., 1998; Sharkey et al., 1999; Fu et al., 2002). These adhesins allow C. albicans cells to be tightly attached to host tissue cells, thereby facilitating the hyphae to invade tissue by mechanical force (Kumamoto and Vinces, 2005). Interestingly, deletion mutants that constitutively grow in filaments show a reduced virulence as well (reviewed by Gow et al., 2002), indicating that hyphae are not the only growth form that is important for virulence. The ability of $C$. albicans to switch from the yeast to the hyphal form and vice-versa is probably necessary to infect the host. As described above (in 1.1.3 Morphology) this transition is induced under certain conditions, however, $C$. albicans is also able to spontaneously switch back and forth between two different phenotypes. This process is called 'phenotypic switching', which is a shift between a yeast form that grows as smooth and white colonies on agar media (white phase) and an elongated, rod-like form that grows as flattened grey colonies (opaque phase) (Rikkerink et al., 1988; Rustchenko et al., 1994; Slutsky et al., 1985, 1987; reviewed by Soll et al., 1993; Soll, 1997). This change can influence several characteristics such as physiological characteristics, adhesion to host cells, virulence and the immune response of the host (Soll, 1997).

\subsection{The cell wall of C. albicans}

The cell wall of the bakers yeast Sacchromyces cerevisiae has been extensively studied over the years which has led to a substantial amount of information about its molecular organisation (reviewed by Orlean 1997; Lipke and Ovalle, 1998; Cabib et al, 2001; Klis et al, 2002, 2006 Lesage and Bussey, 2006) Due to this, it has been designated as a standard model for cell walls of other ascomycetous yeasts, mycelial species and even for basidiomycetous fungi (reviewed by De Groot et al., 2005).

Four major functions for the yeast cell wall have been described: (1) The stabilisation of osmotic conditions within the cell; the cell wall resists the osmotic pressure from the cell, which results in a restricted water influx that prevents disturbance of the internal reaction conditions and a rupture of the plasma membrane. (2) Protection against mechanical stress; 
the sturdiness and high elasticity of the cell wall offers the cell protection against mechanical stress. (3) Cell shape maintenance; the cell wall is needed for morphogenesis, for example in C. albicans the cell wall contributes to the shape of yeast cells, pseudohyphae, true hyphae and chlamydospores. (4) The cell wall as a scaffold for proteins; the polysaccharides in the cell wall can be considered as a supporting framework for the heavily $\mathrm{N}$ - and O-glycosylated proteins that can for example reduce the permeability of the cell wall, thereby protecting the skeletal network of polysaccharides against foreign macromolecules (Klis et al., 2006).

\subsubsection{Molecular organisation of the cell wall}

Electron microscopic data showed that S. cerevisiae and C. albicans have a bi-layered cell wall, consisting of an electron-dense fibrillar outer layer and an underlying transparent inner layer (Chaffin et al., 1998; Tokunaga et al., 1986; Baba et al., 1989; Hagen et al., 2004; Osumi, 1998). Pioneer studies on the cell wall of $S$. cerevisiae revealed that the fibrils can be removed by protease, whereas the inner layer is resistant against proteolytic activity and can be only digested by $\beta$-glucanases (Kopecka et al., 1974; Zlotnik et al., 1984). These data showed that cell wall of $S$. cerevisiae contains a protein-rich upper layer covering a polysaccharide inner layer. Similar data have been obtained with other ascomycetous yeasts and mycelial fungi (reviewed by De Groot et al., 2005). Tokunaga et al. (1990) showed for $C$. albicans that the outer fibrillar layer could attach with the membrane of human buccal epithelial cells, indicating the presence of adhesion proteins in the cell wall.

Further extensive biochemical analysis showed that the cell wall of $S$. cerevisiae consists of an elastic three-dimensional $\beta$-1,3-glucan network, which is kept together through hydrogen bonds. To this framework covalently linked proteins and chitin are attached. Cell wall studies later proved that the cell wall of $C$. albicans has a similar structure (Figure 1) (Klis et al., 2001). 


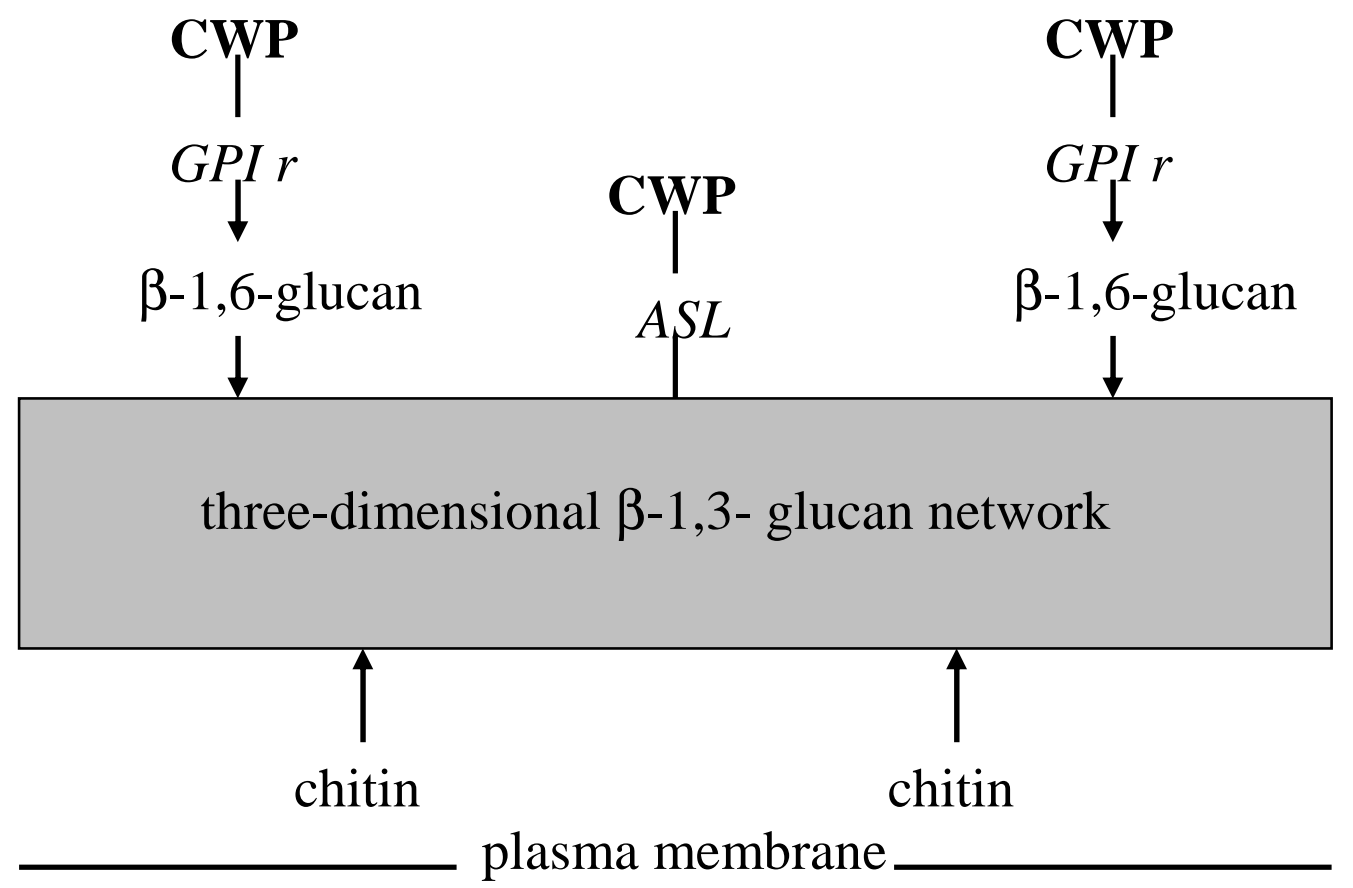

Figure 1. Molecular organisation of the cell wall of $C$. albicans.

The covalently linked cell wall proteins (CWPs) can be classified in two groups: the GPICWPs and the CWPs with an alkali sensitive linkage (ASL), which include the Pir proteins. GPI-CWPs form the majority of the covalently linked proteins. The GPI $r$ is a lipidless remnant of the GPI-anchor. The arrows represent glycosidic linkages and point from the reducing end of a macro molecule to a non-reducing end of an acceptor polysaccharide. For the sake of clarity non-covalently linked proteins are not shown (Adapted from Klis et al., 2006).

\subsubsection{Non-conventional cell wall-associated proteins}

Several studies showed the association of glycolytic enzymes and other abundant cytosolic proteins with the cell wall (Chaffin et al., 1998; Delgado et al., 2003; Edwards et al., 1999, Motshwene et al., 2003; Urban et al., 2003). These proteins can be easily released by reducing agents, like mercaptoethanol, which explains the fact that they are not identified in cell walls washed with a hot solution of SDS and $\beta$-mercaptoethanol (De Groot et al., 2004; Yin et al., 2005)

The absence of glycosylation and an N-terminal signalling peptide indicates that these proteins might be transported to the cell surface by a non-conventional export pathway. However, other possibilities that could explain their presence in the wall have to be considered (reviewed by De Groot et al., 2005). For example, aging or damaged cells could release cytosolic proteins that are -due to their relatively high isolectric point- able to bind to 
the large number of negatively charged phosphate groups, which are present as phophodiester bridges in $\mathrm{N}$ - and $\mathrm{O}$ - carbohydrate side chains in the cell wall.

\subsubsection{Covalently linked cell wall proteins and glycosylation}

Covalently linked cell wall proteins (CWPs) are mostly heavily glycosylated with polysaccharides consisting of mannose molecules (mannan) that are either $\mathrm{N}$-linked or $\mathrm{O}$ linked. N-linked glycosylation is initiated by $\alpha$-glucosidases I and II and $\alpha$-1,2-mannosidase in the endoplasmatic reticulum (ER) generating the oligosaccharide $\mathrm{Man}_{8} \mathrm{GlcNac}_{2}$ to which an outer chain consisting of up to 150 mannose residues is attached in the Golgi (reviewed by Cutler, 2001). O-linked glycosylation is performed by protein- $O$-mannosyltransferases (Pmt proteins) that are located in the ER where they catalyse the addition of mannose to serine or threonine residues (reviewed by Lengler et al., 2008). In the Golgi, the chain is further extended up to five mannose residues by the $\alpha-1,2$-mannosyltransferases Mnt1p and Mnt2p (reviewed by Ernst and Prill, 2001).

Due to its outer location, mannans are readily recognised by the host immune system and therefore they are considered as the most important pathogen-associated molecular patterns (PAMPs) of $C$. albicans. The pattern recognition receptors (PRRs) that are involved in recognising mannan structures are the mannose receptor (MR), Toll-like receptor 4 (TLR4), Toll like receptor 2 (TLR2), DC-SIGN and the dectin 2 receptor (reviewed by Netea et al., 2008). After recognising mannan, the receptors induce several signalling cascades that primarily induce the expression of T helper 1 (TH1)-type cytokines, which confer protection against disseminated C. albicans infections (Netea et al., 2006, 2008: Mencacci et al., 1994). Although less exposed to the outside than mannans, cell wall structures such as glucan and chitin are likely to play a role in the recognition of $C$. albicans (Netea et al., 2008).

\section{Types of covalently linked cell wall proteins}

The covalently linked CWPs are divided in two groups, the GPI-proteins and the Proteins with internal repeats (Pir proteins) or alkali-sensitive linkage (ASL) cell wall proteins (Figure $1)$.

\subsection{Alkali-sensitive linkage proteins}

The PIR CWPs (protein with internal repeats) of S. cerevisiae were the first proteins found to be linked through a mild-alkali-sensitive linkage to the $\beta$-1,3-glucan network (Kandasamy et al., 2000, Kapteyn et al., 1999, Kapteyn et al., 2000, Mrsa et al., 1997 and Toh-e et al., 1993). 
Later their presence has been confirmed in the cell wall of $C$. albicans and other ascomycetous yeasts (Frieman et al., 2002, Jaafar and Zueco, 2004, Kandasamy et al., 2000, Kapteyn et al., 2000 and Weig et al., 2004). At the N-terminal part PIR proteins consist of a pro-peptide that is cleaved off in Golgi apparatus by the serine proteinase Kex2p. Furthermore they contain in the central part repeats that are rich in the amino acid glutamine. The $\mathrm{C}$ terminal region contains the so-called four-cysteine domain, in which four cysteines with fixed spacing are conserved.

During the last years, experimental evidence has accumulated that PIR proteins play a major role in cell wall strengthening. In S. cerevisiae a strong upregulation of PIR genes was observed during cell wall stress (Boorsma et al., 2004, Garcia et al., 2004, Kapteyn et al., 2000 and Lagorce et al., 2003). Deletion mutants of PIR genes in S. cerevisiae and C. albicans show a defective growth phenotype and are sensitive to compounds that affect cell wall assembly (Mrsa and Tanner, 1999; Martinez at al., 2004). All PIR proteins are probably linked to $\beta$-1,3-glucan via their repetitive sequences, which is shown by the release of Pir4p in S. cerevisiae from the cell wall after deleting its single repetitive sequence (Castillo et al., 2003). Recently, it has been shown that Pir4p is attached to the cell wall via a glutamine residue at position 74 within this repetitive sequence (QIGDGQ ${ }_{74} V Q$; Ecker et al., 2006). The authors proposed that between the $\gamma$-carboxyl of a glutamate (originated from the glutamine 74 residue) and a sugar hydroxyl an extremely alkali sensible ester-linkage might be formed. As other PIR members in S. cerevisiae and C. albicans contain more repetitive sequences, multiple linkages can be formed that interconnect several $\beta$-1,3-glucan chains, which enhances cell wall stability.

It has been recently reported that cells walls of $S$. cerevisiae and $C$. albicans contain proteins that do not show homology to PIR proteins, but also are covalently linked to the cell wall with an alkali-sensitive bond (De Groot et al., 2004; Yin et al., 2005), for example, the endo- $\beta-1,3-$ glucanase Scw1p of C.albicans.

\subsection{Glycosylphosphatidylinositol modified (GPI) proteins}

GPI-proteins are present in lower as well as in higher eukaryotic organisms (Eisenhaber et al., 2001). In C. albicans and other fungi they are linked to the plasma membrane or covalently incorporated in the cell wall, in which they perform various functions that range from cell wall assembly to virulence (De Groot et al., 2005; Richard and Plaine, 2007). Nearly all GPI-proteins share common regions in their amino acid sequence: a $\mathrm{N}$-terminal hydrophobic signal sequence which is needed for secretion, a sequence that is rich in serine or 
threonine residues and a C-terminal hydrophobic domain which is cleaved off and replaced with a GPI-anchor, a lipid that resides in the endoplasmatic reticulum. It should be noted that not all GPI-proteins contain the serine/threonine rich domain (Richard and Plaine, 2007). The length C-terminal hydrophobic domain normally varies between 15 or 30 amino acids, which (Udenfriend and Kodukula, 1995) contains a cleavage site (the $\omega$-site) to which the GPIanchor is attached. The $\omega$-site could be an asparagine, serine, glycine, alanine, aspartic acid or cysteine residue followed by two amino acids with short side chains. This $\omega$-region is followed by a spacer region of 4 to 24 amino acids followed by an hydrophobic tail of approximately 10 amino acids (De Groot et al., 2003).

In the last decade, large-scale comparative-genomics studies of fungal GPI-proteins have been made possible due to the availability of fungal genome sequences. The prediction whether proteins contain a GPI-anchor addition is based on characteristics described above. However, the lack of a strict definition for these characteristics, leads often to an identification of a different numbers of GPI-proteins.

Five prediction studies on C. albicans GPI-proteins have been described so far (Sundstrom, 2002; De Groot et al., 2003; Eisenhaber et al., 2004; Garcerá et al., 2003; Richard and Plaine 2007). Sundstrom (2002) predicted 152 ORFs to be coding for GPI-anchored proteins, however, these data were obtained from the incomplete genome assembly 6. De Groot et al., Eisenhaber et al. and Garcera et al. used assembly 19 and predicted 102, 104 and 169 GPIanchored proteins, respectively. In the study of Richard and Plaine (2007) the former three data sets were combined which resulted in a list of 115 GPI-anchored proteins. Strikingly, the number of putative GPI-proteins identified in C. albicans is considerably higher than those identified in S. cerevisiae, which could be explained by the different growth froms of $C$. albicans or its virulence traits.

Several studies showed that some GPI-proteins in S. cerevisiae and C. albicans undergo further processing and are transported from the plasma membrane to the cell wall (Caro et al., 1997). In S. cerevisiae it has been shown that GPI-cell wall proteins (GPI-CWPs) share common sequence motifs. Two different signal sequences for cell surface localization in $S$. cerevisiae have been suggested: (1) the specific amino acid residues valine, isoleucine, or leucine at the site $\omega-4$ or $\omega-5$ upstream of the GPI-attachment site (the $\omega$-site) with tyrosine or asparagine at the site $\omega-2$ acting as a positive signal for cell wall localization and (2) the dibasic residues, arginine and lysine, for instance, in the region upstream of the $\omega$-site for plasma membrane localization (Vossen et al., 1997; Hamada et al., 1999). Richard and Plaine (2007) applied these signal sequence algorithms to their predicted list of $115 \mathrm{GPI}$-anchored 
proteins of $C$. albicans and additionally to a previously published list of $58 \mathrm{GPI}$-proteins of $S$. cerevisiae (Caro et al., 1997). This analysis showed that the percentages of cell wall and membrane-bound proteins are similar for S. cerevisiae and C. albicans, however, in case of $C$. albicans, these predictions are not necessarily in accordance with subsequent experimental data. For example, Dfg5p contains several dibasic amino acids upstream of the putative $\omega$-site, which predicts its localisation in the plasma membrane. However, it is reported that Dfg5p is localized in the plasma membrane as well as in the cell wall (Spreghini et al., 2003), which indicates that this algorithm might be less suitable for predicting the localisation of GPIproteins in C. albicans or that additional signals might be present.

The approximately 100 predicted GPI-proteins from C. albicans can be classified in four groups: (1) the proteins with putative functions related to cell wall biogenesis or remodeling, (2) the proteins with putative functions related to cell-cell adhesion and interactions, (3) the proteins with enzymatic activity and (4) the proteins with unknown functions. The latter comprises the largest group, representing about two-thirds of the total number predicted GPIanchored proteins. Due to their putative localisation at the cell surface several of these proteins might be involved e.g in mediating adhesion of $C$. albicans to host cells, which would designate them as an important class of virulence factors. Additionally, revealing their unique function might explain the highly adaptive behaviour of $C$. albicans in the host, with respect to the immune response.

It is believed that GPI-proteins in eukaryotic cells are mainly located in the plasma membrane and possibly many of them are retained or alternatively are directed to other cell organelles. It has been shown that GPI-proteins are present in lipid rafts, which are specialized regions of the membrane bearing higher levels of cholesterol and sphingolipids. However, among 29 identified proteins in lipid rafts of $C$. albicans, only two are GPI-anchored (Insenser et al., 2006), which is rather a small number compared with rafts of higher eukaryotes (Sharom and Lehto, 2002). This low variety of GPI-anchored proteins is also found in lipid rafts of Cryptococcus neoformans (Siafakas et al., 2006), indicating that this phenomena could be particularly related with fungi.

GPI-CWPs have also been identified directly from isolated cell walls from C. albicans exponential-phase yeast cells (De Groot et al., 2004). By using liquid chromatography-tandem mass spectrometry (LC/MS/MS) analysis, De Groot et al. (2004) identified 14 cell wall proteins, of which 12 are predicted to be GPI-anchored. In view of the approximate 100 computational predicted GPI-anchored proteins of which 30 to $50 \%$ are predicted to be linked to the cell wall, this number is surprisingly low. Although some proteins might not be 
detected because their glycosylated tryptic peptides fall out of the range of the MS-analysis, the authors suggested that these 12 identified GPI-proteins represent almost all the covalently linked proteins in the cell wall of exponential-phase $C$. albicans yeast cells. This view is supported by several facts: (1) The method that was used is sensitive enough to identify a protein even when 500 molecules per cell wall are present. (2) The number of identified proteins did not increase when 100 times more cell walls were used. (3) With SDS-PAGE only a limited number of proteins could be visualised, which was also previously shown for cell wall proteins of S. cerevisiae (Cappellaro et al., 1998; Mrsa et al., 1997, 1999). (4) In the different morphologies of $C$. albicans only a particular set of genes that encode GPI-proteins is expressed, for example Hwp1p, Hyr1p, and Als3p are specific for the hyphal form (Bailey et al., 1996; Hoyer et al., 1998; Staab et al., 1999), whereas Pga24p, Pir1p, and Cht2p are yeast specific and repressed during hyphal growth (Nantel et al., 2002 ; Sohn et al., 2003). The proteins that were identified by De Groot and co-workers originated from cells that were cultured at one particular temperature $\left(30^{\circ} \mathrm{C}\right)$ and in one type of medium; different types of medium and temperatures or other host driven conditions could induce an up-regulation of other GPI-proteins.

\subsubsection{The role of GPI-proteins in the virulence of $C$. albicans}

As described above (in 1.3 Virulence factors of $C$. albicans) several extracellular GPIadhesins are allowing $C$. albicans cells to adhere to host tissue, suggesting these proteins are associated with virulence. However, in most cases, it is difficult to determine whether GPIproteins are directly or indirectly involved in the infection process. Apart from systems biology, transcription analysis and proteomics, the phenotypical analysis of gene deletion mutants is one of the classical and most reliable methods to get insight in the function of a protein. Richard and Plaine (2007) reported in a review that a total 28 deletion mutants exist for genes encoding GPI-anchored proteins in C. albicans, of which 15 have been tested in virulence assays. Within this group, 3 mutants were as virulent as their reference strain and 13 mutants showed a reduction in virulence, which implicates the role of GPI-proteins in the virulence of $C$. albicans. It should be noted that most of these GPI-proteins are not directly involved in the infection process, but their absence in the deletion mutants leads to secondary effects that contribute to a reduced virulence. For the majority of the GPI-proteins the function is not known, however, at the time of writing several laboratories around the world are engaged in generating mutants and testing their phenotypes in virulence models. In the 
section below, we briefly describe a number of $C$. albicans GPI-proteins of which the respective deletion mutants are reported to be attenuated in virulence.

Phr1p, Phr2p, Crh11p, Utr2p and Ecm33p are proteins that are involved in the assembly and modelling of the cell wall (Saporito-Irwin et al., 1995; Ghannoum et al., 1995; Mühlschlegel and Fonzi, 1997; Pardini et al., 2006; Martinez-Lopez et al., 2004, 2006). These GPI-CWPs are necessary for proper cell separation and deletion of the encoding genes mostly has an effect on the ability of generating hyphae, which is crucial for virulence. Moreover, these mutants have a modified cell wall structure or composition, which might alter recognition by the host immune system and could lead to a reduced virulence.

One important characteristic that distinguishes $C$. albicans from other yeasts is that it is able to tightly adhere with host tissue (Borg-Von Zepelin and Wagner, 1995). Adhesion of $C$. albicans cells to host cells is the initial step in the infection process, which is mainly mediated by the GPI-CWPs of the Als (Agglutinin like sequences) protein family and Hwp1p (Hyphal wall protein 1). The first $A L S$ gene was described in 1995 as a homologue of a sexual agglutinin in S. cerevisiae (Hoyer et al., 1995). The Als family comprises 8 members (Hoyer, 2001), of which each exhibits the typical features of a GPI-protein with in addition a central domain that consists of 36-amino acid tandem repeats ( Hoyer, 2001; Zhao et al., 2003). Interestingly, there is a high variation in the number of tandem repeats and the C-terminally located VASES (valine, alanine, serine, glutamic acid and serine) repeats between alleles of the same $A L S$ gene or in sequences of the same $A L S$ gene among different strains. For example, in 66 different $C$. albicans strains 60 different forms of $A L S 7$ were found, generating 49 different genotypes (Zhang et al., 2003). Additionally, an analysis of the genotype data revealed that more tandem repeats are present in the genome of the strains that were more pathogenic. Not only the repeats vary in $A L S$ genes, in a study by Zhao et al. (2003) it was shown for the ALS9 gene that its two alleles vary from each other in the 5' part of the ORF. The repeats in the genome could favour genetic reshuffling of domains, resulting in CWPs with new functions (reviewed by Verstrepen et al., 2004). It has been shown for S. cerevisiae that the variation in intragenic repeats, which mostly occurs in CWPs, alters the phenotypes in different strains (Verstrepen et al., 2005). It is not unlikely that this is also the case for $C$. albicans, which provides an escape mechanism for the fungus against the host immune response. On protein level the structural diversity within the Als family was also confirmed and these variations were likely to be responsible for the functional diversity within the family (Sheppard et al., 2004) 
Deletion mutants have been generated for ALS1 (Fu et al., 2002), ALS3 (Zhao et al. 2004), ALS4 (Zhao et al., 2005), ALS7 (Nobile et al., 2003)) and an attempt to disrupt ALS2 has been made, however the gene seems to be essential to C. albicans viability (Zhao et al., 2005). The als 1 and als 3 null mutants show a reduced adherence and virulence in different kinds of models (Fu et al., 2002; Zhao et al., 2004). The als4 mutant has a reduced ability to adhere but its virulence is comparable to that of the wild type (Zhao et al., 2005), which shows the redundancy of functions within the $A L S$ family. It should be noted that these phenotypes might depend on the background strain that is used, as the sequences of $A L S$ genes greatly vary among different strains. Moreover, a single reference strain can evolve differently from laboratory to laboratory, creating an even more complicated scenario to interpret data from phenotypical analyses.

The reduced virulence and adherence exhibited by the $A L S$ deletion mutants suggests the Als protein family is involved in cell-cell adherence. Other studies confirm this assumption, for example, Als5 expression in S. cerevisiae results in a higher binding capacity to variety of substrates, such as extra-cellular matrix-coated beads, human buccal epithelial cells and various peptide sequences (Gaur et al., 1999, 2002; Klotz et al., 2004). This binding activity seems not to be solely localised to the $\mathrm{N}$-terminal immunoglobulin like region, but also depends on the tandem repeats domain (Rauceo et al., 2006).

Als3p has shown to be important for adhesion and plays a crucial role in biofilm development (Nobile et al., 2006; Nobile and Mitchell, 2005; Zhao et al., 2003). Recently, this protein was discovered as the first fungal invasin that mimics host cell cadherins and induces endocytosis of $C$. albicans by binding to $\mathrm{N}$-cadherin on endothelial cells and E-cadherin on oral epithelial cells (Phan et al., 2007).

Another GPI-CWP that plays a role in adhesion is Hwp1p, which is exclusively expressed in germ tubes and true hyphae (Staab et al., 1999, 2003b). This protein is known as an unconventional adhesin that shares sequence similarties with mammalian small proline-rich proteins, thereby mimicking human transglutaminase substrates. Due to this, covalent bonds are established that enable stable attachments between the germ tubes of $C$. albicans and the host cells (Staab et al., 1999).

An important virulence factor of C. albicans is its extracellular proteolytic activity, which is produced by 10 members of the Sap family. In contrast to the secreted Sap1p-Sap6p, which degrade host proteins and cause tissue damage (Naglik et al., 2003), the GPI-anchored Sap9p and Sap10p seem to target fungal cell surface proteins. Deletion of SAP9 and SAP10 causes misprocessing of $C$. albicans $\mathrm{CWPs}$, resulting in sensitivity against compounds that target the 
cell wall and an attenuated virulence in a model of oral candidosis. Furthermore, the sap10 null mutant exhibits a reduced adhesion to buccal epithelial cells, whereas deletion of SAP9 resulted in an increased adhesion (Albrecht et al., 2006).

Another protein family with enzymatic activity is the phospholipase B family (Plb),that consists of 5 members of which Plb3p, Plb4p and Plb5p are predicted to be GPI-anchored. PLB5 expression is increased in hyphal growth conditions and deletion of the gene results in a reduced organ colonisation in a mice model. During infection, secreted and cell surface linked Plbs are likely to come in close contact with host tissue cells and therefore they could be involved in the degradation of host cell membranes (Theiss et al., 2006).

In order to proliferate during a systemic infection $C$. albicans needs to acquire several nutrients, including iron. Iron acquisition plays a key role in the infection process and therefore it is a major virulence factor. The two highly homologues GPI-proteins Rbt5p and Rbt51p (Pga10p) are upregulated during iron starvation and deletion of the RBT5 gene leads to a reduced ability of $C$. albicans to use haemin and haemoglobin as iron sources, which suggests Rbt5p is involved in iron uptake (Weismann and Kornitzer, 2004).

While residing in the host, $C$. albicans can encounter an oxidative burst from phagocytes, which consists of several reactive oxygen species that react with cellular components. This leads to inactivation of enzymes, to disruption of membranes, to mutations, and ultimately to cell death (Halliwell and Gutteridge, 1990 and 1999). However, C. albicans protects itself with superoxide dismutases (SOD) that detoxify these reactive oxygen species. Mutants lacking the GPI-protein Sod5p (Pga3p) are more sensitive to hydrogen peroxide and exhibit a reduction in virulence in mice (Martchenko et al., 2004).

The function of the hyphal regulated GPI-proteins Hyrlp and Rbt1p remains unclear, as the respective deletion mutants do not show phenotypical differences compared with the wild type (Bailey et al., 1996; Braun et al., 2000).

\subsection{The Predicted GPI-anchored protein 29 (Pga29p)}

The PGA29 gene was initially discovered in a transcription analysis, in which 6333 open reading frames were investigated for differential gene expression between the yeast and hyphal form of $C$. albicans (Nantel et al., 2002). PGA29 was identified as one of the genes being most strongly downregulated by $C$. albicans during its transition from yeast to hyphae and consequently it was designated as 'Repressed during Hyphae Development 3' (RHD3; Nantel et al., 2002). Nantel and co-workers noted that this gene encodes a putative membrane protein which is rich in serine residues. This was confirmed one year later by De Groot et al. 
(2003) who identified Pga29p in a genome-wide analysis to predict GPI-proteins, which indicated the protein is localized at the cell surface and is linked to the plasma membrane and/or cell wall of C. albicans. With the aid of mass spectrometry, the presence of Pga29p in isolated cell walls of exponential-phase yeast cells was proven (De Groot et al., 2004). The study revealed detailed information about the $\mathrm{N}$-terminal signal cleavage peptidase site for Pga29p and SDS-PAGE showed that the protein is abundantly present in yeast cell walls (De Groot et al., 2004). Pga29p is small in size (the unprocessed protein consists of 204 amino acids) and does not contain conserved domains in its amino acid sequence. De Groot and coworkers (2004) reported that it might be needed to maintain the rigidity of the cell wall, which is supported by the fact that $P G A 29$ is among the genes that are highly expressed in protoplasts that regenerate their cell wall (Castillo et al., 2006). In the literature Pga29p has not been classified as a putative virulence factor of $C$. albicans, probably because its expression is low in iron depleted (Lan et al., 2004) as well as in hyphal stimulating conditions (Nantel et al., 2002), both of which are known to particularly induce the expression of genes encoding virulence factors.

\subsection{Aim of the study}

Although our knowledge about the pathogenicity of $C$. albicans on molecular level has been considerably increasing over the last decade, the exact strategy by which this fungal pathogen infects humans remains unclear. In order to successfully proliferate in the host, $C$. albicans needs an ample of genes that are either directly or indirectly related with virulence. Several of these genes encode GPI-proteins that reside in the plasma membrane and/or cell wall and are therefore exposed to the extracellular environment, allowing them to contact host tissue during infection. The function of approximately two-thirds of the predicted GPI-proteins is still unknown. Though transcript profiling studies give researchers hints, speculating about their putative function is often difficult because of the lack of functional homologs in other fungal species. It is believed that a number of these GPI-proteins are involved in virulence and therefore their characterisation will answer a part of the remaining questions concerning the pathogenesis of $C$. albicans.

In this study we characterised Pga29p, an abundant GPI-CWP that belongs to the group of GPI-proteins with unknown function. We generated anti-Pga29p polyclonal antibodies with which we studied the type of linkage through which Pga29p is connected to the cell wall and the Pga29p incorporation in the cell wall of $C$. albicans cells that had grown in different conditions. Further analysis was carried out by testing double deletion mutants in several 
phenotypic assays, including virulence models. Furthermore, we attempted to obtain information about the role of this protein in the host immune response. 


\section{Methods}

\subsection{Chemicals}

Chemicals were purchased from Roth (Karlsruhe, Germany), Merck (Darmstadt, Germany), Sigma Aldrich (München, Germany). Media to culture C. albicans were purchased from Qbiogene and Difco (Merck) and cell culture media were purchased from Biochrom (Berlin, Germany).

\subsection{Kits, plasmids and enzymes}

Enzymes and kits were purchased from Invitrogen (Paisley, UK), New England Biolabs (Ipswich, MA, USA), Novagen (Darmstadt, Germany), Promega (Madison, WI, USA), Qbiogene (Irvine, CA, USA), Qiagen (Hilden Germany), Roche Molecular Diagnostics (Pleasanton, CA, USA) and Stratagene (Cedar Creek, TX, USA).

\section{Table 1. Plasmids}

\section{Plasmids used in this study}

pSTblue-1

pQE30

pQE30-PGA29

pRS-ARG4 $\Delta$ SpeI

pGEM-HIS1

CIp10

CIp10-PGA29

\section{Source}

Novagen, Darmstadt

Qiagen, Hilden

This study

Wilson et al. (1999)

Wilson et al. (1999)

Murad et al. (2000)

This study

\section{Table 2. Enzymes}

\section{Enzymes used in this study}

Restriction enzymes

Taq DNA polymerase

KOD hot start DNA polymerase

Reverse transcriptase

Shrimp alkaline phosphatase

DNA Quick ligase

Quantazym $y \lg ^{\mathrm{TM}}$ ( recombinant $\beta$-1,3-glucanase)

Recombinant $\beta$-1,6-glucanase

\section{Source}

New England Biolabs

Roche

Novagen

Qiagen, Invitrogen

Roche

New England Biolabs

Q-biogene

Bom et al., 1998 


\subsection{Table 3. Media used in this study}

\begin{tabular}{|c|c|}
\hline Media & Components \\
\hline LB * & $5 \mathrm{~g} / \mathrm{l}$ tryptone, $10 \mathrm{~g} / \mathrm{l}$ yeast extract, $5 \mathrm{~g} / \mathrm{l} \mathrm{NaCl}$ \\
\hline YPD * & $10 \mathrm{~g} / \mathrm{l}$ yeast extract, $20 \mathrm{~g} / \mathrm{l}$ peptone, $20 \mathrm{~g} / \mathrm{l}$ glucose \\
\hline YNB * & $\begin{array}{l}6.7 \mathrm{~g} / \mathrm{l} \text { yeast nitrogen base (without amino acids, } \\
\left.\text { with }\left(\mathrm{NH}_{4}\right)_{2} \mathrm{SO}_{4}\right), 20 \mathrm{~g} / \mathrm{l} \text { glucose }\end{array}$ \\
\hline Sabouraud* & Purchased from Oxid \\
\hline Limited iron medium (LIM, filter sterilised) * & $\begin{array}{l}1.7 \mathrm{~g} / \mathrm{l} \text { yeast nitrogen base without copper and } \\
\text { iron ions, } 0.79 \mathrm{~g} / \mathrm{l} \text { complete supplement mixture, } \\
20 \mathrm{~g} / \mathrm{l} \text { glucose, } 5 \mathrm{~g} / \mathrm{l}\left(\mathrm{NH}_{4}\right)_{2} \mathrm{SO}_{4}, 0.25 \mathrm{mM} \mathrm{CuSO} 4 \\
\text { and supplemented with } 100 \mathrm{mM} \text { of } \\
\text { bathophenanthroline disulphonic acid (Sigma } \\
\text { Chemical Co.). }\end{array}$ \\
\hline Modified Lee (filter sterilised) & $\begin{array}{l}35.7 \mathrm{~g} / \mathrm{l} \mathrm{Hepes}, 0.07 \mathrm{~g} / \mathrm{l} \text { arginine, } 0.2 \mu \mathrm{M} \\
\mathrm{ZnSO}_{4} \times 7 \mathrm{H}_{2} \mathrm{O}, 1 \mu \mathrm{M} \mathrm{FeCl}_{3}, 0.2 \mathrm{~g} / 1 \mathrm{MgCl}_{2}, 0.25 \\
\mu \mathrm{M} \mathrm{CuSO}_{4}, 0.147 \mathrm{~g} / \mathrm{l} \mathrm{CaCl}_{2}, \mathrm{pH} 4.5 \text { or } \mathrm{pH} 6.7\end{array}$ \\
\hline SB (N-acetylglucosamine, filter sterilised) & $\begin{array}{l}3.35 \mathrm{~g} / \mathrm{l} \text { of YNB without amino acids, with } \\
\text { ammonium sulphate, } 4.5 \mathrm{~g} / 1 \mathrm{NaCl} \text {. With } 1.1513 \\
\mathrm{~g} / \mathrm{L} \text {-Proline }(10 \mathrm{mM}) \text { or } 0.553 \mathrm{~g} / \mathrm{l} \mathrm{N} \text { - } \\
\text { acetylglucosamine }(2.5 \mathrm{mM})\end{array}$ \\
\hline Rice-Tween-agar* & $25 \mathrm{~g} / 1$ rice, $1 \%(\mathrm{v} / \mathrm{v})$ Tween 80 \\
\hline Spider * & $\begin{array}{l}10 \mathrm{~g} / \mathrm{l} \text { Nutrient Broth, } 10 \mathrm{~g} / \mathrm{l} \text { mannitol, } 2 \mathrm{~g} / \mathrm{l} \\
\mathrm{K}_{2} \mathrm{HPO}_{4} \text {. }\end{array}$ \\
\hline $\mathrm{mDC}$ & $\begin{array}{l}\text { High glucose DMEM with glutamine } \\
\text { supplemented with } 10 \% \mathrm{FCS}, 100 \mathrm{U} / \mathrm{ml} \\
\text { penicillin, } 100 \mu \mathrm{g} / \mathrm{ml} \text { streptomycin and 5-10\% X- } \\
\text { conditioned medium as a source of GM-CSF. }\end{array}$ \\
\hline D-MEM & $\begin{array}{l}\text { For adhesion assay: DMEM supplemented with } \\
1 \mathrm{mM} \text { sodium pyruvate and } 1 \% \text { gentamycin. }\end{array}$ \\
\hline RPMI & RPMI-1640 \\
\hline Modified RPMI & $\begin{array}{l}\text { RPMI-1640 w glutamine w/o bicarbonate, } 25 \\
\text { mM HEPES, 0.02\% Bovine Serum Albumin } \\
\text { (BSA), } 20 \mathrm{mM} \text { Glucose, } 10 \mathrm{mM} \mathrm{NaOH}, 20 \\
\mu \mathrm{g} / \mathrm{ml} \text { uridine. }\end{array}$ \\
\hline
\end{tabular}

*(In case of solid media: $2 \%$ agar, for spider medium $1.35 \%$ ) 
2.4 Table 4. C. albicans strains used in this study

\begin{tabular}{|c|c|c|c|}
\hline Strain & Genotype & $\begin{array}{l}\text { Parental } \\
\text { strain }\end{array}$ & Reference \\
\hline SC5314 & Wild type & -- & $\begin{array}{l}\text { Gillum et al. } \\
\text { (1984) }\end{array}$ \\
\hline BWP17 & 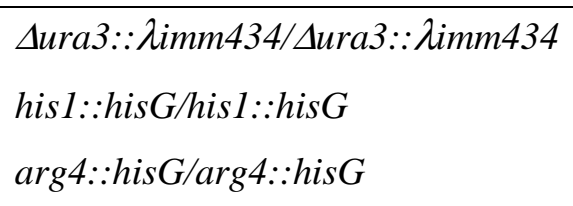 & SC5314 & $\begin{array}{l}\text { Wilson et al. } \\
\text { (1999) }\end{array}$ \\
\hline Apga2/_pga29 & $\begin{array}{l}\text { Apga29/Apga29, } \\
\text { pga29::HIS1/pga29::ARG4, } \\
\text { rp10::URA3 }\end{array}$ & BWP17 & This study \\
\hline Apga29/_pga29/PGA29 & $\begin{array}{l}\text { Apga29/Apga29, } \\
\text { pga29::HIS1/pga29::ARG4, } \\
\text { rp10::PGA29-URA3 }\end{array}$ & BWP17 & This study \\
\hline$\Delta p m t 1 / \Delta p m t 1$ & 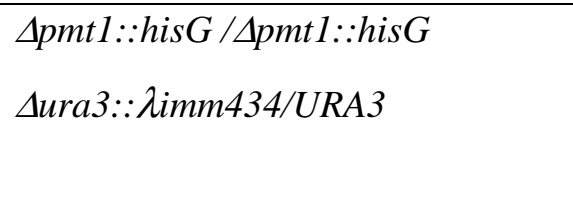 & $\begin{array}{l}\text { CAI4 (Fonzi } \\
\text { and Irwin, } \\
\text { 1993) }\end{array}$ & $\begin{array}{l}\text { Prill et al. } \\
(2005)\end{array}$ \\
\hline$\Delta p m t 2 / P M T 2$ & 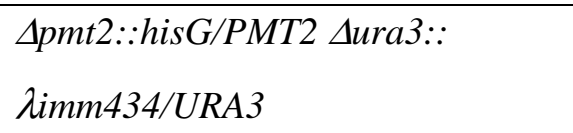 & CAI4 & $\begin{array}{l}\text { Prill et al. } \\
(2005)\end{array}$ \\
\hline$\Delta p m t 4 / \Delta p m t 4$ & 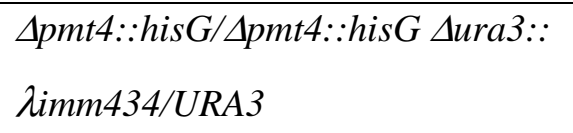 & CAI4 & $\begin{array}{l}\text { Prill et al. } \\
(2005)\end{array}$ \\
\hline$\Delta p m t 5 / \Delta p m t 5$ & 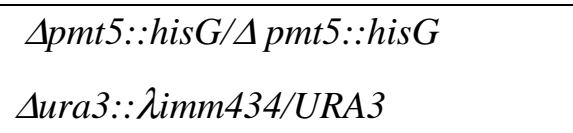 & CAI4 & $\begin{array}{l}\text { Prill et al. } \\
(2005)\end{array}$ \\
\hline$\Delta p m t 6 / \Delta p m t 6$ & 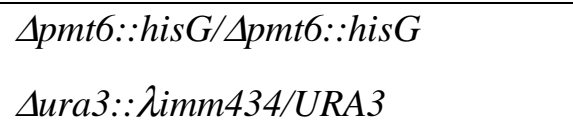 & CAI4 & $\begin{array}{l}\text { Prill et al. } \\
(2005)\end{array}$ \\
\hline$\Delta e f g 1 / \Delta e f g 1$ & 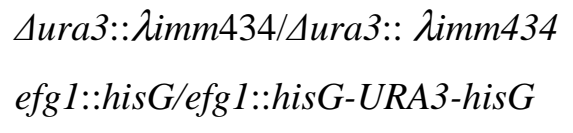 & CAI4 & $\begin{array}{l}\text { Lo et al. } \\
\text { (1997) }\end{array}$ \\
\hline $\begin{array}{l}\Delta e f g 1 / \Delta e f g 1 \\
\Delta c p h 1 / \Delta c p h 1\end{array}$ & 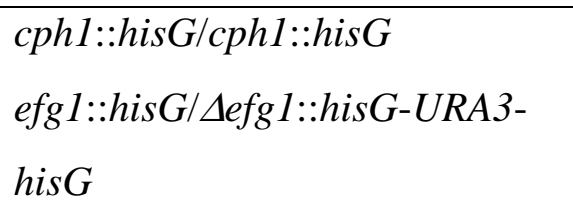 & CAI4 & $\begin{array}{l}\text { Lo et al. } \\
\text { (1997) }\end{array}$ \\
\hline
\end{tabular}


Table 5. E. coli strains used in this study

\begin{tabular}{|c|c|c|}
\hline Strain & Genotype & Source \\
\hline DH5 $\alpha$ & $\begin{array}{l}\text { F end Al hsd R17 }\left(r_{k}^{-}, m_{k}^{-}\right) \text {sup } \\
\text { E44 thi-1 l' rec A1 gyr A96 rel } \\
\text { A1 } \triangle(\text { arg F lac ZYA) U } 169 \\
\text { y80 } \triangle \text { lacZ } \Delta M 15\end{array}$ & Qiagen, Hilden, Germany \\
\hline M15 with plasmid pREP4 & $\begin{array}{l}\mathrm{F}^{\prime} \operatorname{proA}^{+} B^{+} \text {lacI }^{q} \Delta(\text { lacZ }) M 15 \\
z z f: \because \operatorname{Tn} 10\left(\mathrm{Tet}^{\mathrm{R}}\right) / f h u A 2 g \ln V \\
\Delta(\text { lac-proAB) thi-1 } \Delta(\text { hsdS- } \\
m c r B) 5\end{array}$ & Qiagen, Hilden, Germany \\
\hline NovaBlue Singles ${ }^{\mathrm{TM}}$ & $\begin{array}{l}\text { endA1 hsdR17 }\left(\mathrm{r}_{\mathrm{k}}^{-} \mathrm{m}_{\mathrm{k}}^{+}\right) \text {supE44 } \\
\text { thi-1 recA1 gyrA96 relAl lac } \\
\mathrm{F}^{\prime}\left[\text { proA }^{+} B^{+} \text {lacl }{ }^{q} Z \Delta\right. \\
\text { M15::Tn10 }\left(\mathrm{Tet}^{\mathrm{R}}\right)\end{array}$ & $\begin{array}{l}\text { Novagen, Darmstadt, } \\
\text { Germany }\end{array}$ \\
\hline $\begin{array}{l}\text { XL1-Blue supercompetent } \\
\text { cells }\end{array}$ & $\begin{array}{l}\text { recAl endA1 gyrA96 thi-1 } \\
\text { hsdR17 supE44 relA1 lac }\left[\mathrm{F}^{\prime}\right. \\
\text { proAB lacIqZAM15 Tn10 } \\
\text { (Tetr)] }\end{array}$ & Stratagene, La Jolla, CA \\
\hline
\end{tabular}

\subsection{Primers that were used in this study}

Table 6. Primers used for recombinant expression of PGA29 in E. coli

$\begin{array}{lll}\text { Primer name } & \text { Primer sequence } & \text { Localisation (in bp) } \\ \text { ExCaPGA31-F } & \text { CGGCGGATCCACCATCTCATCCATTCAATTATTTGCC } & 44-72 \\ \text { ExCaPGA31-R } & \text { GCGCAAGCTTACCTTCAAAGTTGGAAACAGAGGC } & 523-555 \\ \text { PGA29-pm-F } & \text { CCGTTAGACAATTGTTCACTTTGGGTGGTG } & 227-256 \\ \text { PGA29-pm-R } & \text { CACCACCCAAAGTGAACAATTGTCTAACGG } & 227-256 \\ \text { PGA29-pm2-F } & \text { CCGTTAGACAATCGTTCACTTTGGGTGGTG } & 227-256 \\ \text { PGA29-pm2-R } & \text { CACCACCCAAAGTGAACGATTGTCTAACGG } & 227-256\end{array}$


Table 7. Primers used to generate digoxigenin PCR probes (Northern blot experiments)

$\begin{array}{lll}\text { Primer name } & \text { Primer sequence } & \text { Localisation (in bp) } \\ \text { Act1F-RT } & \text { ATGAAGCCCAATCCAAAAGAGGTA } & 122-145 \\ \text { Act1R-RT } & \text { GAAATCCAAAGCAACGTAACACAA } & 601-624 \\ \text { Pga29F-RT } & \text { TCTGCTCTTGCTACCATCTCATCC } & 34-57 \\ \text { Pga29R-RT } & \text { AGCAACAACAGCAGCCATACCA } & 579-600 \\ \text { PGA30F-RT } & \text { CAAAACATACTGAAGCTCCAACTA } & 491-514 \\ \text { PGA30R-RT } & \text { AATAGCAGCAGCAGCAAGAG } & 800-819 \\ \text { PGA31F-RT } & \text { TAAAGGTGGTGATGGTGCTATTCC } & 597-620 \\ \text { PGA31R-RT } & \text { ACCACCAGTGAGGGCGTTAG } & 995-1014\end{array}$

Table 8. Primers used for PCR based transformation (Capital letters represent the sequence of the untranslated region of $P G A 29)$

Primer name

PGA31pGEM-F

PGA31pGEM-R
Primer sequence

TTAGTTCATTATAACAAAAAAACAAATTA

GTTATACCCATCAAATCAAACgttttcccagtcacgacgtt

TAGAATTAAAAGTCCGCAACGGATACATA

ATTAGTCTTGCTCTTGCTTTAtgtggaattgtgagcggata

Table 9. Primers used to generate the PGA29 PCR product for complementation, to verify mutants with PCR and to generate digoxigenin PCR probes (Southern blot)

$\begin{array}{lll}\text { Primer name } & \text { Primer sequence } & \text { Localisation (in bp) } \\ \text { Kompl-PGA29-F } & \text { gtcgacACAAATGGGTTCGGCTTCTT } & -898--878 \\ \text { Kompl-PGA29-R } & \text { acgcgtATTCTGACCGTTGTTGCCACTT } & +464-+486 \\ \text { PGA29-F } & \text { ATAGTGGTGGTGGAGGAGAACAA } & -827--804 \\ \text { HIS-R } & \text { GGACGATTATATTGACCATTTCTG } & 605-628 \\ \text { HIS-F } & \text { GAGTGGTGCCGATATACAGTTTAG } & 87-110 \\ \text { PGA29-R } & \text { CCAACTTTGCGTGAGACCA } & +322-+341 \\ \text { ARG4-R } & \text { CCACAAAAGAAAAACCCTGACTCA } & 874-897 \\ \text { ARG4-F } & \text { CCATTCTTGTCTGATTTGTTCTAA } & 217-240 \\ \text { RP10-1F } & \text { TTTTAGGGGCAATCAGCAACATA } & -861--838 \\ \text { CIp10.2-R } & \text { TGGAAAGCGGGCAGTGAG } & 3175-3192 \\ \text { PGA29-best-knk-F } & \text { GAAGTGGCAACAACGGTCAGA } & +364-+385 \\ \text { URA3-F } & \text { CCTCACCAGTAGCACAACGAT } & 47-67 \\ \text { RP10-3R } & \text { AATTTCCTGACTTTCTGTATCTA } & +372-+395 \\ \text { URA3-R } & \text { TGTCATAATAAGCCAATCAAATCC } & 592-615 \\ \text { ARG4-S-F } & \text { TGAGTCAGGGTTTTTCTTTTGTGG } & 874-897 \\ \text { ARG4-S-R } & \text { TTAGAACAAATCAGACAAGAATGG } & 217-240\end{array}$


Table 10. RT-PCR primers used in infected RHE experiment

$\begin{array}{ll}\text { Primer name } & \text { Primer sequence } \\ \text { GAPDH-F } & \text { GCACCACCAACTGCTTAGCACC } \\ \text { GAPDH-R } & \text { GTCTGAGTGTGGCAGGGACTC } \\ \text { GM-CSF-F } & \text { GTGGCCTGCAGCATCTCTGCAC } \\ \text { GM-CSF-R } & \text { CCTGGACTGGCTCCCAGCAGTC } \\ \text { TNF- } \alpha-F & \text { GGGACCTCTCTCTAATCAGCCCTCTGG } \\ \text { TNF- } \alpha-R & \text { GACGGCGATGCGGCTGATGG } \\ \text { IL-1 } \alpha-F & \text { CACTCCATGAAGGCTGCATGG } \\ \text { IL-1 } \alpha-R & \text { ACCCAGTAGTCTTGCTTTGTGG } \\ \text { IL-1 } \beta-F & \text { CGATCACTGAACTGCACGCTCCG } \\ \text { IL-1 } \beta-R & \text { GGTGAAGTCAGTTATATCCTGGCCG } \\ \text { IL-6-F } & \text { CACAGACAGCCACTCACCTC } \\ \text { IL-6-R } & \text { TTTCTCCGTGACCGTCTTTT } \\ \text { IL-8-F } & \text { GCAGCTCTGTGTGAAGGTGCAG } \\ \text { IL-8-R } & \text { GCATCTGGCAACCCTACAACAG }\end{array}$

Table 11. RT-PCR Primers used in Candida- mDC interaction assay

$\begin{array}{ll}\text { Primer name } & \text { Primer sequence } \\ \text { ACT1-F } & \text { GGTCATCACTATTGGCAACG } \\ \text { ACT-R } & \text { TCCATACCCAAGAAGGAAGG } \\ \text { IFN- } \beta-F & \text { TCAGAATGAGTGGTGGTTGC } \\ \text { IFN- } \beta-\mathrm{R} & \text { GACCTTTCAAATGCAGTAGATTCA } \\ \text { IFN- } \gamma \text {-F } & \text { TCAAGTGGCATAGATGTGGAAGAA } \\ \text { IFN- } \gamma \text {-R } & \text { TGGCTCTGCAGGATTTTCATG } \\ \text { IL-10-F } & \text { GGTTGCCAAGCCTTATCGGA } \\ \text { IL-10-R } & \text { ACCTGCTCCACTGCCTTGCT } \\ \text { IL-12-F } & \text { GGAAGCACGGCAGCAGAATA } \\ \text { IL-12-R } & \text { AACTTGAGGGAGAAGTAGGAATGG } \\ \text { TNF- } \alpha-F & \text { CAAAATTCGAGTGACAAGCCTG } \\ \text { TNF- } \alpha-R & \text { GAGATCCATGCCGTTGGC }\end{array}$

\subsection{Basic Local Alignment Search Tool (BLAST)}

To find homologs of Pga29p, the Pga29p protein sequence was used to search against the NCBI database (http://blast.ncbi.nlm.nih.gov/Blast.cgi), the FGI Candida database (http://www.broad.mit.edu/annotation/genome/candida_group/Blast.html) and the Candida dubliniensis data base (http://www.genedb.org/genedb/cdubliniensis/). 


\subsection{Anti-Pga29p polyclonal antibodies}

\subsubsection{Cloning of $P G A 29$ in the pQE30 expression vector}

The coding sequence of PGA29 extending from codon 15 (at the signal cleavage site) to codon 182 (before the predicted GPI-anchoring site) was amplified with primers ExCaPGA31-F and ExCaPGA31-R (Table 8). The amplicon was cloned as a BamHI-HindIII PCR fragment in the pQE30 vector, thereby generating pQE30-PGA29. In this way the ORF included of a polyhistidine tag, which was necessary for Ni-purification. C. albicans does not follow the universal codon usage, for it translates the leucine-specific CTG codon in a serine. Because the CTG codon at position 193 is translated as leucine in E. coli, we introduced two point mutations, using the primers PGA29-pm-F and PGA29-pm-R (Table 6) for the first point mutation and the primers PGA29-pm2-F and PGA29-pm2-R (Table 6) for the second point mutation.unsing the QuickChange II Site-directed mutagenesis kit (Stratagene). The point mutations were confirmed by restriction analysis with enzyme $M f e I$ and by sequencing. The pQE30-PGA29 vector was transformed in the E. coli strain M15 and recombinant Pga29p was isolated and purified under denatured conditions ( $8 \mathrm{M}$ urea).

\subsubsection{PGA29 overexpression and purification}

An overnight culture of $E$. coli M15 (with pREP4) with the pQE30-PGA29 vector was 50 times diluted in 1 liter LB broth containing $100 \mu \mathrm{g} / \mathrm{ml}$ ampicillin and $25 \mu \mathrm{g} / \mathrm{ml}$ kanamycin. The culture was incubated at $37^{\circ} \mathrm{C}$ with vigorous shaking until an optical density at $600 \mathrm{~nm}$ $\left(\mathrm{OD}_{600}\right)$ of 0.6 was reached. PGA29 expression was induced by adding IPTG to a final concentration of $1 \mathrm{mM}$ and the culture was further incubated for 5 hours. Cells were harvested by centrifugation at $4000 \times \mathrm{g}$ for $20 \mathrm{~min}$ and were frozen with liquid nitrogen. The cell pellet was thawed on ice and cells were lysed by resuspending them in buffer B ( $5 \mathrm{ml}$ per gram wet weight), which contains $100 \mathrm{mM} \mathrm{NaH}{ }_{2} \mathrm{PO}_{4}, 10 \mathrm{mM}$ Tris-Cl, $8 \mathrm{M}$ urea, $\mathrm{pH}$ 8.0. The cells were gently shaken for $1 \mathrm{hr}$ at room temperature and subsequently the lysate was centrifuged at $10,000 \times \mathrm{g}$ for $30 \mathrm{~min}$ in order to pellet the cellular debris. The supernatant was collected in 50 $\mathrm{ml}$ tubes and $1 \mathrm{ml}$ of $50 \% \mathrm{Ni}-\mathrm{NTA}$ resin slurry was added to $4 \mathrm{ml}$ lysate. This mixture was gently shaken for $1 \mathrm{hr}$ at room temperature and subsequently loaded in empty columns. After the flow-through was collected the Ni-NTA resin was two times washed with $4 \mathrm{ml}$ buffer $\mathrm{C}$, which contains $100 \mathrm{mM} \mathrm{NaH}_{2} \mathrm{PO}_{4}, 10 \mathrm{mM}$ Tris-Cl, $8 \mathrm{M}$ urea, $\mathrm{pH}$ 6.3. Recombinant Pga29p was eluted from the Ni-NTA resin by adding 4 times $0.5 \mathrm{ml}$ buffer $\mathrm{D}\left(100 \mathrm{mM} \mathrm{NaH}_{2} \mathrm{PO}_{4}, 10\right.$ $\mathrm{mM}$ Tris-Cl, $8 \mathrm{M}$ urea, $\mathrm{pH}$ 5.9) followed by addition of 4 times $0.5 \mathrm{ml}$ buffer E (100 mM $\mathrm{NaH}_{2} \mathrm{PO}_{4}, 10 \mathrm{mM}$ Tris-Cl, $8 \mathrm{M}$ urea, $\mathrm{pH} 4.5$ ). 


\subsubsection{Generation of anti-Pga29p polyclonal antibodies.}

Recombinant Pga29p was dialysed 3 times against phosphate-buffered saline (PBS) in order to decrease the urea concentration. The immunisation procedure was performed by a commercial company (Eurogentec, Liège, Belgium). Two New Zealand White rabbits were immunised with the $200 \mu \mathrm{g}$ protein on day $0,14,28$ and 50. On day 65 the rabbits were sacrificed and serum was collected. The serum was tested for anti-Pga29p activity by using immuno-blotting with recombinant Pga29p and HF-pyridine cell wall extract as antigens.

\subsection{Cell wall extraction, digestion and immuno blot analysis}

\subsubsection{Cell wall isolation}

For cell wall isolation we used a method that was developed in the laboratory of Frans Klis from the university of Amsterdam (De Groot et al., 2004). An overnight culture was diluted up to an $\mathrm{OD}_{600}$ of $0.1 \mathrm{in} 300 \mathrm{ml}$ YPD medium. The cells were harvested in the midexponential growth phase $\left(\mathrm{OD}_{600}=2.0\right)$ with centrifugation for $10 \mathrm{~min}$ at $4000 \times \mathrm{g}$ at $4{ }^{\circ} \mathrm{C}$. The cells were one time washed with $200 \mathrm{ml}$ of distilled water and centrifuged for $10 \mathrm{~min}$ at $4000 \times \mathrm{g}$ at $4^{\circ} \mathrm{C}$. Then the cell were washed in $200 \mathrm{ml}$ of $10 \mathrm{mM}$ Tris-HCl, $\mathrm{pH} 75$ and centrifuged for $10 \mathrm{~min}$ at $4000 \times \mathrm{g}$ at $4^{\circ} \mathrm{C}$. In order to weaken the cells, cell pellets were frozen in liquid nitrogen and subsequently thawed. The cell pellets were resuspended in $10 \mathrm{mM}$ Tris$\mathrm{HCl}, \mathrm{pH} 75$ and divided over 6 screw-cap tubes. The tubes were centrifuged for $1 \mathrm{~min}$ at $9000 \times \mathrm{g}$. After the supernatant was discarded, the cell pellets were resuspended in $200 \mu 10$ $\mathrm{mM}$ Tris-HCl, $\mathrm{pH} 75$. Cold glass beads with a diameter of approximately $500 \mathrm{~nm}$ (Sartorius, Göttingen, Germany) were added to the cells and the excess of dry beads was discarded. In total $30 \mu$ protease inhibitor was added to the cells ( $5 \mu$ per tube). The tubes were cooled down on ice and then transferred into the Fast Prep machine (Fastprep FP120, Bio101, Savant). To break the cells the samples were shaken for $20 \mathrm{sec}$ at speed 6 and were subsequently transferred on ice. After 5 min cooling on ice, the tubes were shaken again for $20 \mathrm{sec}$ at speed 6. The samples were transferred on ice and $1 \mathrm{M}$ of ice-cold $\mathrm{NaCl}$ was added to inhibit protease activity. The content of the tubes was collected in a $50 \mathrm{ml}$ tube and the supernatant was transferred in a second $50 \mathrm{ml}$ tube. The remaining glass beads in the first tube were six times washed by shaking vigoursly with $5 \mathrm{ml}$ of $1 \mathrm{M} \mathrm{NaCl}$. After every washing step the supernatant was collected in the second $50 \mathrm{ml}$ tube. This tube was centrifuged for $10 \mathrm{~min}$ at $4000 \times \mathrm{g}$ and the cell wall pellet was one time washed with $40 \mathrm{ml}$ of $1 \mathrm{M} \mathrm{NaCl}$ and two times with $40 \mathrm{ml}$ of distilled water. The cell wall pellets were resuspended in $5 \mathrm{ml}$ of distilled water and was divided over 5 eppendorf tubes of $2 \mathrm{ml}$. The tubes were centrifuged for $5 \mathrm{~min}$ 
at 20,000 $\times \mathrm{g}$. The pellets were resuspended in $1 \mathrm{ml}$ SDS extraction buffer of $\mathrm{pH} 7.8$ which contains $50 \mathrm{mM}$ Tris-HCl, $100 \mathrm{mM}$ EDTA, 2\% SDS and $100 \mathrm{mM} \beta$-mercapto-ethanol. The samples were boiled in a hot block for 5 min and subsequently cooled down at room temperature for $5 \mathrm{~min}$. The samples were centrifuged for $5 \mathrm{~min}$ at $20,000 \times \mathrm{g}$. Resuspending and boiling the samples in SDS extraction buffer was two times repeated. Then the samples were three times thoroughly washed in $1.5 \mathrm{ml}$ distilled water. The cell wall pellets were frozen in liquid nitrogen and freeze-dried overnight in a freeze dryer (Edwards). After freezedrying the dry-weight of the cell wall pellets was determined.

\subsubsection{Cell wall digestions with enzymes and chemicals}

For each cell wall digestion we routinely used $4 \mathrm{mg}$ of dry-weight cell wall. In case of double treatments ( $\beta$-1,3-glucanase and subsequently $\beta$-1,6-glucanase or $\beta$-1,6-glucanase and subsequently $\mathrm{NaOH}) 8 \mathrm{mg}$ cell wall was used.

For $\beta$-1,3-glucanase digestion, cell walls were resuspendend in $200 \mu \mathrm{l} 50 \mathrm{mM}$ Tris-HCL, $\mathrm{pH}$ 7.4, $0.7 \mu \mathrm{l} \beta$-mercapto-ethanol and $6 \mu \mathrm{l}$ Quantazyme. Cell walls were incubated at $37^{\circ} \mathrm{C}$ and were shaken in an Eppendorf shaker at $850 \mathrm{rpm}$. In case of a second treatment with $\beta-1,6-$ glucanase, the supernatant was dialysed (Spectrum laboratories, Canada, 3500 kDa MWCO) overnight in 41 of distilled water and subsequently freeze-dried.

For $\beta$-1,6-glucanase digestion, cell walls were resuspended in $200 \mu 1 \mathrm{Na}_{2} \mathrm{HPO}_{4}$ at $\mathrm{pH} 5.5,2 \mu \mathrm{l}$ protease inhibitor, $2,5 \mu 1 \beta$-1,6-glucanase. Cell walls were incubated at $37^{\circ} \mathrm{C}$ and were shaken in an Eppendorf shaker at $850 \mathrm{rpm}$. Prior to a second treatment with $\mathrm{NaOH}$, cell walls were two times boiled in SDS extraction buffer and three times washed in distilled water followed by freeze-drying overnight.

Besides $\beta$-1,6-glucanase digestion a second method was used to liberate GPI-proteins from the cell wall. Cell walls were resuspendend in $300 \mu l$ hydrogen fluoride pyridine (HFpyridine, Fluka) and were incubated for three hrs on ice. The samples were gently mixed every $30 \mathrm{~min}$. In order to quench the HF-pyridine, $300 \mu \mathrm{l}$ of distilled water was added to the samples. The samples were further diluted with $1.4 \mathrm{ml}$ of distilled water and were transferred to a dialysis tube. Dialysis was done overnight against distilled water. In order to dialyse efficiently, the water was changed several times until the samples obtained an appropriate $\mathrm{pH}$ value. Samples were collected in $14 \mathrm{ml}$ tubes (Greiner) and centrifuged at $4000 \times \mathrm{g}$. The supernatant was used for immuno-blot analysis. 
For mild alkali treatment cell walls were resuspendend in $91 \mu \mathrm{l}$ of ice-cold $30 \mathrm{mM} \mathrm{NaOH}$ solution and were incubated at $4^{\circ} \mathrm{C}$ overnight. The samples were neutralized by adding $109 \mu \mathrm{l}$ of ice-cold $30 \mathrm{mM}$ acetic acid.

\subsubsection{Immuno-blot analysis}

Three times Laemmli sample buffer $\mathrm{pH} 8.9$ was added to $\beta$-1,3-glucanase, $\beta$-1,6-glucanase and $\mathrm{NaOH}$ cell wall protein extracts and were heated at $100^{\circ} \mathrm{C}$ for 5 minutes. After cooling down at room temperature, samples were centrifuged at $20,000 \times \mathrm{g}$ in order to pellet the cell walls. For SDS-PAGE analysis $30 \mu \mathrm{l}$ of the supernatant was loaded per lane, which is equal to the amount of protein released from $0.4 \mathrm{mg}$ dry-weight cell walls. The proteins were separated on $11 \%$ polyacrylamide gels with Laemmli buffer and were transferred overnight to polyvinylidene difluoride membranes.

To enhance specificity of Pga29p detection, membranes were treated with $50 \mathrm{mM}$ periodic acid, $100 \mathrm{mM}$ sodium acetate at room temperature for $30 \mathrm{~min}$ with shaking. This treatment was not performed for membranes that would be treated with Concanavalin A (Con A) antibodies. The membranes were washed in PBS for $10 \mathrm{~min}$ and were subsequently blocked for 1 hour with a solution 5\% skim milk powder in PBS pH 7.2 (for Con A antibody treatment: blocking was performed in $3 \%(\mathrm{w} / \mathrm{v}) \mathrm{BSA}, 5 \mathrm{mM} \mathrm{CaCl}{ }_{2}$ and $2.5 \mathrm{mM} \mathrm{MnCl}_{2}$ in PBS pH 6.8). Membranes were incubated for 1-2 hours with anti-Pga29p polyclonal antibodies (1000 times diluted) or with Con A antibodies in blocking buffer, were subsequently washed three times in PBS and were incubated for 2 hours with Goat-AntiRabbit-Peroxidase antibodies in blocking buffer (no secondary antibody is needed for membranes treated with Con A antibodies, for these are labelled with peroxidase). Membranes were washed for 4 times in PBS and were incubated for 1 min with ECL solutions (GE Healthcare, Buckinghamshire, UK). High performance chemiluminescence films (GE Healthcare, Buckinghamshire, UK) were exposed for 2, 5 and $10 \mathrm{~min}$. Differences in expression between the samples were determined with the program ScanPack 3.0 (Grus and Nuske, Aachen, Germany). 


\subsection{PGA29 expression in hyphae}

\subsubsection{RNA isolation from C. albicans}

An overnight culture was diluted up to an $\mathrm{OD}_{600}$ of $0.1 \mathrm{in} 20 \mathrm{ml}$ YPD medium. The cells were harvested at an $\mathrm{OD}_{600}$ of 1 or further incubated at $37^{\circ} \mathrm{C}$ with $10 \%$ fetal calf serum (FCS) for $15 \mathrm{~min}, 30 \mathrm{~min}$ or $45 \mathrm{~min}$. The samples were centrifuged for $5 \mathrm{~min}$ at $4000 \times \mathrm{g}$ at $4^{\circ} \mathrm{C}$. The cell pellets were resuspended in $1 \mathrm{ml}$ DEPC-water and transferred to $2 \mathrm{ml}$ eppendorf tubes. The samples were centrifuged for $1 \mathrm{~min}$ at $20,000 \times \mathrm{g}$ and the pellets were resuspended in $600 \mu \mathrm{l}$ TES, which contains $10 \mathrm{mM}$ Tris-HCl pH 7.5, $10 \mathrm{mM}$ EDTA and 0.5\% SDS. To this $600 \mu \mathrm{l}$ acidic phenol were added followed by $20 \mathrm{sec}$ of vortexing. The samples were incubated for $60 \mathrm{~min}$ at $65^{\circ} \mathrm{C}$ and were vortexed every $15 \mathrm{~min}$ for $10 \mathrm{sec}$. Then the tubes were incubated for exactly $10 \mathrm{sec}$ in a mixture of ethanol and dry-ice and were subsequently centrifuged for $10 \mathrm{~min}$ at $20,000 \times \mathrm{g}$. Five hundred $\mu \mathrm{l}$ of the water phase were collected in new tubes and $500 \mu \mathrm{l}$ acidic phenol were added. The samples were vortexed for $10 \mathrm{sec}$ and incubated for $10 \mathrm{sec}$ in a mixture of ethanol and dry-ice. Then the samples were centrifuged for $10 \mathrm{~min}$ at $20,000 \times \mathrm{g}$ and subsequently $400 \mu \mathrm{l}$ of the water phase were collected in a new tube. To this $400 \mu \mathrm{l}$ neutral phenol/chloroform/isoamylalcohol (25:24:1) were added, followed by $10 \mathrm{sec}$ of vortexing. The samples were centrifuged for $10 \mathrm{~min}$ at 20,000×g and $300 \mu \mathrm{l}$ of the water phase were collected in a new tube. RNA was precipitated with $30 \mu \mathrm{l}$ of 3 M sodium acetate $\mathrm{pH} 5.2$ and $750 \mu 1$ 100\% ethanol. The samples were gently mixed and were incubated for $5 \mathrm{~min}$ in a mixture of ethanol and dry-ice. To collect the RNA the samples were centrifuged for $10 \mathrm{~min}$ at $20,000 \times \mathrm{g}$ and were subsequently washed in $500 \mu \mathrm{l}$ of $70 \%$ ethanol. The RNA pellets were air-dried and dissolved in $50 \mu \mathrm{l}$ of DEPC-water. The concentration of the RNA was measured spectrophotometrically at $260 \mathrm{~nm}$.

\subsubsection{Northern blot analysis}

For Northern blot analysis we used $20 \mu \mathrm{g}$ RNA per sample, which was dissolved in $20 \mu \mathrm{l}$ DEPC-water. To the samples $5 \times$ RNA sample buffer was added, which contained $1 \times$ MOPS buffer, $5 \times$ blue juice loading dye, $5.7 \%$ formaldehyde and $30.8 \%$ formamide. Then the samples were incubated at $65^{\circ} \mathrm{C}$ for $10 \mathrm{~min}$ and were cooled on ice for $5 \mathrm{~min}$. The samples were loaded on a $1.2 \%$ agarose gel $(150 \mathrm{ml})$, which contained $1 \times$ MOPS buffer and $2.7 \mathrm{ml}$ of $37 \%$ formaldehyde. Electrophoresis was performed at $65 \mathrm{~V}$ in $1 \times$ MOPS buffer. Prior to blotting, the gels were two times washed for $20 \mathrm{~min}$ in $250 \mathrm{ml} \mathrm{DEPC}$-water in order to remove the formaldehyde. RNA was transferred for $16 \mathrm{hrs}$ on a nylon-membrane (Hybond- 
$\mathrm{N}+$, GE Healthcare) with a $20 \times \mathrm{SSC}$ solution. After transferring the RNA, the membranes were washed in $6 \times \mathrm{SSC}$ and UV-treated with $700 \mathrm{~kJ}$ for $30 \mathrm{sec}$ (Hoefer UVC500 UV Crosslinker, MA, USA) in order to cross-link the RNA to the membranes. The membranes were incubated for 1 to $2 \mathrm{hrs}$ at $42^{\circ} \mathrm{C}$ in prehybridisation solution, which contained $50 \%$ formamide, $6 \times \mathrm{SSC}, 5 \times$ Denhardts reagent, $0.5 \%$ SDS and $100 \mu \mathrm{g}$ hering sperm DNA (5 min boiled prior to adding). Five to $10 \mu \mathrm{l}$ of the digoxygenin PCR probes (PGA29, PGA30, PGA31 and ACT1; for primer sequences see Table 7.) were diluted in $100 \mu 1$ water and boiled for $5 \mathrm{~min}$ followed by the addition of $100 \mu \mathrm{l}$ of formamide. The probes were incubated on ice for $5 \mathrm{~min}$ and were subsequently added to the prehybridisation solution. After an overnight incubation at $42^{\circ} \mathrm{C}$, the membranes were washed two times for $20 \mathrm{~min}$ at $42^{\circ} \mathrm{C}$ in $200 \mathrm{ml}$ washing buffer containing $2 \times \mathrm{SSC}$ and $0.5 \%$ SDS. Then the membranes were washed two times for $30 \mathrm{~min}$ at $65^{\circ} \mathrm{C}$ in a washing buffer containing $0.1 \times \mathrm{SSC}$ and $0.5 \%$ SDS. The membranes were equilibrated for $1 \mathrm{~min}$ in washing buffer which contained $0.1 \mathrm{M}$ maleic acid, $0.15 \mathrm{M}$ sodium chloride and $0.2 \%$ Tween $\mathrm{pH} 7.5$. The membranes were incubated for 1 to 2 hrs with a blocking buffer which was produced as follows: $5 \mathrm{~g}$ of milk powder was dissolved in $20 \mathrm{ml}$ distilled water. Then $1 \mathrm{M}$ of sodium hydroxide solution was added and the mixture was heated till a light brownish color appeared. The solution was cooled down and $5 \mathrm{ml}$ of 1 $\mathrm{M}$ maleic acid was added, resulting in a final concentration of $50 \mathrm{mM}$ maleic acid. Under constant stirring the solution was titrated with $1 \mathrm{M} \mathrm{HCl}$ to a $\mathrm{pH}$ of 8.0. To remove precipitated caseine, the solution was centrifuged at $4000 \times \mathrm{g}$ and the supernatant was collected.

After blocking, the membranes were incubated with blocking buffer and $10 \mu \mathrm{l}$ of antidigoxigenin-POD Fab fragments (Roche) per $10 \mathrm{ml}$ blocking buffer was added. After $1 \mathrm{hr}$ of incubation, the membranes were two times washed with washing buffer which contained 0.1 $\mathrm{M}$ maleic acid, $0.15 \mathrm{M}$ sodium chloride and $0.2 \%$ Tween $\mathrm{pH}$ 7.5. Then the membranes were briefly washed in one time PBS, pH 7.2 and were incubated for 1 min with ECL solutions (GE Healthcare). Exposure times to high performance chemiluminescence films (GE Healthcare, Buckinghamshire, UK) ranged from $20 \mathrm{~min}$ to $16 \mathrm{hrs}$.

\subsection{PGA29 deletion}

\subsubsection{Generation of gene disruption cassettes}

To knock-out both alleles of PGA29, gene disruption cassettes were generated by PCR using the primers PGA31pGEM-F and PGA31pGEM-R (Table 8). The plasmids pGEM-HIS1 and pRS-ARG4 $\Delta$ SpeI (Wilson et al., 1999) were used as a template. As selectable markers we 
used ARG4 and HISI with flanking regions of 50 bp that share homology with the untranslated regions of PGA29. To complement the URA3 auxotrophy in the double deletion mutants, we used the CIp10 (Murad et al., 2000), which integrates in the RPS10 locus. For complementation of PGA29, a SalI-MluI PGA29 PCR fragment of 1900 bp was amplified with primers Kompl-PGA29-F and Kompl-PGA29-R (Table 9.) and was subsequently digested and cloned in the CIp10 plasmid, generating CIp10-PGA29. The PGA29 fragment consisted of 898 bp promoter region and 486 bp terminator region. For transformation CIp10 and CIp10-PGA29 were linearized with the restriction enzyme StuI.

\subsubsection{Transformation of C. albicans}

For the most part, we used the transformation protocol from Walther and Wendland (2003). From an overnight culture, the BWP17 strain was inoculated in $50 \mathrm{ml}$ YPD medium supplemented with $80 \mathrm{mg} / \mathrm{ml}$ uridine at an $\mathrm{OD}_{600}$ of 0.2 . Cells were incubated at $30^{\circ} \mathrm{C}$ at 200 rpm. After reaching an $\mathrm{OD}_{600}$ of 1.0 , cells were collected by centrifugation with $4000 \times \mathrm{g}$ at $4^{\circ} \mathrm{C}$ and were one time washed in $30 \mathrm{ml}$ sterile water. Subsequently cells were washed with $30 \mathrm{ml}$ TEL, which contains $10 \mathrm{mM}$ Tris-HCl, $1 \mathrm{mM}$ EDTA and $100 \mathrm{mM}$ lithium acetate, $\mathrm{pH}$ 7.5. The cell pellet was resuspended in $1.5 \mathrm{ml}$ TEL. The transformation mixture contained 100 $\mu \mathrm{l}$ cells, $100 \mu \mathrm{g}(10 \mu \mathrm{l})$ Yeast Maker Carrier DNA (Clontech), 600 $\mu 1$ 40\% Polyethylene glycol 4000 in TEL and 10-15 $\mu \mathrm{g}$ knock-out cassette dissolved in 25-100 $\mu$ l water. After vortexing, the transformation mixture was incubated overnight at $30^{\circ} \mathrm{C}$. The next day heat shock was performed at $44^{\circ} \mathrm{C}$ for $15 \mathrm{~min}$. Cells were pelleted with $800 \times \mathrm{g}$ and were subsequently resuspended in $200 \mu \mathrm{l}$ TE, which contains $10 \mathrm{mM}$ Tris- $\mathrm{HCl}$ and $1 \mathrm{mM}$ EDTA, $\mathrm{pH}$ 7.5. Cells were plated out on $\mathrm{YNB}+2 \%$ glucose agar medium, which was supplemented with $20 \mu \mathrm{g} / \mathrm{ml}$ arginine, $20 \mu \mathrm{g} / \mathrm{ml}$ histidine and $40 \mu \mathrm{g} / \mathrm{ml}$ uridine as required and were incubated at $30^{\circ} \mathrm{C}$. After 2 to 4 days colonies were subcultured for genomic DNA isolation.

\subsubsection{DNA isolation from C. albicans}

To harvest cells, a $10 \mathrm{ml}$ overnight YPD culture was centrifuged in a $50 \mathrm{ml}$ tube for $5 \mathrm{~min}$ at $4000 \times \mathrm{g}$. The cell pellet was washed with $1 \mathrm{ml}$ of $1 \mathrm{M}$ sorbitol and the cells were divided over two $2 \mathrm{ml}$ eppendorf tubes. The samples were centrifuged for $5 \mathrm{~min}$ at $20,000 \times \mathrm{g}$. Then the cells were resuspended in $1 \mathrm{ml}$ zymolyase solution, which contains $0.64 \mathrm{M}$ sorbitol, $30 \mathrm{mM}$ potassium phosphate $\mathrm{pH}$ 7.5, $6.4 \mathrm{mM}$ DTT and $0.25 \mathrm{mg} / \mathrm{ml}$ zymolase $20 \mathrm{~T}$ (Seikagaku Corporation, Tokyo, Japan). The samples were incubated at $37^{\circ} \mathrm{C}$ for $1.5-2 \mathrm{hrs}$ and were 
gently mixed every $20 \mathrm{~min}$. Then the samples were centrifuged for $1 \mathrm{~min}$ at $20,000 \times \mathrm{g}$ and the pellets were subsequently washed with $1 \mathrm{ml}$ of $1 \mathrm{M}$ sorbitol. After $5 \mathrm{~min}$ centrifugation for 5 min, the samples were resuspended in $600 \mu \mathrm{l}$ of $50 \mathrm{mM}$ EDTA/0.2\% SDS solution followed by addition of $600 \mu \mathrm{l}$ of phenol/chloroform. The samples were vortexed for $20 \mathrm{sec}$ and were subsequently centrifuged for $10 \mathrm{~min}$ at $20,000 \times \mathrm{g}$. Five hunderd $\mu \mathrm{l}$ of the water phase were collected and transferred to a new tube. The phenol/chloroform extraction was repeated and $400 \mu \mathrm{l}$ of the water phase was collected. Then $400 \mu \mathrm{l}$ of chloroform were added to the samples and after vortexing for $10 \mathrm{sec}$ the samples were centrifuged for $10 \mathrm{~min}$ at $20,000 \times \mathrm{g}$. Three hundred $\mu \mathrm{l}$ of the water phase was collected and transferred to a new tube. For precipitation, $30 \mu \mathrm{l}$ of $3 \mathrm{M}$ sodium acetate $\mathrm{pH} 5.2$ solution and $660 \mu \mathrm{l}$ of $100 \%$ ethanol were added to the samples. The samples were gently mixed and were incubated for overnight at $20^{\circ} \mathrm{C}$. The next day samples were centrifuged for $10 \mathrm{~min}$ at $20,000 \times \mathrm{g}$ and were subsequently washed with $500 \mu \mathrm{l}$ of $70 \%$ ethanol. The DNA pellets were air-dried and were subsequently dissolved in $50 \mu \mathrm{l}$ water. To remove the RNA, $1 \mu \mathrm{l}$ of $10 \mathrm{mg} / \mathrm{ml}$ RNAse A was added to the samples. After mixing, the samples were stored overnight at $4^{\circ} \mathrm{C}$. In order to estimate the DNA concentration, $1 \mu \mathrm{l}$ of each sample was checked visually on a $1 \%$ agarose gel.

\subsubsection{Southern blotting}

Eight $\mu \mathrm{g}$ digested genomic DNA per sample and $12.5 \mu \mathrm{l}$ of the digoxygenin DNA molecular weight marker were loaded on a $0.8 \%$ agarose gel. Electrophoresis was performed overnight at $20 \mathrm{~V}$. In order to depurinate the DNA, the gel was washed in $0.25 \mathrm{M} \mathrm{HCl}$ solution. Then the gel was washed two times for $20 \mathrm{~min}$ in denaturing solution, which contains $1.5 \mathrm{M} \mathrm{NaCl}$ and $0.5 \mathrm{M} \mathrm{NaOH}$, followed by two times washing for $20 \mathrm{~min}$ in neutralisation solution which contains $1.5 \mathrm{M} \mathrm{NaCl}$ and $0.5 \mathrm{M}$ Tris- $\mathrm{HCl} \mathrm{pH}$ 8.0. DNA was transferred for $16 \mathrm{hrs}$ on a nylonmembrane (Hybond-N+, GE Healthcare) with a $20 \times \mathrm{SSC}$ solution. After transferring the DNA, the membranes were washed in $6 \times \mathrm{SSC}$ and UV-treated with $700 \mathrm{~kJ}$ for $30 \mathrm{sec}$ (Hoefer UVC500 UV Crosslinker, MA, USA) in order to cross-link the DNA to the membranes. The membranes were incubated for $2 \mathrm{hrs}$ at $37^{\circ} \mathrm{C}$ in prehybridisation solution (see Northern blotting). Five to $10 \mu \mathrm{l}$ of the digoxygenin PCR probes (ARG4, HIS1 and URA3; for primers see Table 9.) were diluted in $100 \mu \mathrm{l}$ water and boiled for $5 \mathrm{~min}$ followed by the addition of $100 \mu \mathrm{l}$ of formamide. The probes were incubated on ice for $5 \mathrm{~min}$ and were subsequently added to the prehybridisation solution. After an overnight incubation at $37^{\circ} \mathrm{C}$, the membranes were washed two times for $20 \mathrm{~min}$ at $37^{\circ} \mathrm{C}$ in $200 \mathrm{ml}$ washing buffer containing $2 \times \mathrm{SSC}$ and 
$0.5 \%$ SDS. Then the membranes were washed two times for $30 \mathrm{~min}$ at $65^{\circ} \mathrm{C}$ in a washing buffer containing $0.1 \times \mathrm{SSC}$ and $0.5 \%$ SDS. The membranes were equilibrated in PBS $\mathrm{pH} 7.2$ for $1 \mathrm{~min}$ at room temperature followed by $1 \mathrm{hr}$ blocking in 5\% milk powder, $0.1 \%$ Tween and PBS pH 7.4. Then $10 \mu \mathrm{l}$ anti-digoxigenin-POD Fab fragments (Roche) per $10 \mathrm{ml}$ blocking buffer were added. After 2 hrs of incubation, the membranes were washed three times for 10 min with PBS and $0.1 \%$ Tween $\mathrm{pH}$ 7.2. Then the membranes were incubated with ECL solutions and high performance chemiluminescence films (GE Healthcare, Buckinghamshire, UK) were exposed for 7-60 min.

\subsection{Cell wall composition analysis}

\subsubsection{Electron microscopy}

Cells were harvested at $2000 \mathrm{rpm}$ using a Stat Spin Microprep 2 table top centrifuge. The pellet was resuspended with $10 \%$ Dextran. A drop of the paste was placed on a flat embedding specimen holder (Leica Microsystems, Wetzlar, D-35578 Germany) and frozen in a Leica EM PACT high pressure freezer, and Automatic Freeze Substitution Unit (AFS). The samples were substituted at $-90^{\circ} \mathrm{C}$ in a solution containing anhydrous acetone, $0.1 \%$ tannic acid for $24 \mathrm{hrs}$ and in anhydrous acetone, $2 \% \mathrm{OsO}_{4}$ for additional $8 \mathrm{hrs}$. After a further incubation over $20 \mathrm{hrs}$ at $-20^{\circ} \mathrm{C}$ samples were warmed up to $+4^{\circ} \mathrm{C}$ and subsequently washed with anhydrous acetone. The samples were embedded at room temperature in Agar 100 (Epon 812 equivalent) at $60^{\circ} \mathrm{C}$ over $24 \mathrm{hrs}$. Images were taken in a Philips CM120 electron microscope (Philips Inc.) using a TemCam 224A slow scan CCD camera (TVIPS, Gauting, Germany).

\subsubsection{Chitin determination}

For each strain $4 \mathrm{mg}$ of dry weight cell walls was resuspended in $100 \mu \mathrm{l} 1 \mathrm{M} \mathrm{NaOH}$ solution and were subsequently boiled for $10 \mathrm{~min}$ in order to extract proteins. After cooling at room temperature, $1 \mathrm{M}$ of $\mathrm{HCl}$ was added followed by centrifugation for $5 \mathrm{~min}$ at $20,000 \times \mathrm{g}$. The supernatant was collected for protein determination. The cell wall pellets were hydrolysed in $1 \mathrm{ml}$ of $6 \mathrm{M} \mathrm{HCl}$ at $100^{\circ} \mathrm{C}$ for $17 \mathrm{hrs}$. A standard curve was generated with different concentrations of $\mathrm{D}(+)$-glucosamine. The $\mathrm{HCl}$ was evaporated by air stream at $100^{\circ} \mathrm{C}$. The samples were resuspended in $1 \mathrm{ml}$ distilled water and were centrifuged for $10 \mathrm{~min}$ at $20,000 \times \mathrm{g}$. The supernatants were tranferred to new eppendorf tubes. To $0.1 \mathrm{ml}$ sample (supernatant) $0.1 \mathrm{ml}$ Solution A was added, which contains $1.5 \mathrm{M} \mathrm{Na}_{2} \mathrm{CO}_{3}$ solution and $4 \%$ 
acetylacetone. The samples were incubated at $100^{\circ} \mathrm{C}$ for $20 \mathrm{~min}$, subsequently cooled down at room temperature and $0.7 \mathrm{ml}$ of $96 \%$ ethanol was added followed by the addition of $0.1 \mathrm{ml}$ solution $\mathrm{B}$, which contains $1.6 \mathrm{~g}$ of $p$-dimethyl-aminobenzaldehyde, $30 \mathrm{ml}$ of concentrated $\mathrm{HCl}$ and $30 \mathrm{ml}$ of $96 \%$ ethanol. After incubation of $1 \mathrm{hr}$ at room temperature, the OD was measured at $520 \mathrm{~nm}$.

\subsubsection{Protein determination}

The protein concentration of cell walls was determined with the bicinchoninic acid protein assay (BCA assay, Pierce Biotechnology). To $10 \mu \mathrm{l}$ of the supernatant (see Chitin determination) $1 \mathrm{ml}$ of BCA solution was added. A standard curve was generated with different concentrations of BSA $(0-10 \mu \mathrm{g})$. The samples were $30 \mathrm{~min}$ incubated at $37^{\circ} \mathrm{C}$ and were measured spectrophotometrically at $563 \mathrm{~nm}$.

\subsubsection{Determination of the mannose/glucose ratio}

In order to determine the glucose/mannose ratio of the cell walls, the polysaccharides in cell wall preparations were hydrolyzed by using $\mathrm{H}_{2} \mathrm{SO}_{4}$ (sulphuric acid) (Dallies et al. 1998). For each strain 3 independent cell wall samples were used. Briefly, $4 \mathrm{mg}$ of dry weight cell walls were incubated with $100 \mu 172 \%(\mathrm{v} / \mathrm{v}) \mathrm{H}_{2} \mathrm{SO}_{4}$ for $3 \mathrm{hrs}$ at room temperature. Samples were then diluted with $575 \mu \mathrm{l}$ distilled water to obtain a $2 \mathrm{M} \mathrm{H}_{2} \mathrm{SO}_{4}$ solution, and incubated for 4 hrs at $100^{\circ} \mathrm{C}$. Samples were analyzed by HPLC (LKB) on a REZEX organic acid analysis column (Phenomenex, Torrance, CA) at $40^{\circ} \mathrm{C}$ with $7.2 \mathrm{mM}$ sulphuric acid as eluent, using a RI 1530 refractive index detector (Jasco, Great Dunmow, UK). The chromatograms were analyzed using AZUR chromatography software and compared with chromatograms of known amounts of mannose and glucose.

\subsubsection{Cell wall proteome of the Apga29/4pga29 mutants}

\subsubsection{Sample preparation for MS analysis}

Samples for in-solution digestions were desalted and rebuffered with $50 \mathrm{mM} \mathrm{NH}_{4} \mathrm{HCO}_{3}$ by using 0.5-kDa-cutoff centrifugal filters (Millipore). In-solution digestion with trypsin (sequencing grade; Roche Diagnostics, Indianapolis, Ind.) was carried out overnight at $37^{\circ} \mathrm{C}$ using a CWP/trypsin ratio of 50:1. 


\subsubsection{MS analysis}

After digestion, peptides were desalted and collected on Omix $\mathrm{C}_{18}$ pipette tips (Varian), washed with $0.1 \%$ formic acid, and eluted with $60 \%$ acetonitrile- $0.1 \%$ formic acid.

Proteolytic digests derived from $30 \mu \mathrm{g}$ of freeze-dried cell walls were fractionated on a 150$\mathrm{mm}$ by $75-\mu \mathrm{m}$ (length $\times$ inner diameter) reversed-phase capillary column (PepMap $\mathrm{C}_{18}$; Dionex) using an Ultimate nano-LC system (Dionex). The peptides were separated over a period of 30 min with a two-step linear gradient of 0 to $50 \%$ acetonitrile plus $0.1 \%$ formic acid, and the outflow at $300 \mathrm{nl} / \mathrm{min}$ was directly electrosprayed into the Q-Tof1 (Waters) operating in data-dependent MS and MS/MS mode. The Masslynx software (Waters) was instructed to select ions ranging from $\mathrm{m} / \mathrm{z}, 350$ to 1,500 with a charge state of at least $2+$ above a base peak intensity (BPI) ion count threshold of 40 for collision-induced fragmentation using argon as the collision gas. The resulting MS/MS spectra were processed with the Biolynx tool of the Masslynx software program, which generated a peak list (.pkl file) with all precursor and product ions calculated to the corresponding $\mathrm{MH}^{+}$charge state. Each

LC/MS/MS run was repeated at least twice, thereby excluding abundant ions from previous runs. For protein identification, the resulting spectra and amino acid sequences were analyzed using MASCOT software and compared with in silico digests of the CandidaDB protein database (http://genolist.pasteur.fr/CandidaDB/). This database was created by the European Union-funded consortium Galar Fungail by performing independent annotation of sequence data (contig assembly 19) obtained from the Stanford Genome Technology Center (http://www-sequence.stanford.edu/group/candida).

\subsection{Phenotypic analysis}

\subsubsection{Growth determination at different $\mathrm{pH}$ values}

To determine the growth rate we cultured our strains in liquid YPD medium with $1 \%$ glucose at different $\mathrm{pH}$ values. Medium was buffered with $10 \mathrm{mM} \mathrm{CH}_{3} \mathrm{COONa}$ (for $\mathrm{pH} 4.0$ and 5.0), $10 \mathrm{mM} \mathrm{NaH}_{2} \mathrm{PO}_{4}$ (for $\mathrm{pH} 6.0$ and 7.0) and $10 \mathrm{mM}$ Tris- $\mathrm{HCl}$ (for $\mathrm{pH} 8.0$ and $\mathrm{pH} 9.0$ ). Overnight cultures were diluted with water until a turbidity of $0.5 \mathrm{McF}$ arland units was reached. Cells were diluted 100 times and subsequently $100 \mu$ cells were mixed with $100 \mu 1$ of 2 times concentrated medium. The cells were cultured in 96 -wells plates at $30^{\circ} \mathrm{C}$ and $\mathrm{OD}_{600}$ was measured at 15 min time intervals. 


\subsubsection{Growth rate determination with microdilution spot assay}

An overnight YNB culture was diluted up to an $\mathrm{OD}_{600}$ of 0.2 and incubated at $30^{\circ} \mathrm{C}, 200 \mathrm{rpm}$. After reaching an $\mathrm{OD}_{600}$ of 1.0, the cells were diluted to a cell density of $8.0 \times 10^{5}$ in $50 \mathrm{mM}$ Tris- $\mathrm{HCl}, \mathrm{pH}$ 7.5. This cell suspension was serially diluted using $1 / 5$ dilution steps. In this way, six different dilutions were made and of each $3 \mu$ was spotted on the surface of the YPD or YNB agar medium that was supplemented with $0-75 \mu \mathrm{g} / \mathrm{ml}$ Calcofluor White $(\mathrm{CFW})$ or 0.01-0.05\% sodium dodecyl sulphate (SDS).

\subsection{3 $\beta$-1,3-glucanase sensitivity assay}

To determine the sensitivity to $\beta$-1,3-glucanase of the mutants we used the recombinant $\beta-1,3$ glucanase Quantazym. From an overnight YNB culture, fresh cultures were inoculated to a starting $\mathrm{OD}_{600}$ of 0.1 and were subsequently grown at $30^{\circ} \mathrm{C}$ till an $\mathrm{OD}_{600}$ of 2.0 was reached. Then the cultures were collected by centrifugation, washed one time in $50 \mathrm{mM}$ Tris- $\mathrm{HCl}, \mathrm{pH}$ 7.5 and resuspened in the same solution. The cells were diluted to an $\mathrm{OD}_{600}$ of 1.0 in $50 \mathrm{ml}$ of Tris-HCL, pH 7.5 and $\beta$-mercaptoethanol was added to a final concentration of $40 \mathrm{mM}$. After an incubation of 1 hour at room temperature, $5 \mathrm{U} / \mathrm{ml}$ Quantazym was added and the samples were incubated in a water bath at $37^{\circ} \mathrm{C}, 150 \mathrm{rpm}$. The decrease of the $\mathrm{OD}_{600}$ was measured over a time period of 1 hour. The experiment was repeated two times and from the average values a curve was generated

\subsubsection{Determination of antimycotic susceptibility using E-test}

The E-test (Inverness, Cologne) was used to asses the susceptibility to Fluconazole, Intraconazole, Voriconazole, Caspofungin, 5-Fluocytosin and Amphotericin B. Five colonies from Sabouraud agar were collected and resuspended in water. The cells were diluted to 0.5 McFarland units and were streaked out on RPMI agar medium supplemented with $0.05 \%$ methylene blue. E-test strips were laid on top of the agar medium and the plates were incubated for $24 \mathrm{hrs}$ at $35^{\circ} \mathrm{C}$. Growth inhibition was determined visually according to the suggestions of the manufacturer.

\subsubsection{Yeast-to-hyphae transition}

The ability of the mutants to generate hyphae was tested in several media. Serum induced hyphae formation was tested in liquid or solid YPD medium. For liquid medium, yeast cells were grown to the mid-log phase $\left(\mathrm{OD}_{600}=0.5\right)$ at $30^{\circ} \mathrm{C}$ in YPD medium. The cells were then 
harvested by centrifugation and two times washed in PBS. The cells were resuspended in prewarmed YPD medium $+10 \% \mathrm{FCS}, \mathrm{pH} 7.0$ (unbuffered) and incubated at $30^{\circ} \mathrm{C}$ and $37^{\circ} \mathrm{C}$ for 5 hours. Every $30 \mathrm{~min}$ the cells were observed with light microscopy in order to check germ tube development. For hyphae formation on solid YPD medium with 10\% FCS, a liquid overnight culture of yeast cells was two times washed in PBS. To determine the number of cells per ml, cells were counted in a Neubauer counting chamber. The cell suspension was diluted accordingly and 200 cells per Petri dish were plated out. The cells were incubated at $30^{\circ} \mathrm{C}$ and $37^{\circ} \mathrm{C}$ for 7 days.

For testing pH-regulated hyphal formation we used modified Lee's medium (Buffo et al., 1984). Briefly, cells were plated out on YNB plates and incubated overnight at $30^{\circ} \mathrm{C}$. The next day single colonies were collected and were incubated in modified Lee's medium, $\mathrm{pH}$ 4.5 at $25^{\circ} \mathrm{C}$ for 24 hours. To induce hyphae, $0.5 \mathrm{ml}$ of this culture was diluted in $25 \mathrm{ml}$ of modified Lee's medium, pH 6.7. Over a time period of 5 hours, every 30 min hyphal formation was checked with light microscopy.

For N-acetylglucosamine induced hyphal formation an overnight YPD culture was harvested by centrifugation and two times washed with PBS. Cells were resuspended at an $\mathrm{OD}_{600}=1.0$ in $25 \mathrm{ml}$ pre-warmed SB medium with $10 \mathrm{mM}$ proline. After 1 hour incubation at $30^{\circ} \mathrm{C}$, cells were inoculated at an $\mathrm{OD}_{600}$ of $0.1 \mathrm{in} 25 \mathrm{ml}$ pre-warmed $\mathrm{SB}$ medium with $2.5 \mathrm{mM} \mathrm{N}$ acetylglucosamine. The cells were incubated at $37^{\circ} \mathrm{C}$ for 5 hours and every 30 min hyphal formation was checked with light microscopy.

Nutrient-deprived hyphal induction was performed with Spider medium with mannitol as a sole carbon source (Liu et al., 1994). An overnight YPD culture was two times washed in PBS. To determine the number of cells per ml, cells were counted in a Neubauer counting chamber. The cell suspension was diluted accordingly and 200 cells were plated out per Petri dish. The cells were incubated for 7 days at $30^{\circ} \mathrm{C}$ or $37^{\circ} \mathrm{C}$.

Quorum sensing-based induction of hyphae was carried out in YPD, pH 7.5 buffered with a correct proportion of $\mathrm{Na}_{2} \mathrm{HPO}_{4}$ and $\mathrm{NaH}_{2} \mathrm{PO}_{4}$ to a $100 \mathrm{mM}$ final concentration. Cells were grown either at $30^{\circ} \mathrm{C}$ or $37^{\circ} \mathrm{C}$ to the stationary phase. Hyphal growth was triggered by diluting these cultures to an $\mathrm{OD}_{600}$ of 0.5 in fresh pre-warmed buffered YPD (Enjalbert and Whiteway, 2005). The cells were observed every 30 min over a time period of 5 hours.

Chlamydospore formation was tested on Rice-Tween agar. From YNB agar colonies were collected with a loop and were streaked out on Rice-Tween agar. In order to reduce the 
oxygen concentration, a coverslip was placed on the cells and were incubated at $25^{\circ} \mathrm{C}$ for 5 days.

\subsubsection{Hyphae-to-yeast-transition}

Hyphal growth was induced in $10 \mathrm{ml}$ YPD + 10\% FCS as described above. After 3.5 hours of hyphal growth, hyphae were collected by centrifugation and three times washed in $1 \times$ PBS. In order to stimulate blastoconidia growth, hyphae were resuspended in $20 \mathrm{ml}$ YPD and incubated at $30^{\circ} \mathrm{C}$. Blastoconidia formation was observed every $30 \mathrm{~min}$ over a time period of 7 hours.

\subsubsection{Adhesion assays}

Three different adhesion assays were used in this study. In the first assay the colony forming units were counted after incubating the $C$. albicans cells with plastic or Caco-2 cells (Dieterich et al, 2002). Caco-2 cells were grown in D-MEM medium supplemented with 10\% FCS in 24-well polystyrene plates. The cells were incubated at $37^{\circ} \mathrm{C}$ in a $5 \% \mathrm{CO}_{2}, 95 \%$ humidity atmosphere and grown to a confluent stage. C. albicans strains were grown at $30^{\circ} \mathrm{C}$ to the mid-log phase or stationary phase and were diluted in $250 \mu \mathrm{D}$ D-MEM medium supplemented with $10 \%$ FCS without the addition of antibiotics to a concentration of 400 cells $/ \mathrm{ml}$. The cells were distributed in the 24 -well plates and incubated at $37^{\circ} \mathrm{C}, 5 \% \mathrm{CO}_{2}$ for $15,30,45,60$ and $120 \mathrm{~min}$. Non-adherent cells were collected by vigorously shaking of the plates followed by aspirating the media. The media with non-adherent cells was plated out on YPD agar. In addition each well was washed with PBS and this was also plated out. Adherent cells were scraped off using a cell scraper (LPS life sciences) and $300 \mu \mathrm{l}$ PBS. The cells were plated out on YPD agar and incubated at $30^{\circ} \mathrm{C}$ overnight. The next day colony forming units were counted.

In the second assay, adhesion of $C$. albicans yeast cells was determined on tissue culturetreated and non-treated polystyrene Petri dishes. Cells were grown in YPD at $30^{\circ} \mathrm{C}$ or $37^{\circ} \mathrm{C}$ for 24 hours and were diluted in YPD or PBS, pH 7.4 to an $\mathrm{OD}_{600}$ of 2.0. Cells were spotted in $25 \mu \mathrm{l}$ drops on the plates and were incubated for 3, 4, 6 and $24 \mathrm{hrs}$ in a humidified chamber at $30^{\circ} \mathrm{C}$ or $37^{\circ} \mathrm{C}$. The drops were carefully aspirated and on the adherent cells $25 \mu 1$ of $0.1 \%$ crystal violet solution was spotted. After an incubation of $30 \mathrm{~min}$ at room temperature, cells were washed with water or a $1 \mathrm{M} \mathrm{NaCl}$ solution. The adhesion of cells was visually determined. 
For the hyphal adhesion assay, cells were grown in YPD at $30^{\circ} \mathrm{C}$ or $37^{\circ} \mathrm{C}$ for 24 hours and were diluted in modified RPMI to a concentration of 100 or 200 cells $/ \mathrm{ml}$. The cells were distributed in tissue culture treated 24 -well plates $\left(1 \mathrm{ml}\right.$ per well) and were incubated at $37^{\circ} \mathrm{C}$ in a humidified chamber. Cells were incubated for 3 days and adhesion was examined at intermediate times by gently shaking the plates. After shaking, the proportion of adherent and non-adherent colonies was assessed.

\subsection{Phenotypic analysis in infection models}

\subsubsection{Mouse model for systemic candidosis}

For infection studies, parental and mutant strains were grown at $30^{\circ} \mathrm{C}$ in YED agar plates $(1 \%$ Difco Yeast extract, 2\% glucose, and 2\% agar). After $24 \mathrm{hrs,} \mathrm{cells} \mathrm{were} \mathrm{harvested,} \mathrm{washed}$ twice with PBS and diluted to the desired density in the same buffer for injection into the lateral tail vein of the mice at a volume of $0.5 \mathrm{ml}$.

Both male and female BALB/c mice, ranging in age from 12 to 16 weeks and with a weight of about $18 \mathrm{~g}$, were used in the virulence studies. All animal studies were carried out in cooperation with the Animal Facilities of the School of Medicine at the Universidad Complutense of Madrid.

\subsubsection{Reconstituted Human Epithelial model based on oral candidosis}

Well-established models of reconstituted human oral epithelium (oral RHE), based on the buccal epithelial carcinoma cell line TR146, were supplied by SkinEthic Laboratories, Nice, France (Rupniak et al., 1985). Strains were cultured over 3 days in order to obtain synchronized yeast populations. Strains were streaked out on Sabouraud agar medium and were incubated for 24 hours at $37^{\circ} \mathrm{C}$. Colonies were collected with a loop and were resuspended in $5 \mathrm{ml} 0.9 \% \mathrm{NaCl}$ solution. The cells were washed three times in $0.9 \% \mathrm{NaCl}$ solution and were resuspended in $5 \mathrm{ml}$ water. The cell density was determined with a Neubauer counting chamber and the suspensions were diluted to $2 \times 10^{6}$ cells $/ \mathrm{ml}$. The cells were collected by centrifugation and were resuspended in $10 \mathrm{ml}$ YPD medium. Cultures were grown in $15 \mathrm{ml}$ Falcon tubes for 16 hours at $25^{\circ} \mathrm{C}, 200 \mathrm{rpm}$. The next day the cells were 3 times washed as described above and the suspensions were diluted to $4 \times 10^{6}$ cells $/ \mathrm{ml}$. The cells were collected by centrifugation and resuspended in $10 \mathrm{ml}$ YPD. The cultures were grown in $15 \mathrm{ml}$ Falcon tubes for 24 hours at $37^{\circ} \mathrm{C}, 200 \mathrm{rpm}$. Cells were 3 times washed in $1 \times \mathrm{PBS}$ and the cell suspensions were adjusted to $2.0 \times 10^{6}$ cells in $50 \mu \mathrm{l} 1 \times \mathrm{PBS}$. Oral RHE 
samples were incubated with or without $2 \times 10^{6}$ cells in $50 \mu \mathrm{PBS}$ for $24 \mathrm{~h}$ at $37^{\circ} \mathrm{C}$ with $5 \%$ $\mathrm{CO}_{2}$ at $100 \%$ humidity. All experiments were performed in the absence of antibiotics and antimycotics.

\subsubsection{Light microscopy}

Light microscopical studies were performed as previously described using paraffin-embedded oral RHE specimens (Schaller et al. 2002, 2004). Briefly, a part of each specimen was fixed, postfixed and embedded in glycide ether, and cut using an ultramicrotome (Ultracut). Semithin sections $(1 \mu \mathrm{m})$ were studied with a light microscope after staining with $1 \%$ toluidine blue and $1 \%$ pyronine $\mathrm{G}$ (Merck). The histological changes of the mucosa were evaluated on the basis of 50 sections from five different sites for each infected epithelium.

\subsubsection{Epithelial cell damage assay}

In all experiments, the release of LDH from epithelial cells into the surrounding medium at 24 hours was used as a measure of epithelial cell damage. LDH activity was analysed spectrophotometrically by measuring the reduced nicotinamide adenine dinucleotide disappearance rate at $340 \mathrm{~nm}$ as a main wavelength during the LDH-catalysed conversion of pyruvate to lactate according to Wróblewski and John (1955). The determination of the LDH activity was performed by using the Cytotoxicity Detection Kit (Roche).

\subsubsection{RNA isolation and quantitative RT-PCR}

Total RNA was isolated from oral RHE samples using the NucleoSpin RNA II-kit (MachereyNagel, Düren, Germany) including DNA digestion. For assessing RNA concentration and purity, UV spectroscopy was used (Bio Photometer, Eppendorf). cDNA was synthesized using the Superscript III first-strand synthesis supermix for qRT-PCR (Invitrogen) according to the manufacturer's instructions. Real-time PCR reactions were performed on a Light Cycler 480 instrument with LightCycler 480 SYBR Green I Master (Roche Molecular Diagnostics) in a total reaction volume of $10 \mu$ l. Primer pairs that were used for amplification are listed in table 10. Data on the expression level were obtained in the form of crossing point (CP) values based on the 'second derivative maximum' method as computed by the LightCycler 480 software (Roche Molecular Diagnostics). Both standard and experimental samples were performed in triplicate and the average $\mathrm{Cp}$ reading used. Fold difference in gene expression was normalized to the housekeeping genes YWHAZ and G6PD, since detailed preliminary investigations using 10 different housekeeping genes (ALDOA, B2M, G6PD, GAPDH, 
HMBS, POLR2A, SDHA, TBP, UBC and YWHAZ) indicated that these genes showed the most constant level of expression.

\subsubsection{Determination of cytokine release}

Culture medium was collected after 24 hrs of infection and assayed for GM-CSF, IL-6, IL-8, and TNF- $\alpha$, using commercially available ELISA kits (DuoSet; R\&D Systems, Minneapolis, MN, USA).

\subsection{Interaction assays with immune cells}

\subsubsection{Primary culture myeloid dendritic cells (mDCs)}

This protocol is based on method described previously by Inaba et al. (1992). The bone marrow isolation was performed as described above for mMPs. Black six mice (6-8 weeks old) were dissected, bones were rinsed with 70\% ethanol and PBS and subsequently kept on ice in ice-cold PBS. At the knee joint, the femur and tibia were separated and the bone marrow was flushed by using a $20 \mathrm{ml}$ syringe with a 27GX374 needle with DMEM with 10\% FCS, $100 \mathrm{U} / \mathrm{ml}$ penicilin and $100 \mu \mathrm{g} / \mathrm{ml}$ streptomycin. The bone marrow cell suspension was centrifuged at $700 \times \mathrm{g}$ for $7 \mathrm{~min}$. The pellet was resuspended in $1 \mathrm{ml}$ of red cell lysis buffer, $\mathrm{pH}$ 7.2, which contained $10 \mathrm{mM} \mathrm{KHCO}_{3}, 150 \mathrm{mM} \mathrm{NH}_{4} \mathrm{Cl}$ and $0.1 \mathrm{mM}$ EDTA. Lysis was immediately stopped with $1 \mathrm{ml}$ of $\mathrm{mDC}$ medium. Cells were collected by centrifugation at $700 \times \mathrm{g}$ for $7 \mathrm{~min}$ and the pellet was resuspended in $5 \mathrm{ml} \mathrm{mDC}$ medium. The cell density was determined and the suspension was distributed in a 24 well plate with $1.0 \times 10^{6}$ cells per well in $1 \mathrm{ml}$. Cells were incubated at $37^{\circ} \mathrm{C}$ in a $5 \% \mathrm{CO}_{2}, 95 \%$ humidity atmosphere and grown for 4 days. Then $0.5 \mathrm{ml}$ was removed from each well and $1 \mathrm{ml}$ of fresh $\mathrm{mDC}$ medium was added. After 3 days, non-adherent mDC aggregates were collected by flushing the medium against the well wall with a $1 \mathrm{ml}$ Pipet set at $800 \mu \mathrm{l}$, in order to limit the amount of adherent cells to be taken up. All cells were pooled and replated to a desired cell density.

\subsubsection{In vitro interaction of $\mathrm{mDCs}$ with $C$. albicans strains.}

Overnight YPD cultures of the C. albicans strains were diluted in $25 \mathrm{ml}$ YPD medium to an $\mathrm{OD}_{600}$ of $0.2-0.3$ and were incubated at $30^{\circ} \mathrm{C}$ until $\mathrm{OD}_{600}$ of 1.0 was reached. The cells were collected by centrifugation at $1200 \times \mathrm{g}$ for $5 \mathrm{~min}$ and were washed one time in PBS. After centrifugation the cells were resuspended in $1 \mathrm{ml}$ of PBS and the cell density was determined by using a CASY cell counter (Innovatis, Bielefeld, Germany). The fungal cells were diluted 
in pre-warmed high-glucose DMEM medium without phenol red so that that the fungalmammalian cell interaction was performed at a ratio of 2 fungal cells per mDC (multiplicity of infection ration, MOI).

One day prior to the interaction assay, the $\mathrm{mDCs}$ were plated at a cell density of $1.0-1.25 \times 10^{5}$ cells $/ \mathrm{cm}^{2}$ in a volume of cell culture medium of $0.2-0.4 \mathrm{ml} / \mathrm{cm}^{2}$ and were incubated at $37^{\circ} \mathrm{C}$ in a $5 \% \mathrm{CO}_{2}, 95 \%$ humidity atmosphere.

The media from the mDC culture dishes were aspirated and were replaced with high-glucose DMEM without phenol red with or without $C$. albicans. The Candida- mDCs interaction was performed at a 2:1 MOI in a $2 \mathrm{ml}$ volume in $6 \mathrm{~cm}$ dishes. The Candida cell suspension was simply added to the mDC media in a $200 \mu \mathrm{l}$ volume. The dishes were incubated at $37^{\circ} \mathrm{C}$ in a $5 \% \mathrm{CO}_{2}, 95 \%$ humidity atmosphere for a $20 \mathrm{~min}$ 'infection pulse'. After the infection pulse cells were either collected or further incubated for an additional 90 min time period.

\subsubsection{RNA isolation from mDCs and quantitative RT-PCR}

The dishes were placed on ice and the media was removed, cell layers were collected by scrapping in $175 \mu \mathrm{l}$ RNA lysis buffer (Promega). The samples were centrifuged at $11,000 \times \mathrm{g}$ for $8 \mathrm{~min}$ and the supernatants were collected. RNA extraction was performed with the SV Total Isolation System (promega), according to the instructions of the manufacturer. Samples were eluted in $50 \mu \mathrm{l}$ RNase-free sterile water. The RNA concentration was measured at an $\mathrm{OD}_{260}$ and the quality of the samples was checked on a $1 \%$ agarose urea-TBE gel.

Reverse transcription was performed with $1 \mu \mathrm{g}$ total RNA. Real-time PCR reactions were performed on a Light Cycler 480 instrument with LightCycler 480 SYBR Green I Master (Roche Molecular Diagnostics). Primers that were used for amplification are listed in table 11.

\subsubsection{Determination of oxidative burst in PMNs upon interaction with $C$. albicans.} To determine the oxidative burst of human PMNs upon interaction with our C. albicans strains, we used a method which is based on the conversion of Dichlorfluorescein Diacetat (DCFH-DA) to the green fluourescent Dichlorfluorescein (DCF) by oxygen radicals (Radsak et al., 2004). The Candida - PMN interaction was performed at a MOI of 1:1 or 5:1 in 96well plates with $25 \mu \mathrm{M}$ DCF-DA in $100 \mu \mathrm{l}$ RPMI 1640 supplemented with 5\% FCS. As a positive control we incubated the PMNs with $50 \mathrm{ng} / \mathrm{ml}$ phorbol 12-myristate 13-acetate (PMA). The relative fluorescence units (RFU) were measured every 5 minutes in an ELISAreader (GENios, Tecan, Crailsheim) at $37^{\circ} \mathrm{C}$ for $145 \mathrm{~min}$. Experiments were repeated four times. 


\section{Results}

Pga29p was identified in a genome-wide screen for putative GPI-proteins in C. albicans (De Groot et al., 2003). The extracellular presence of the protein was confirmed with mass spectrometry, revealing that it resides in the cell wall via a covalent linkage (De Groot et al., 2004). Interestingly, cell wall protein extracts analysed with Coomassie stained SDS-PAGE gels showed that Pga29p is abundantly present in the cell wall of yeast cells (De Groot et al., 2004), which is reflected in the MS identification of a large number of peptides from cell walls treated with trypsin. The Pga29p family comprises the three members Pga29p, Pga30p and Pga31p which are small GPI-CWPs that are covalently linked in the cell wall (De Groot et al., 2003, 2004; Castillo et al., 2008). Pga29p shares 50\% and 45\% sequence identity with Pga30p and Pga31p, respectively (Castillo et al., 2008) and the encoding genes are located at chromosome 4 within a range of 7467 base pairs. In order to obtain information about the distribution of Pga29p homologs in other fungal species, we performed BLAST searches with the Pga29p protein sequence against the NCBI protein database, the Fungal Genome Initiative Candida database at the Broad institute and the Candida dubliniensis database. In order to obtain a selective group of proteins a stringent E-value cut off of $1.0 \times 10^{-4}$ was used. We found homologs in other human pathogenic Ascomycetes: C. dubliniensis, C. guilliermondii, $C$. parapsilosis, C. tropicalis, C. lusitaniae, Lodderomyces elongisporus and in Debaryomyces hansenii and Pichia stipitis (Table 16, Appendix). For none of these identified homologs functional characteristics do exist so far. Additionally, these BLAST results show that homologs of Pga29p are widespread among well-known virulent Candida species

\subsection{Antibody generation against Pga29p}

In order to study Pga29p in detail, we generated polyclonal antibodies against this protein. This was achieved by cloning PGA29, adapting the sequence for the altered codon usage by performing targeted point mutations and producing recombinant Pga29p in E. coli. The purified protein was subsequently used for rabbit immunisation. Briefly, we cloned a truncated form of the PGA29 open reading frame that extended from codon 15 to codon 182 , thereby omitting the hydrophobic N-terminal signal and GPI-anchor motif sequence. $C$. albicans is a Candida species that translates the leucine CUG codon in serine. Consequently, we introduced two point mutations in the CTG codon at position 193 of PGA29, generating a TCG codon which is translated in E. coli as a serine. We overexpressed the truncated PGA29 in $E$. coli and verified the protein production with SDS-PAGE analysis (not shown). 
Recombinant Pga29p was bearing a $6 \times$ His-tag, which facilitated the purification with $\mathrm{Ni}$ NTA resin (Figure 1A). The purified recombinant Pga29p was used for rabbit immunisation (described in the methods section) and the presence of anti-Pga29p antibodies in the collected rabbit serum samples were tested with immuno-blot analysis. The strong signal on the membrane showed that the antibodies against recombinant Pga29p were successfully generated (Figure 1B). In order to investigate whether these antibodies specifically recognize endogenous Pga29p, we first treated isolated cell walls of the C. albicans wild type SC5314 with the chemical HF-pyridine, which specifically cleaves phosphodiester bonds, through which GPI-CWPs are linked to $\beta$-1,6-glucan chains (De Groot et al., 2004). This HF-pyridine cell wall extract was separated by SDS-PAGE and transferred to a PVDF membrane, which was treated with our anti-Pga29p serum. We observed a specific signal (Figure 1C), that was of identical size as the Pga29p band in the Coomassie brilliant blue stained SDS-gel from De Groot et al. (2004) (Figure 1D), thereby confirming that the serum contained polyclonal antibodies that specifically recognise Pga29p.

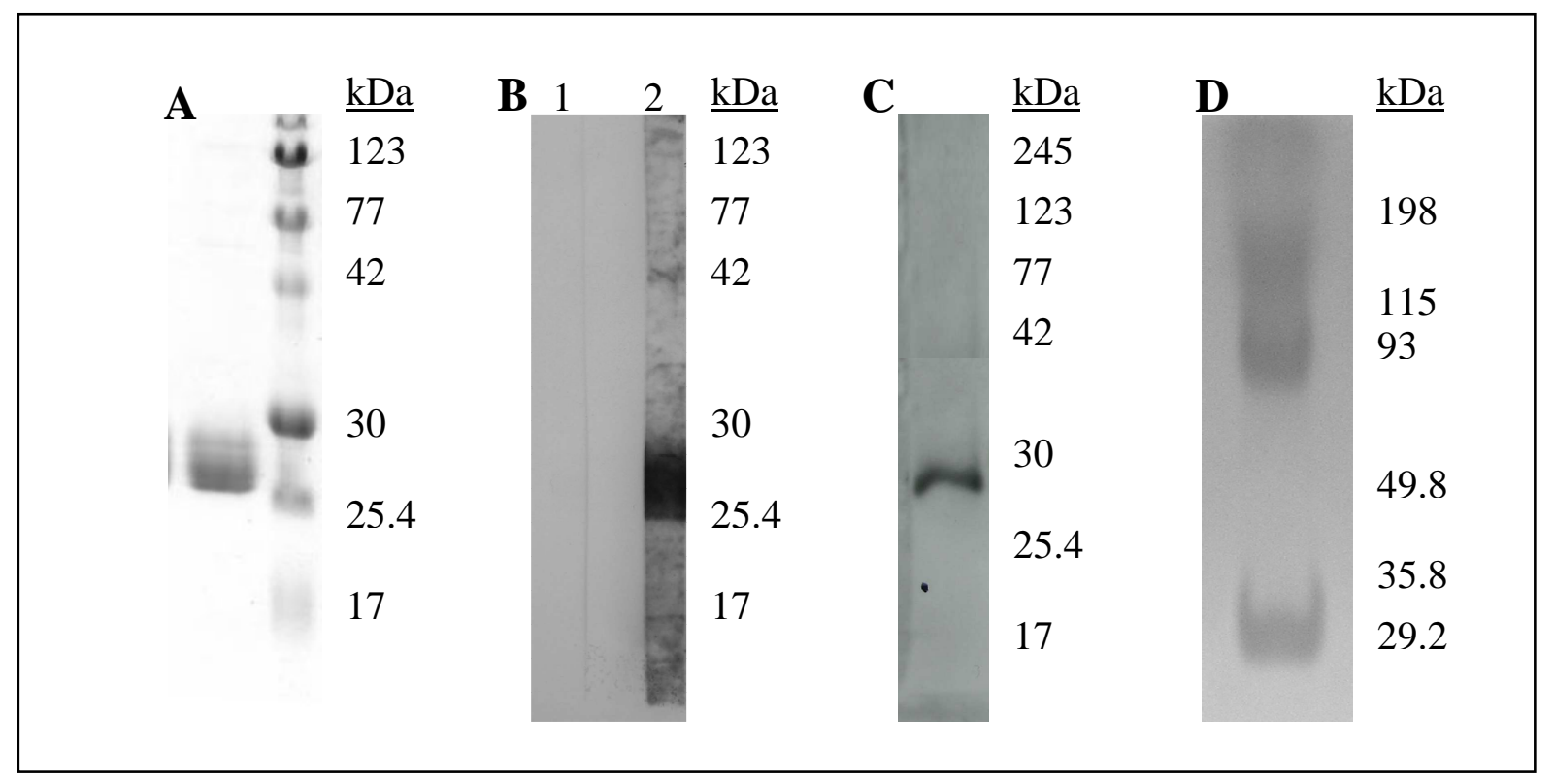

Figure 1. Generation of anti-Pga29p polyclonal antibodies.

(A) SDS-PAGE analysis (11\%, Coomassie brilliant blue stained) of purified recombinant Pga29p.

(B) Immuno-blot analysis with rabbit anti-Pga29p serum and recombinant Pga29p as an antigen. Lane 1) Rabbit serum before immunisation. Lane 2) Rabbit serum after immunisation. (C) HFpyridine cell wall extract was separated with SDS-PAGE analysis (11\%) and analysed with Immuno-blot analysis by using anti-Pga29p serum.(D) SDS-PAGE analysis (Coomassie brilliant blue stained gradient gel 2-20\%) of HF-pyridine cell wall extract, from which the $29.2 \mathrm{kDa}$ band was identified as Pga29p (De Groot et al., 2004). The numbers at the right of the figures indicate the sizes of standard molecular mass markers. 


\subsection{Pga29p incorporation into the cell wall}

Different treatments can be used to release CWPs from purified cell walls such as HFpyridine or $\beta$-1,6-glucanase to release GPI-proteins, $\beta$-1,3-glucanase to release GPI- and proteins with an alkali sensitive linkage and $30 \mathrm{mM} \mathrm{NaOH}$ to exclusively release proteins with an alkali sensitive linkage (Klis et al., 2001; Figure 2A). In 2004, De Groot and coworkers mass spectrometrically identified Pga29p in purified cell walls of C. albicans indicating that the protein is covalently attached To unequivocally verify how Pga29p is incorporated into the carbohydrate backbone of the cell wall, we treated yeast cell walls with $\beta$-1,3-glucanase or $\beta$-1,6-glucanase and analysed the supernatants of these samples with immuno-blot assays. Digesting cell walls with $\beta-1,6-$ glucanase released Pga29p (Figure 2B, lane 1), whereas digesting cell walls with $\beta$-1,3glucanase released a high molecular weight smear (lane 3 ). The $\beta$-1,3-glucanase extract was dialysed and subsequently used for a second treatment with $\beta$-1,6-glucanase, which shifted the signal to $30 \mathrm{kDa}$ (lane 4) indicating the release of Pga29p from a bigger complex: in the high molecular smear in lane 3 is Pga29p attached to large fragments of $\beta$-1,3-glucan. Digesting these fragments with $\beta$-1,6-glucanase resulted in the release of Pga29p (lane 4), which proved that this protein is covalently linked to $\beta$-1,3-glucan via $\beta$-1,6-glucan chains. The cell wall protein Cwp1p in S. cerevisiae and C. glabrata is either single linked via $\beta-1,6-$ glucan or double linked via $\beta$-1,6-glucan and through an alkali labile linkage (Kapteyn et al., 2001; Weig et al., unpublished data). In order to show whether this is also the case with Pga29p we additionally treated (i) $\beta$-1,6-glucanase digested cell walls (lane 2) and (ii) untreated cell walls (lane 5) with $30 \mathrm{mM} \mathrm{NaOH}$ to unravel a possible second linkage which is alkali labile. However, no signal was detected; indicating that Pga29p no additional linkage to the cell wall via an alkali labile bond. 

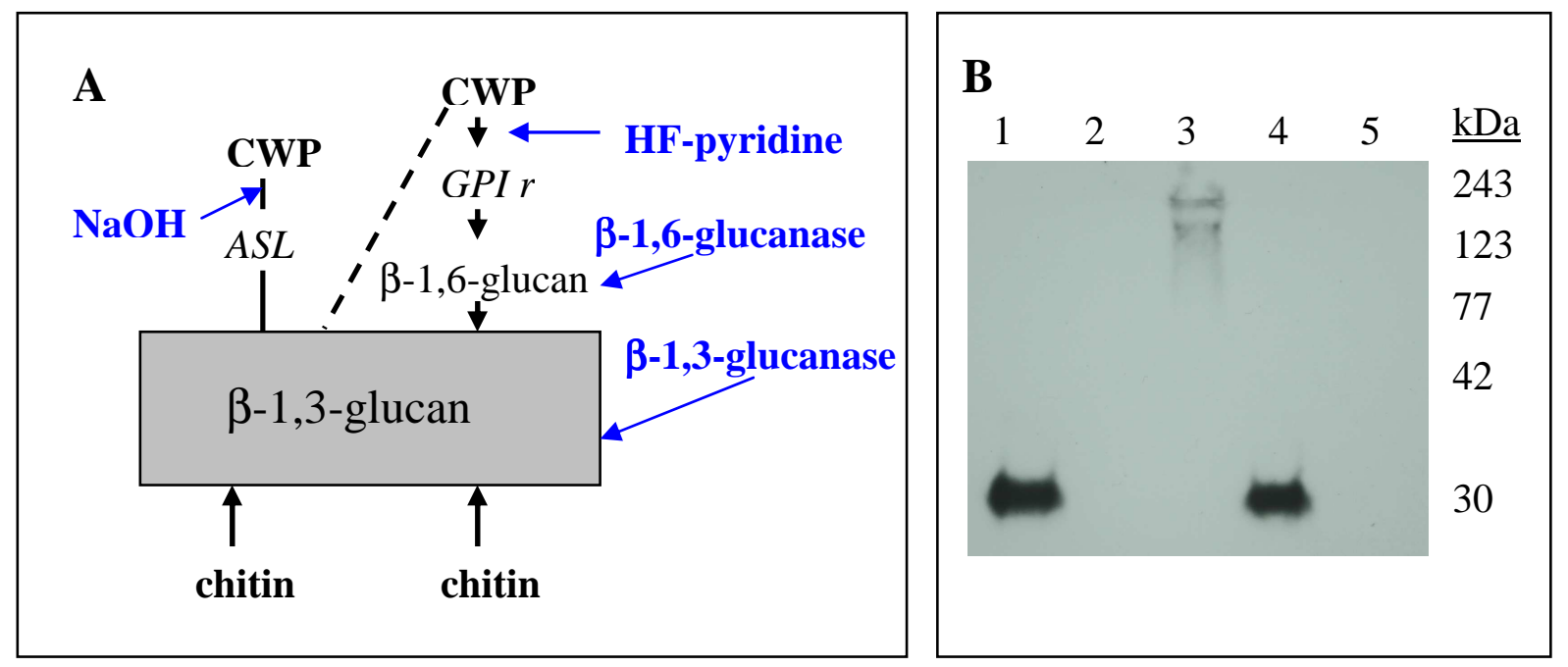

Figure 2. Covalent incorporation of Pga29p in the cell wall of C. albicans.

(A) Covalently linked cell wall proteins (CWP) can be liberated from the cell wall with different chemicals and enzymes, which are shown in blue. The black arrows indicate glycosdic linkages and point from the reducing end of a macro molecule to a non-reducing end of an acceptor polysaccharide. The dashed line indicates the double linkage by which some GPI-CWPs are linked. $A S L$ and GPI $r$ indicate the alkali sensitive linkage and the GPI remnant, respectively.

(B) Cell wall proteins were separated by SDS-PAGE (11\%) and analysed by immuno-blotting using anti-Pga29p polyclonal antibodies. Lane 1) $\beta$-1,6-glucanase extract. Lane 2) $\mathrm{NaOH}$ extract of cell walls previously treated with $\beta$-1,6-glucanase. Lane 3) $\beta$-1,3-glucanase extract. Lane 4) $\beta$-1,3glucanase extract treated with $\beta$-1,6-glucanase. 5) $\mathrm{NaOH}$ extract. Sizes of standard molecular mass markers are shown at the right.

\subsection{Pga29p is a yeast-specific protein}

\subsubsection{PGA29 expression during the yeast-to-hyphal transition}

The CWP incorporation drastically changes upon the morphological transition of C. albicans from the yeast to the hyphal form, an important process for virulence (Sohn et al., 2003;

Ebanks et al., 2006; Castillo et al., 2008). Furthermore, the expression of several genes that encode GPI-proteins is related with particular growth forms, for example HWPl is exclusively expressed in the hyphal form (Staab et al., 1999). Yeast wall protein 1 (Ywp1, Pga24p) is an example of a GPI-protein that specifically related to the yeast from of $C$. albicans (Nantel et al., 2002; Sohn et al., 2003; Granger et al., 2005). We showed previously that Pga29p is abundantly present in the yeast form of C. albicans (De Groot et al., 2004). To examine whether the protein level changes during the transition from yeast to hyphae, cell walls were isolated from $C$. albicans cells that were induced to develop hyphae by stimulation with $10 \%$ serum and a temperature shift from $30^{\circ} \mathrm{C}$ to $37^{\circ} \mathrm{C}$. After two hours of hyphal induction the Pga29p level in the cell wall clearly decreased, but remained detectable even 
after 4 hours of hyphal growth (Figure 3A). Additionally, Northern blot analysis showed that $P G A 29$ transcript levels rapidly decreased within 45 minutes during the yeast-to-hyphae transition (Figure 3B). These data show that Pga29p is a yeast-specific protein, though the protein retains in the cell wall for several hours after hyphal induction.
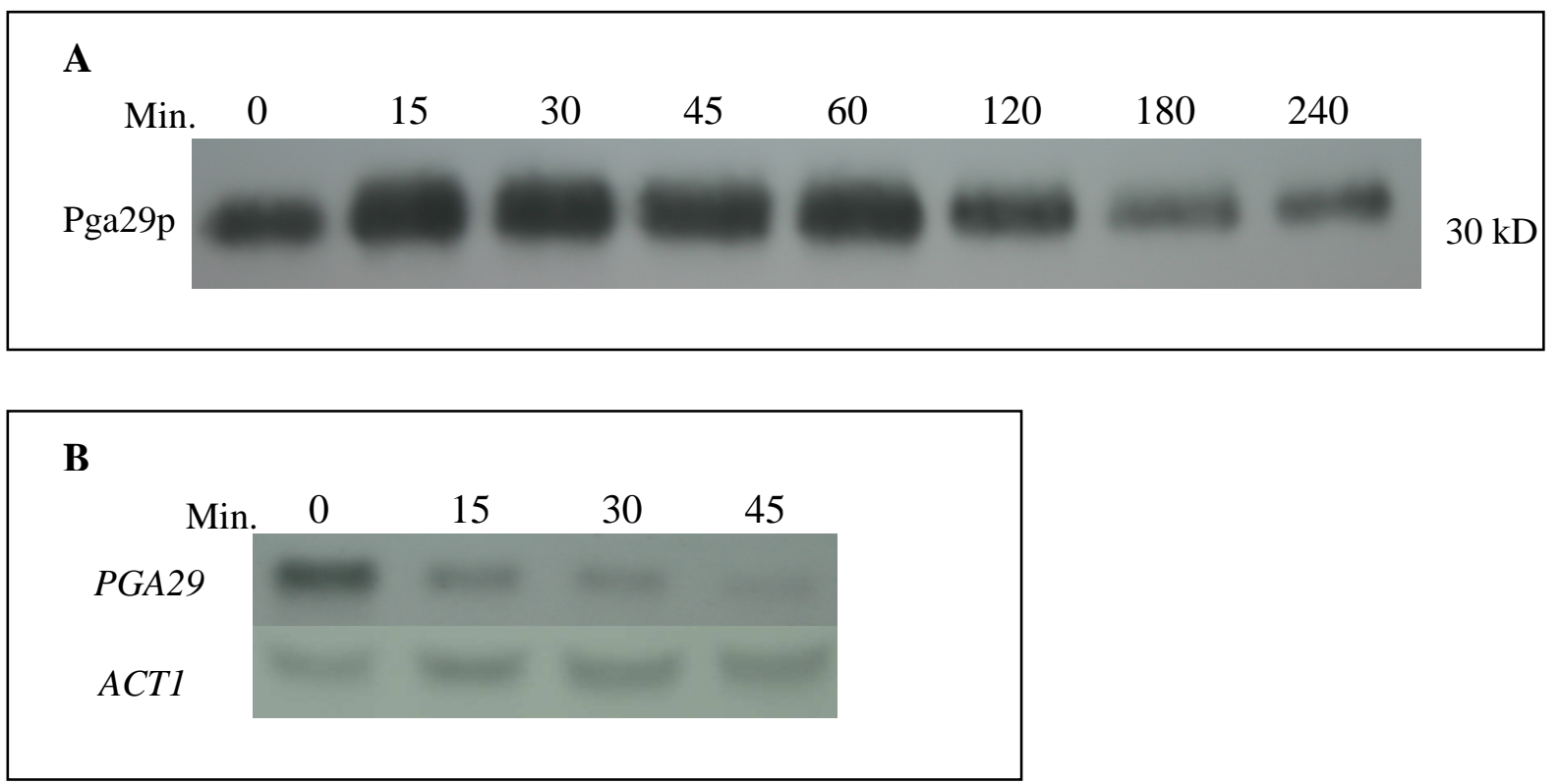

Figure 3. PGA29 expression in yeast-to-hyphal transition.

Immuno-blot (A) and Northern blot (B) analyses were used to study the expression of PGA29 during the transition from yeast to hyphae. (A) In the immuno-blot analysis, Pga29p was detected with the generated anti-Pga29p polyclonal antibodies. Each lane was loaded with $\beta$-1,6-glucanase extract derived from $0.4 \mathrm{mg}$ dry-weight cell walls. (B) In the Northern blot analysis, PGA29 transcript was detected with a digoxygenin probe. As a loading control a probe against ACTl transcript was used. The numbers indicate the time in minutes after hyphal induction.

\subsubsection{PGA29 expression in deletion mutants that are impaired in hyphal development}

$E F G 1$ and $C P H 1$ encode transcription factors that regulate the transition from yeast to hyphae in C. albicans. Nantel et al. (2002) showed an increased expression of PGA29 in $\Delta e f g / \Delta e f g 1$ (2.5 times) and $\Delta e f g 1 / \Delta e f g 1 \Delta c p h 1 / \Delta c p h 1$ (3.9 times) mutants. Both strains are impaired in their ability for hyphal development. In order to investigate whether Pga29p is highly incorporated in the cell wall of these mutants, we analysed $\beta$-1,6-glucanase CWP extracts with immuno-blot analysis (Figure 4). This revealed that the cell wall of the $\Delta e f g 1 / \Delta e f g 1$ mutant (lane 1) contained 1.17 times and $\Delta e f g 1 / \Delta e f g 1 \Delta c p h 1 / \Delta c p h 1$ mutant (lane 2) contains 2.28 times more Pga29p than the wild type (lane 3), which supports the idea that Pga29p is a yeast-specific protein and that Efg1p and Cph1p negatively regulate its expression.

To determine whether these transcription factors might directly regulate PGA29 expression we searched by in silico analysis for their potential binding sites in the $2 \mathrm{~kb}$ region upstream 
of the start codon of PGA29. Efg1p was shown to bind to the consensus sequences CANNTG (known as E-box) (Leng et al., 2001). The exact binding site for Cph1p is not known, however for our studies we used the consensus sequence TGAAACA, which is a specific binding site for the S. cerevisiae transcription factor Ste12p, a homologue of Cph1p. We found in total 8 E-box sequences (Figure 5) upstream of the PGA29-ORF which suggests that Efg1p might directly regulate $P G A 29$ via these binding sites. Ste12 binding sites were not identified with the preliminary approach described above. However, it should be stressed that this approach is based on information derived from bakers yeast and therefore this result does not reliably exclude Cph1 as a direct regulator of PGA29.

\section{$1 \quad 2 \quad 3$}

$30 \mathrm{kDa}$

Figure 4. Pga29p incorporation in cell walls of $C$. albicans $\Delta e f g / \Delta e f g 1$ and $\Delta e f g 1 / \Delta e f g 1$ $\Delta c p h 1 / \Delta c p h 1$ mutants.

$\beta$-1,6-glucanase cell wall protein extracts of the mutants and of the control strain were separated by SDS-PAGE (11\%) and analysed by immuno-blotting using anti-Pga29p polyclonal antibodies. Lane 1) $\Delta$ efg $1 / \Delta e f g 1$. Lane 2) $\Delta$ efg $1 / \Delta e f g 1 \Delta c p h 1 / \Delta c p h 1$. Lane 3) SC5314.

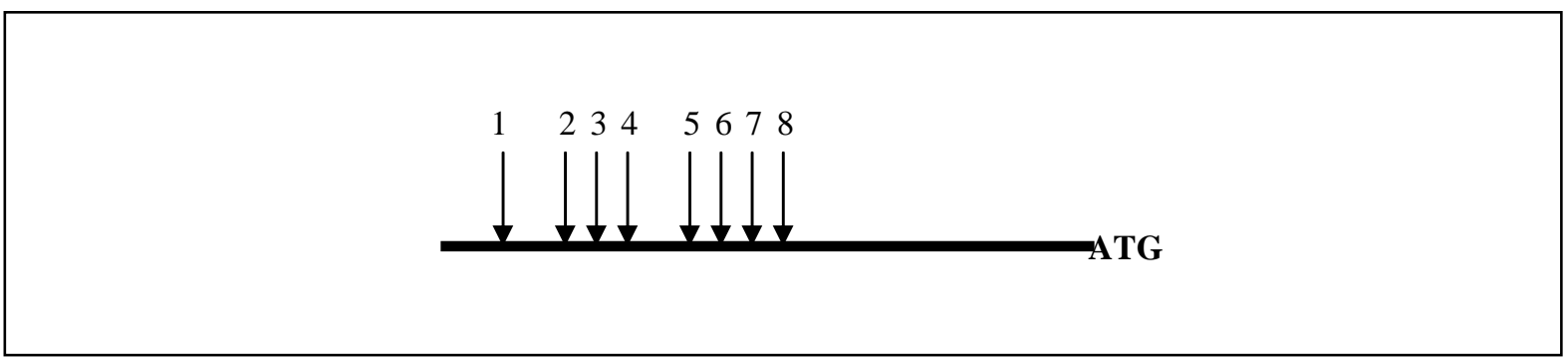

Figure 5. E-boxes in the $P G A 29$ promoter sequence.

We searched for E-boxes (CANNTG) 2000 base pairs upstream of the start codon of PGA29. In total 8 E-boxes were found, which were mainly located in the first 1000 base pairs of the promoter region. E-box \#1) 177. \#2) 411. \#3) 501. \#4) 613. \#5) 840. \#6) 968. \#7) 1006. \#8) 1104 (in base pairs) 


\subsection{Functional analysis of Pga29p}

\subsubsection{Pga29p upregulation under cell wall stress}

In order to elucidate the function of Pga29p, we sought for conditions in which Pga29p is upregulated. Pga29p is a small protein without any conserved domains, therefore it seems possible that this GPI-protein may have a structural role for maintaining cell wall integrity in C. albicans. To investigate this, we analysed $\beta$-1,6-glucanase protein extracts from yeast cell walls which were isolated from cells that underwent cell wall stress during growth. The level of incorporated Pga29p increased 2.2 times in cells that were grown in YPD supplemented with $25 \mu \mathrm{g} / \mathrm{ml} \mathrm{CFW}$, a compound which induces cell wall perturbation due to its binding to chitin in the cell wall (Figure 6, lane 2). However, Pga29p upregulation was not observed during growth in the presence of SDS (Figure 6, lane 3), a detergent that penetrates the plasma membrane and consequently disorganises its structure. Our data suggest that Pga29p upregulation is more related with perturbation of the cell wall and

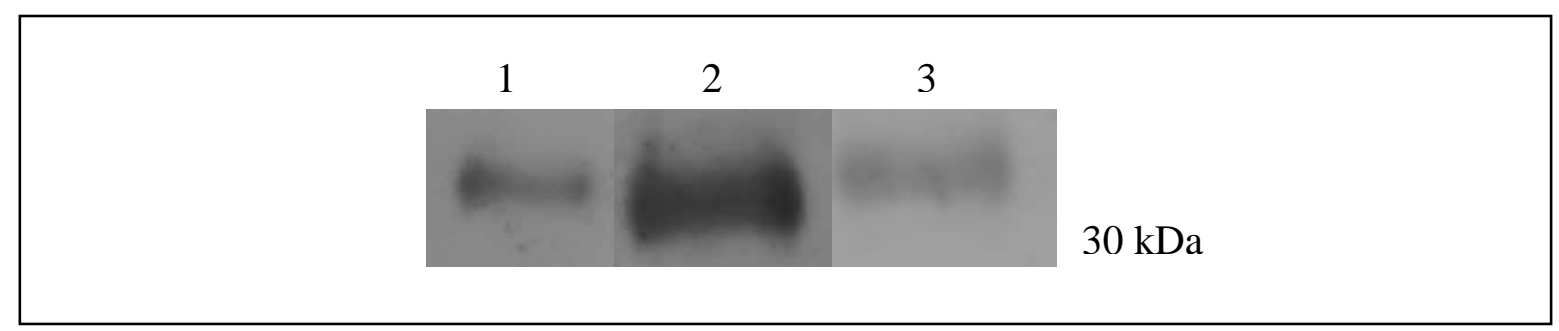

Figure 6. Pga29p incorporation under CFW and SDS stress.

C. albicans wild type SC5314 cells were grown under $25 \mu \mathrm{g}$ CFW or $0.01 \%$ SDS and were harvested when an $\mathrm{OD}_{600}$ of 2.0 was reached. Isolated cell walls were treated with $\beta-1,6-$ glucanase and the extracts were analysed by immuno-blotting using anti-Pga29p polyclonal antibodies. Lane 1) Wild type SC5314 grown in YPD medium at $30^{\circ} \mathrm{C}$. Lane 2) Wild type SC5314 grown under CFW-stress. Lane 3) Wild type SC5314 grown with 0.01\% SDS

We also searched for growth conditions that induce downregulation of Pga29p. As mRNA levels of PGA29 decrease during the yeast-to-hyphal transition, we selected two factors that play a role in hyphal development. A neutral $\mathrm{pH}$ and a temperature of $37^{\circ} \mathrm{C}$ are two major factors for hyphal development. Downregulation was not observed when cells were grown at a $\mathrm{pH} 7.5$, whereas a strong downregulation was observed under high temperatures of $37^{\circ} \mathrm{C}$ and $42^{\circ} \mathrm{C}$ (Figure 7 ). 


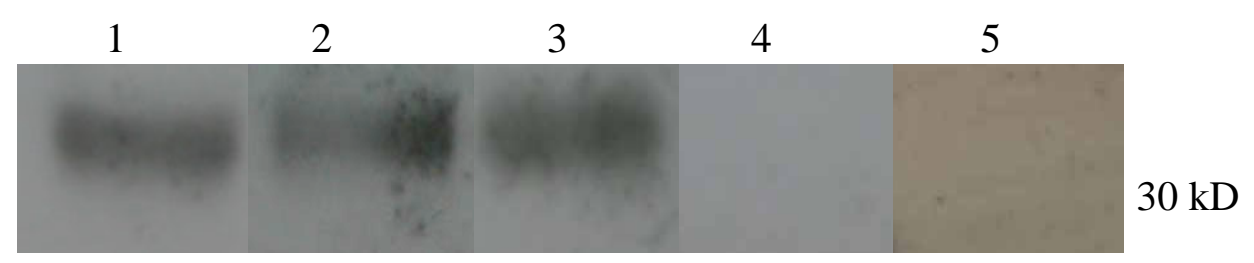

Figure 7. Pga29p incorporation under different $\mathrm{pH}$ values and temperatures.

C. albicans wild type SC5314 cells were grown at different $\mathrm{pH}$ values and temperatures. After $\mathrm{OD}_{600}$ of 2.0 was reached, cells were harvested and cell walls were isolated. Cells walls were treated with $\beta$-1,6-glucanase and extracts were analysed by immuno-blotting using anti-Pga29p polyclonal antibodies. Lane 1) $\mathrm{pH}$ 4.0. Lane 2) $\mathrm{pH}$ 5.75. Lane 3) $\mathrm{pH}$ 7.5. Lane 4) $37^{\circ} \mathrm{C}$. Lane 5) $42^{\circ} \mathrm{C}$.

\subsection{Generation of $P G A 29$ deletion mutants}

To more deeply explore the function of Pga29p, we introduced double allele deletions in the triple auxotrophic strain BWP17 (Wilson et al., 1999), by using PCR products as disruption cassettes that consist of a selectable marker (HISI or ARG4) and at both ends 50 base pairs that share homology to the PGA29 untranslated genome sequence. To complement the URA3 auxothrophy in the Apga29/4pga29 mutants, we directed the linearized CIp10 vector to the RPS10 locus, which facilitates appropriate expression of URA3 (Brand et al., 2004). This locus was also used to generate the revertants (_pga29/Apga29/PGA29) with the linearized CIp10-PGA29 vector.

\subsubsection{Verification of $P G A 29$ deletion}

The first allele of PGA29 was disrupted with a HIS1 knock-out cassette (Figure 8), of which the integration at the PGA29 locus was confirmed by two different PCRs. For correct integration at the 5 prime region a PCR was performed with the primers PGA29-F (binding position: -827- -804) and HIS-R (binding position: 605-628) that resulted in a product of 1799 base pairs (Figure 9A, lane 2). For correct integration at the 3 prime region a PCR was performed with the primers HIS-F (binding position: 87-110) and PGA29-R (binding position: $+322-+341$ ) that resulted in a 2433 bp product (Figure 9A, lane 1). Sequencing of both PCR products confirmed correct integration of the HISl knock-out cassette. Southern blot analysis was performed in order to verify the single integration of the HIS1 knock-out cassette in the genome. Genomic DNA of mutants was digested with the restriction enzyme EcoRI, which cuts up- and downstream of the knock-out cassette at the positions -854 and +2122 , respectively (Figure 8 ). The expected fragment size of 4890 base pairs was confirmed 
by using a probe against HIS1, which was generated with primers HIS-F and HIS-R (Figure 9B).

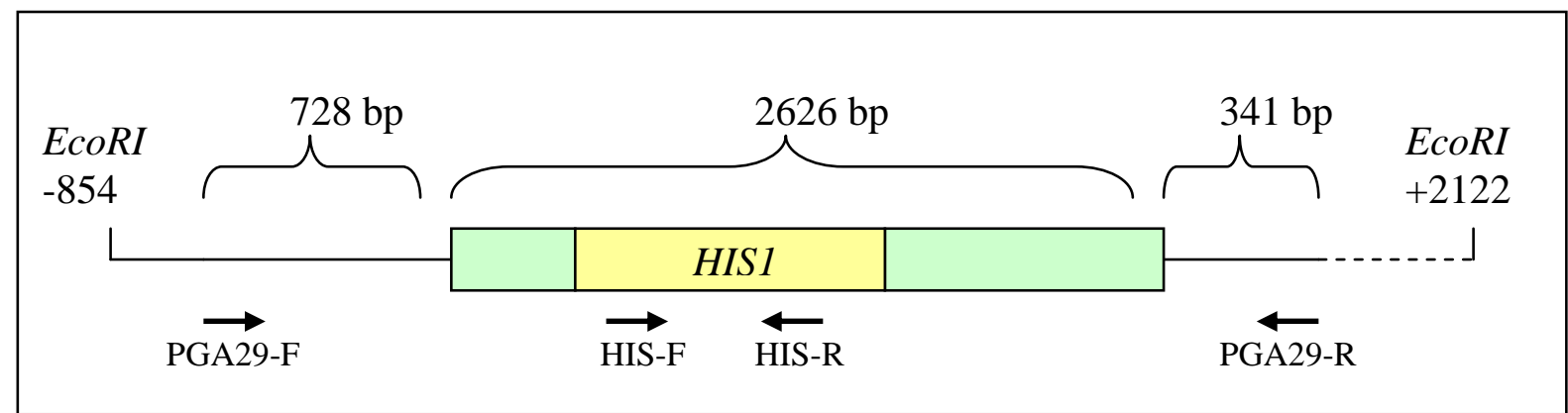

Figure 8. Verification of the integration of the HIS1 knock-out cassette with PCR and Southern blot analysis. Schematic representation of PGA29 deletion with the HISI knock-out cassette. The yellow region represents the HIS1 ORF. The green regions represent HIS1 promoter, HIS1 terminator and plasmid (pGEM-HIS1) sequences. The arrows indicate the primer binding positions. EcoRI cuts in the PGA29 untranslated regions at positions -854 and +2122 . Sizes of the knock-out cassette and untranslated regions are indicated in base pairs (bp).

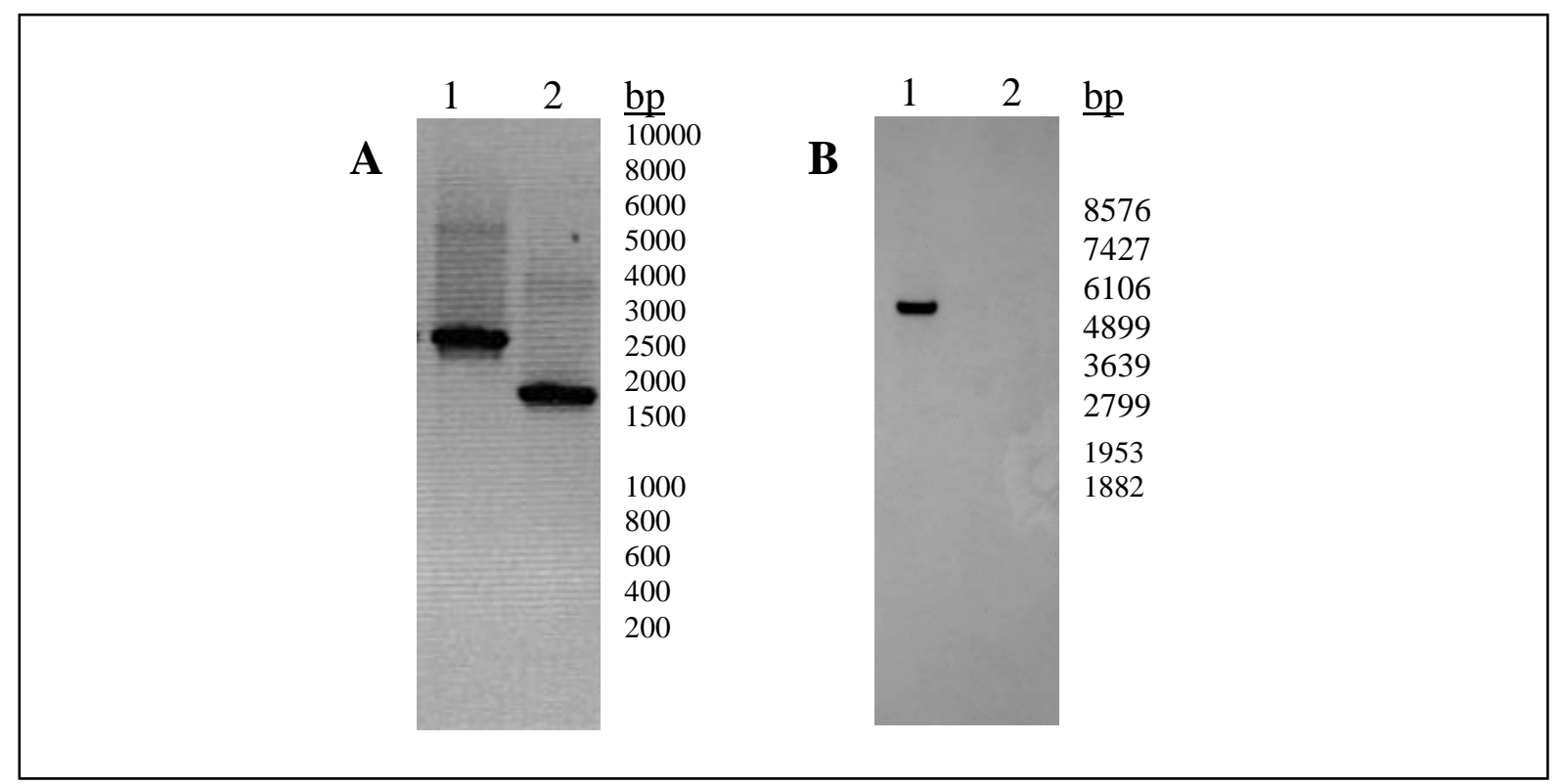

Figure 9A and $\mathrm{B}$. Verification of the integration of the HIS1 knock-out cassette with PCR and Southern blot analysis. (A) Two different PCRs were performed which resulted in products that included the genome and HIS1 cassette sequences. The PCR products were visualised by agarose gel electrophoresis. Lane 1) PCR of 3 prime region. Lane 2) PCR of 5 prime region. (B) Detection of the 4890 bp EcoRI fragment with Southern blot analysis. EcoRI digestion of genomic DNA from the mutant (lane1) and from the parental strain BWP17 (negative control) (lane2). The numbers at the right indicate the size of standard markers in base pairs.

The second allele was disrupted with the $A R G 4$ knock-out cassette (Figure 10), which integrated in the anti-sense direction of the PGA29 locus. Correct integration was confirmed by amplifying the 5 prime region with the primers PGA29-F (binding position: -827- -804) 
and ARG4-R (binding position: 874-897), which resulted in a product of 1453 base pairs (Figure 11A, lane 1). Additionally, the 3 prime region was amplified with the primers ARG4F (binding position: 217-240) and PGA29-R (binding position: +322 - +341), which resulted in a fragment of 1119 base pairs (Figure 11A, lane 2). Both PCR products were sequenced and confirmed correct integration of the ARG4 knock-out cassette. For Southern analysis, genomic DNA of the mutants was digested with the restriction enzyme $M f e I$, which cuts upand downstream of the ARG4 knock-out cassette at positions -1253 and +3325 (Figure 10). This $M f e I$ fragment of 6738 base pairs was detected by using a probe against ARG4 (Figure 11B, lane 1), which was generated with the primers ARG4-S-F and ARG4-S-R. An additional signal was observed of 2942 base pairs (Figure 11B, lane 2), which is due to the binding of the $A R G 4$ probe with remaining sequences of the $A R G 4$ locus. This was confirmed by using MfeI digested genomic DNA from the parental strain BWP17 as control.

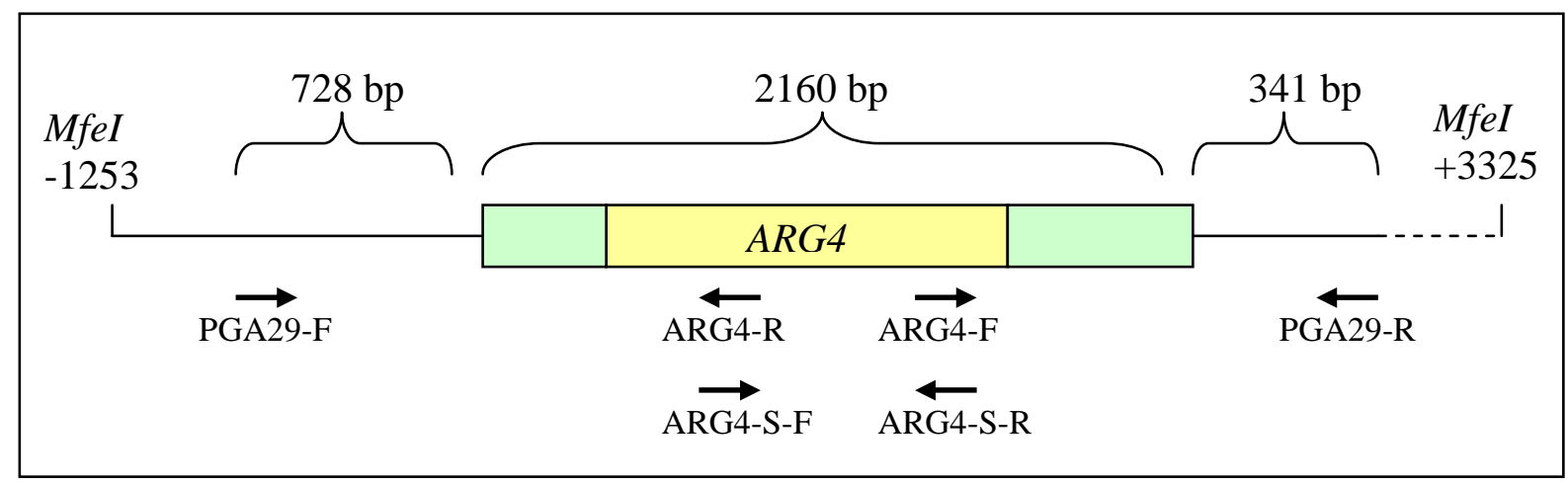

Figure 10. Verification of the integration of the $A R G 4$ knock-out cassette with PCR and Southern blot analysis. Schematic representation of PGA29 deletion with the ARG4 knock-out cassette. The yellow region represents the ARG4 ORF. The green regions represent $A R G 4$ promoter, $A R G 4$ terminator and plasmid (pRS-ARG4 $\triangle$ SpeI) sequences. The arrows indicate the primer binding positions. MfeI cuts in the PGA29 untranslated regions at positions -1253 and +3325 . Sizes of the knock-out cassette and untranslated regions are indicated in base pairs (bp). 


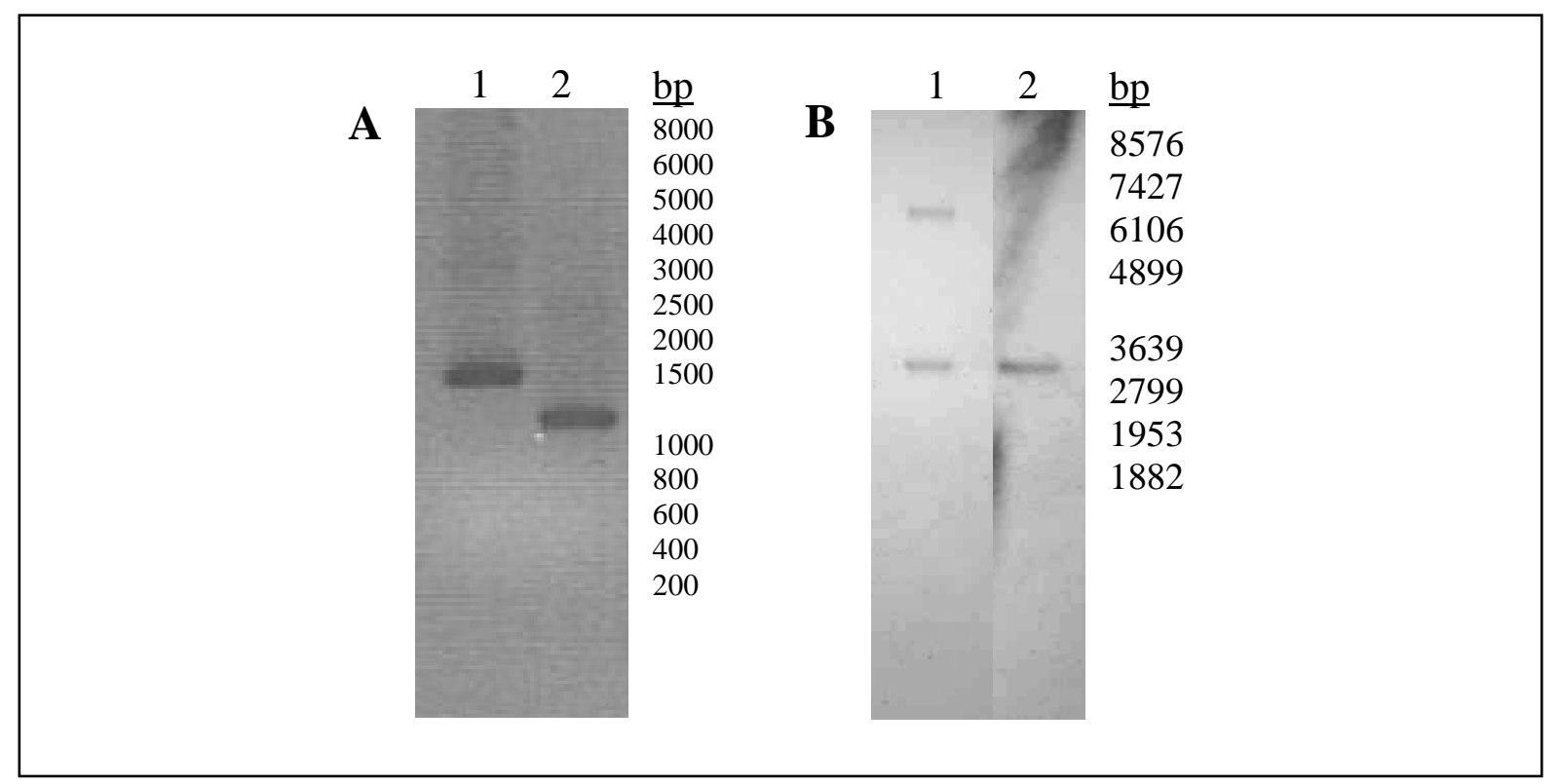

Figure 11A and $B$. Verification of the integration of the $A R G 4$ knock-out cassette with PCR and Southern blot analysis. (A) Two different PCRs were performed which resulted in products that included the genome and ARG4 cassette sequences. The PCR products were visualised by agarose gel electrophoresis. Lane 1) PCR of 5 prime region. Lane 2) PCR of 3 prime region. (B) Detection of the $6711 \mathrm{bp} \mathrm{MfeI} \mathrm{fragment} \mathrm{with} \mathrm{Southern} \mathrm{blot} \mathrm{analysis.} \mathrm{MfeI} \mathrm{digestion} \mathrm{of} \mathrm{genomic}$ DNA from the mutant (lane 1) and from parental BWP17 strain (lane2). The ARG4 probe hybridized with remaining sequences in the orginal $A R G 4$ locus, which resulted in an extra signal with a size of $2942 \mathrm{bp}$. The numbers at the right indicate the size of standard markers in base pairs.

\subsubsection{Verification of $U R A 3$ and $P G A 29$ complementation}

The integration of the CIp10 plasmid in the RPS10 locus was verified by two different PCRs and Southern analysis (Figure 12). The 5 and 3 prime regions were amplified with the primers RP10-1F (binding position:-861- -838) and CIp10.2-R (binding position in CIp10: 31753192) and URA3-F (binding position: 47-67) and RP10-3R (binding position: +372 - +395), which resulted in the fragments of 1971 and 1767 base pairs (Figure 13A), respectively. Both PCR products were sequenced and this confirmed correct integration of the CIp10 plasmid. For Southern blot analysis, genomic DNA of the mutants was digested with the restriction enzyme EcoRI, which cuts in the cassette and further downstream in the genome sequence at positions 133 of the $U R A 3 \mathrm{ORF}$ and +2130 of the RP10 untranslated region (Figure 12). The expected fragment EcoRI of 3422 base pairs was detected by using a probe against URA3 (Figure 13B), which was generated with the primers URA3-F (binding position: 47-67) and URA3-R (binding position: 592-615).

The integration of the CIp10-PGA29 plasmid in the RP10 locus was confirmed by two different PCRs and Southern analysis (Figure 14). For correct integration at the 5 prime region a PCR was performed with the primers RP101F (binding position:-861- -838) and PGA29-best-knk-F (binding position: +364 - +385) which resulted in a 1746 bp product 
(Figure 11B). For correct integration at the 3 prime region the PCR was performed as previously described for CIp10 integration (Figure 15A). Sequencing of both PCR products confirmed correct integration of the CIp10-PGA29 plasmid. Southern blot analysis was performed in order to verify the single integration of the CIp10-PGA29 plasmid (Figure 15B). This was performed as previously described for CIp10 integration.

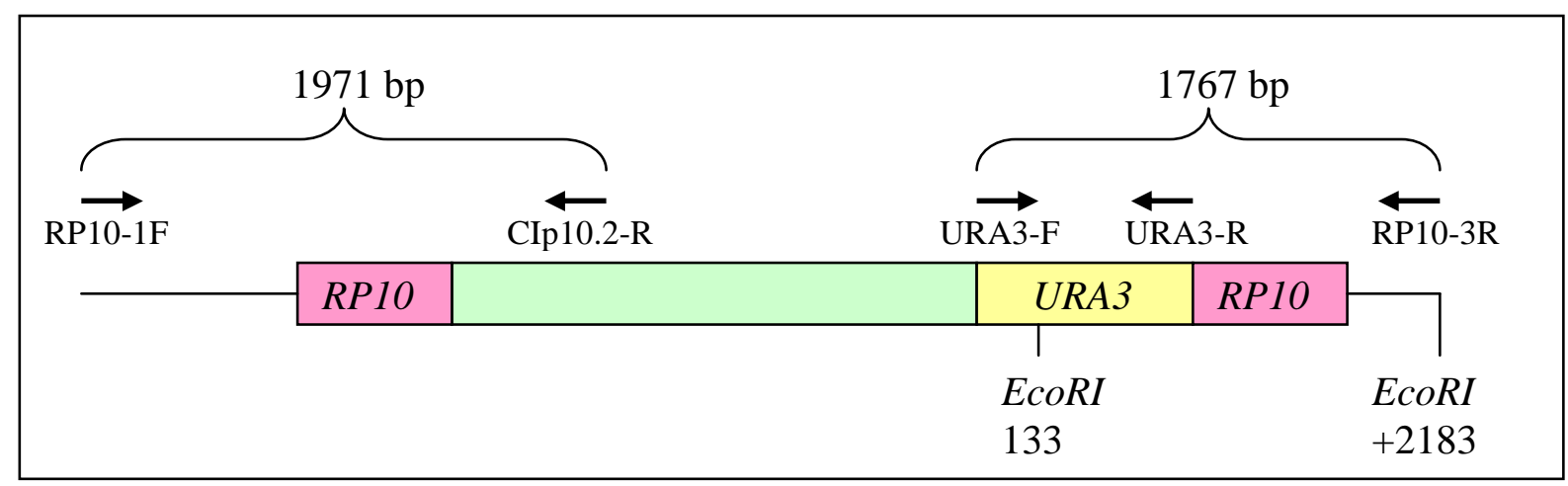

Figure 12. Verification of the integration of CIp10 with PCR and Southern blot analysis. Schematic representation of the URA3 complementation in the Apga29/Apga29 strain with the linearised CIp10. The yellow region represents the URA3 ORF. The green regions represent plasmid sequences of CIp10. The red regions represent the RP10 loci. One extra RP10 locus was generated with CIp10 integration. The arrows indicate the primer binding positions. EcoRI cuts in the URA3 ORF at position 133 and in the RP10 untranslated region ( 3 prime) at position +2122 . Sizes of the knock-out cassette and untranslated regions are indicated in base pairs (bp).

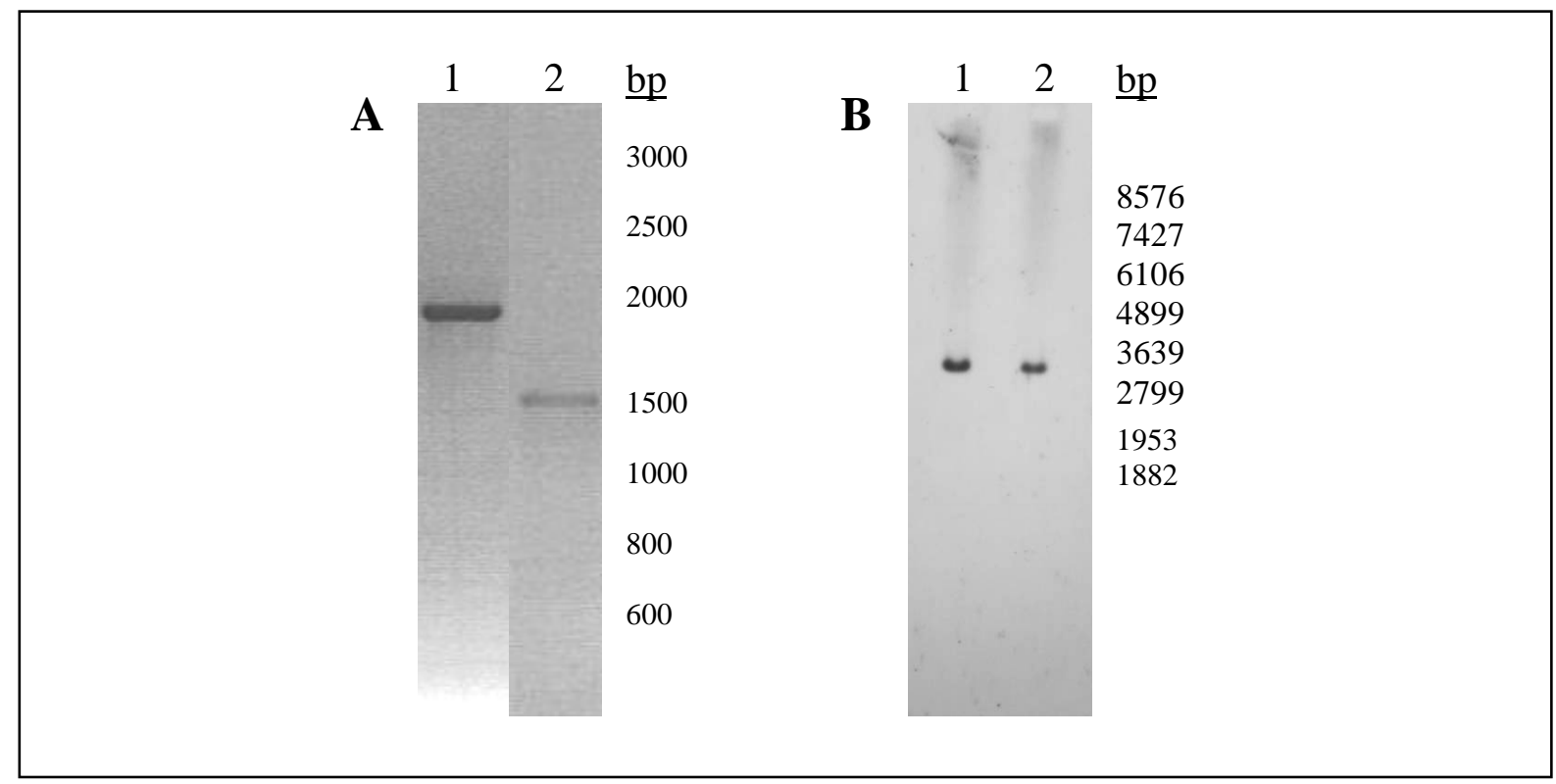

Figure 13A and B. Verification of the integration of CIp10 with PCR and Southern blot analysis. (A) Two different PCRs were performed which resulted in products that included the genome and CIp10 sequences. The PCR products were visualised by agarose gel electrophoresis. Lane 1) PCR of 5 prime region. Lane 2) PCR of 3 prime region. (B) Detection of the $3422 \mathrm{bp} \mathrm{EcoRI}$ fragment with Southern blot analysis with URA3 probe. Lane 1 and 2) EcoRI digestion of genomic DNA of two transformants. The numbers at the right indicate the size of standard markers in base pairs. 


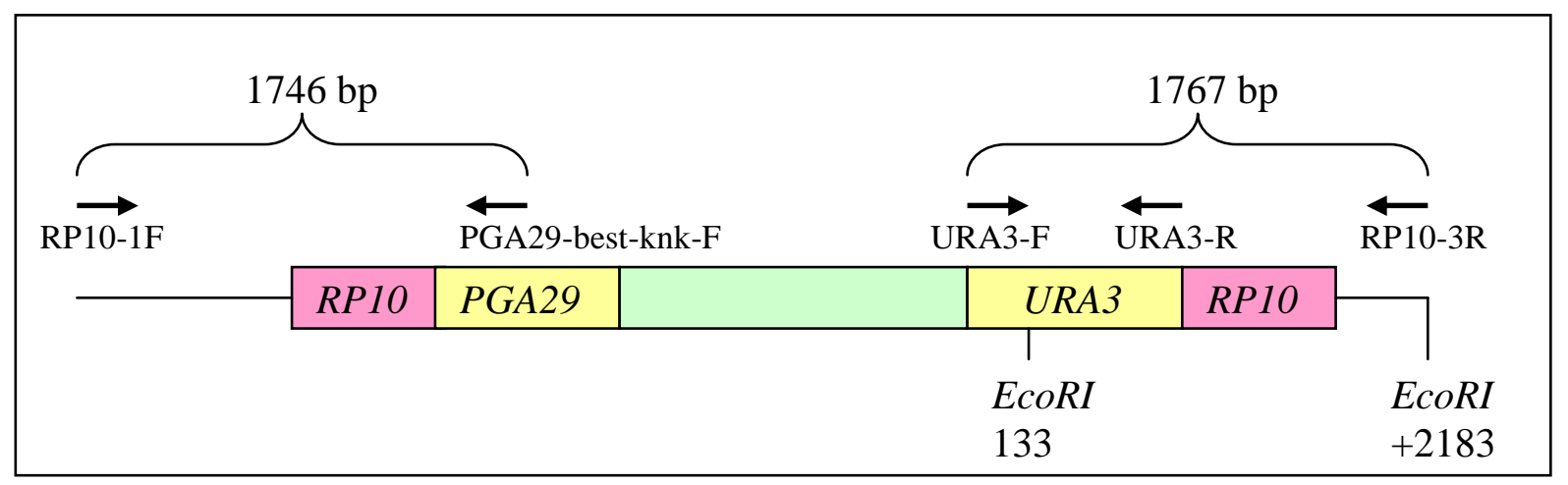

Figure 14. Verification of the integration of CIp10-PGA29 with PCR and Southern blot analysis. Schematic representation of the PGA29 and URA3 complementation in the Apga29/4pga29 strain with the linearised CIp10-PGA29. The yellow region represents the PGA29 gene and URA3 ORF. The green regions represent plasmid sequences of CIp10. The red regions represent the $R P 10$ loci. One extra RP10 locus was generated with CIp10 integration. The arrows indicate the primer binding positions. EcoRI cuts in the URA3 ORF at position 133 and in the RP10 untranslated region ( 3 prime) at position +2122 . Sizes of the knock-out cassette and untranslated regions are indicated in base pairs (bp).

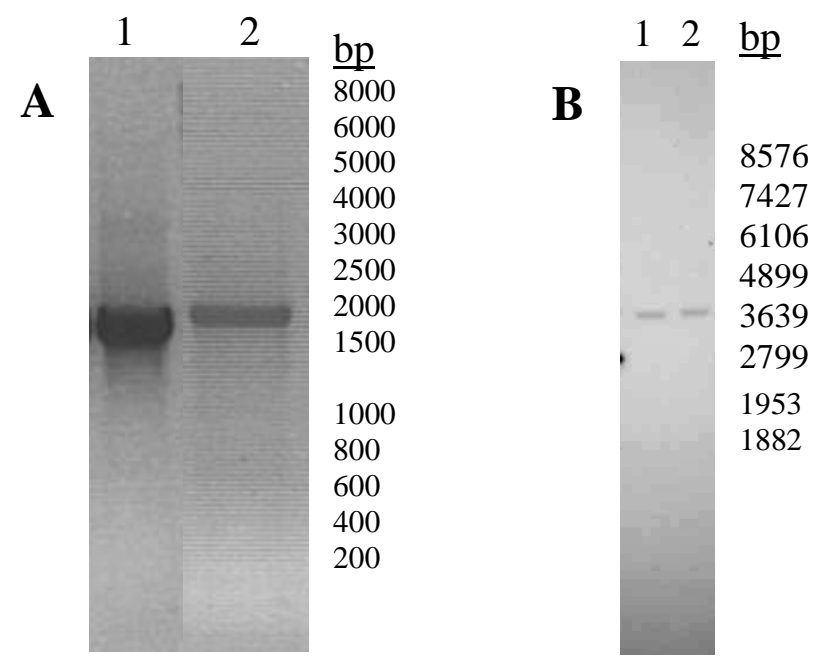

Figure 15A and $\mathrm{B}$. Verification of the integration of CIp10-PGA29 with PCR and Southern blot analysis. (A) Two different PCRs were performed which resulted in products that included the genome and CIp10-PGA29 sequences. The PCR products were visualised by agarose gel electrophoresis. Lane 1) PCR of 5 prime region. Lane 2) PCR of 3 prime region. (B) Detection of the 3422 bp EcoRI fragment with Southern blot analysis with URA3 probe. Lane 1 and 2) EcoRI digestion of genomic DNA of two transformants. The numbers at the right indicate the size of standard markers in base pairs. 
In order to confirm that the deletion mutants were no longer able to produce a PGA29 gene product, we performed Northern blot (not shown) and immunoblot analysis. These analyses showed that the Apga29/Apga29 mutants lacked PGA29 expression and the reconstituted strains properly expressed PGA29 (Figure 16).

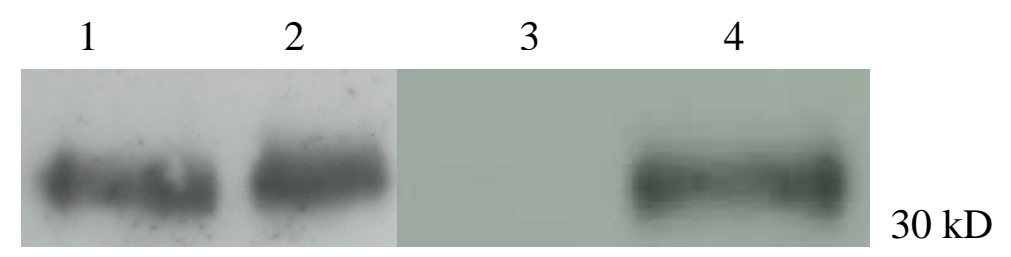

Figure 16. Generation of PGA29 deletion mutants.

Cell walls were isolated from mid-log phase cells $\left(\mathrm{OD}_{600}\right.$ of 2.0$)$ and were treated with $\beta-1,6-$ glucanase. Proteins were separated by SDS-PAGE (11\%) and analysed by immuno-blotting using anti-Pga29p polyclonal antibodies.Lane 1) Wild type SC5314. Lane 2) $\Delta p g a 29 / P G A 29$. Lane 3) Apga29/_pga29. Lane 4) Apga29/_pga29/PGA29.

\subsection{Cell wall composition of the Apga29/4pga29 mutants}

Pga29p is abundantly present in yeast cell walls, therefore its absence in the deletion mutants might effect the cell wall composition. In order to unravel morphological differences in the structure of the cell wall between the Apga29/4pga29 and control strains, mid-log phase yeast cells were high-pressure frozen (cryofixation), and analysed with transmission electron microscopy. Structural differences were quantified by measuring the thickness of the fibrillar and glucan layer (Figure 17). No differences were observed between the cell walls of the mutant and revertant strain, which implies the cell wall structure is not affected upon PGA29 deletion (Table 12). Additionally, differences were found in the thickness of both cell wall layers between the wild type SC5314 and Apga29/4pga29/PGA29 strain (Table 12), which is probably due to the background strain used and could also be related to the ectopic expression of the auxothropic markers ARG4, HIS1 and URA3 (see 4. Discussion). 


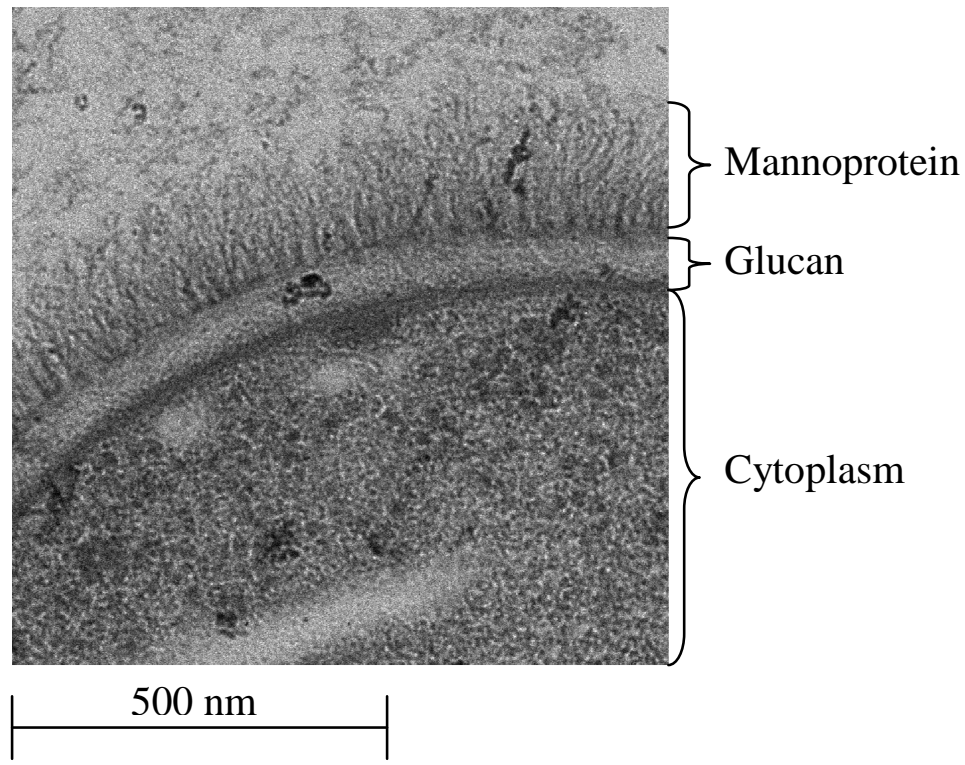

Figure 17. EM photograph of $C$. albicans cell wall.

The upper fibrillar layer consists of mannoproteins, whereas the inner layer consists mainly of glucan.The thickness of the two layers was measured in a total of 100 individual cells of the mutant, revertant and wild type strain, respectively

Table 12. Thickness of the glucan and mannoprotein layer

Of each strain 100 cells were selected to measure the thickness of the glucan and mannoprotein layer. The numbers indicate the mean values in $\mathrm{nm}$.

\begin{tabular}{lll}
\multicolumn{1}{c}{ Strain } & Glucan & Mannoprotein \\
\hline Apga29/Apga29 & 114.31 & 51.71 \\
Apga29/_pga29/PGA29 & 115.01 & 50.47 \\
SC5314 & 98.19 & 76.85
\end{tabular}

Next, we determined the composition and possible changes in the concentration of chitin, protein, and the mannose/glucose ratio in the cell wall of the $\Delta p g a 29 / \Delta p g a 29$ strain in comparison to the control strains. To quantify the chitin concentration, cell walls were treated with $\mathrm{HCl}$ which resulted in the release of $\mathrm{N}$-acetylglucosamine residues that were colorimetrically measured. A difference in chitin concentration was not observed for our strains (Table 13; Figure 18A).

To determine the protein concentration, cell walls were treated with a boiling $\mathrm{NaOH}$ solution. This treatment hydrolyses CWPs and releases single amino acids, that can be quantified using a colorimetric assay. We did not observe any significant differences in the CWP concentration between the strains (Table 13; Figure 18A). 
Next, we measured the mannose/glucose ratio, by treating cell walls with $\mathrm{H}_{2} \mathrm{SO}_{4}$ which hydrolyses polysaccharides. The samples were analysed with HPLC on an organic acid analysis column and the ratios between the different sugars were determined. The Apga29/4pga29 mutants showed a significant reduction in the mannose/glucose ratio compared with the control strains (Table 13; Figure 18B), which indicates a reduction of mannan in the mutants cell wall.

\section{Table 13. Cell wall composition.}

Cell walls of each strain were isolated from two different cultures. The samples were analysed in triplo from which the mean values were calculated. The chitin and protein concentration was determined in percentage. Mannose and glucose values were divided in order to obtain the mannose/glucose ratio (M/G). SD indicates the sample standard deviation.

\begin{tabular}{l|lllllll} 
& \multicolumn{2}{|c}{ 4pga29/4pga29 } & \multicolumn{2}{c}{ Apga29/4pga29/PGA29 } & \multicolumn{2}{c}{ SC5314 } \\
& mean & SD & mean & SD & mean & SD \\
\hline Chitin (\%) & 5.15 & 0.34 & 5.37 & 0.65 & 4.66 & 1.02 \\
Protein (\%) & 10.60 & 0.69 & 9.53 & 1.12 & 9.14 & 0.73 \\
M/G & 0.309 & 0.0025 & 0.513 & 0.0033 & 0.470 & 0.0105
\end{tabular}


A

Chitin and protein concentration

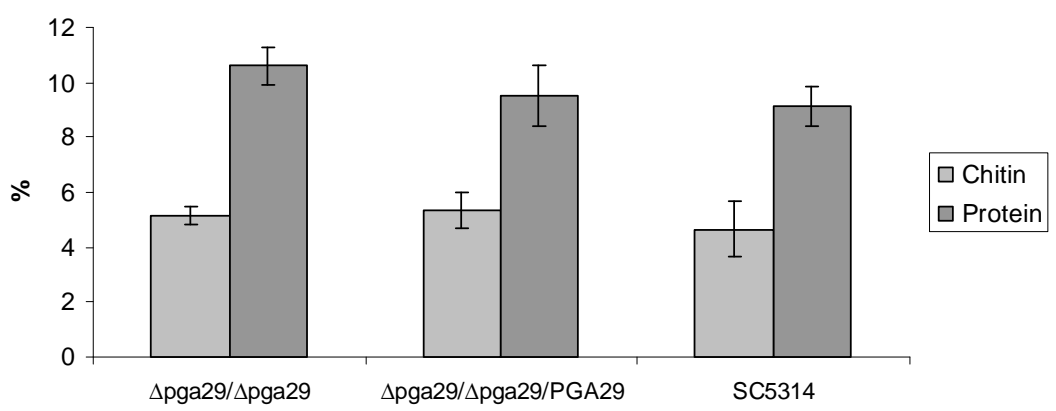

Mannose/Glucose ratio

B

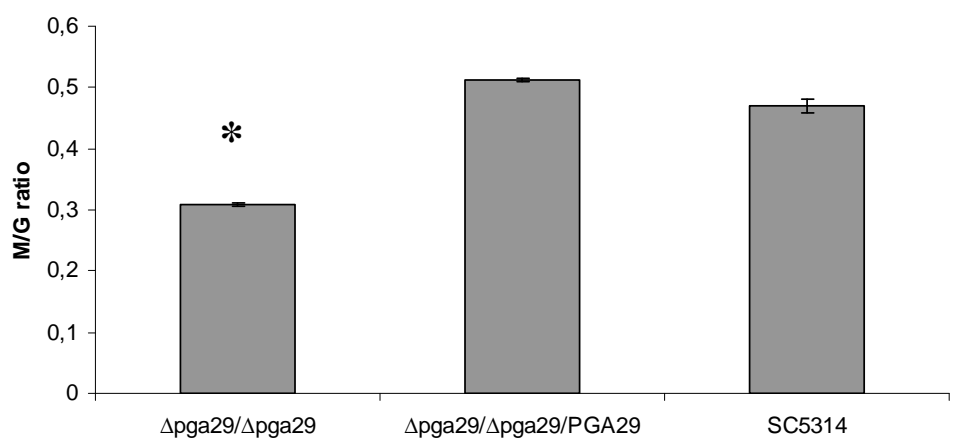

Figure 18. Cell wall composition analysis of the 4pga29/4pga29 strain.

The $C$. albicans strains were cultured under conditions in which $P G A 29$ is abundantly expressed (YPD medium at $30^{\circ} \mathrm{C}$ ) and harvested at an $\mathrm{OD}_{600}$ of 2.0. The isolated cell walls were treated with $\mathrm{NaOH}$, to release protein, with $\mathrm{HCl}$ (Chitin) and with $\mathrm{H}_{2} \mathrm{SO}_{4}$ (mannan, glucan) to release monosaccharides. Protein and chitin were quantified using a colorimetric assay. Mannose and glucose were determined with HPLC.

(A) Chitin and protein concentration (indicated in \%) and (B) mannose/glucose ratio in cell walls of Apga29/Apga29, Apga29/_pga29/PGA29 and wild type SC5314. The asterisk indicates a significant lower mannose/glucose ratio compared with the control strains $(T$-test, $P<0.05)$

\subsection{Phenotypic analysis of $P G A 29$ deletion mutants}

\subsubsection{Growth rate of $\Delta p g a 29 / 4 p g a 29$ mutants}

We determined whether deletion of PGA29 affected the growth rate in the Apga29/4pga29 strain. Because C. albicans is capable to grow in a wide $\mathrm{pH}$ range, we tested our strains for growth in a pH range from $\mathrm{pH} 4.0$ to $\mathrm{pH} 9.0$. These assays showed that PGA29 deletion did not alter the growth rate at the different $\mathrm{pH}$ values, as indicated by a comparison of the Apga29/4pga29 deletion mutant and the revertant (Figure 19). 


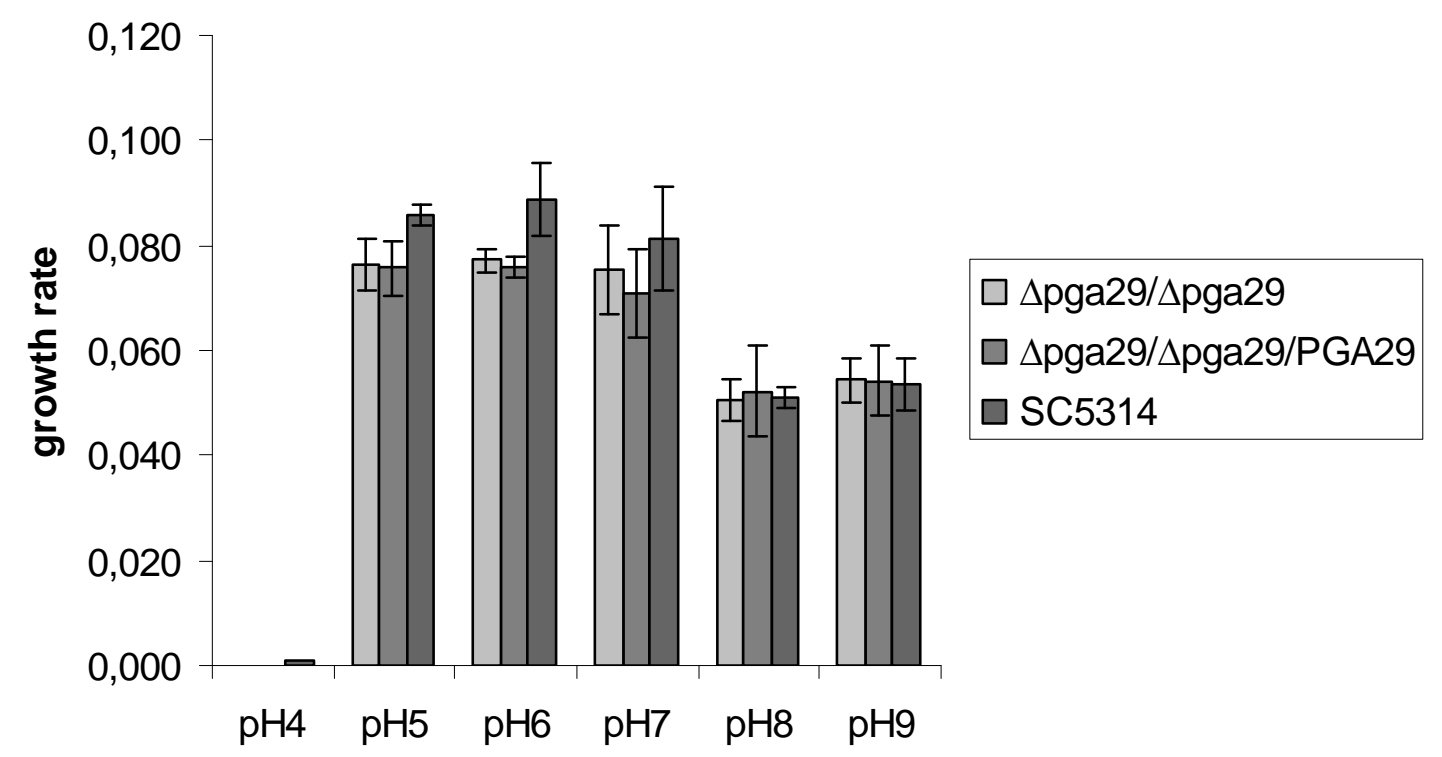

Figure 19. Growth rate determination of the $4 p g a 29$ mutants.

Growth rate of mutant, revertant and wild type was determined at different $\mathrm{pH}$ values. From overnight cultures, cells were inoculated in 96 -well plates and incubated at $30^{\circ} \mathrm{C}$. Two independent Apga29/4pga29 strains and two Apga29/4pga29/PGA29 strains were used. From each strain 6 cultures were grown. The $\mathrm{OD}_{600}$ was measured at 15 minutes time intervals from which the average slope was calculated.

\subsubsection{CFW and other cell wall stress}

The observed upregulation of Pga29p under CFW stress (Figure 6) could imply a compensatory effect induced by $C$. albicans in order to fortify its cell wall. To analyse this possiblity, Apga29/4pga29 mutants were cultured under different CFW concentrations on YPD or YNB agar (Figure 20) in order to monitor the impact on the growth. Interestingly, no increased $\mathrm{CFW}$-sensitivity was observed between the mutants and the revertant strains. Applying additional stresses, for example an increase $\left(40^{\circ} \mathrm{C}\right)$ or decrease $\left(25^{\circ} \mathrm{C}\right)$ in temperature and an increase in osmolarity, did not significantly alter the sensitivity of the mutant for CFW. Subsequently, the Apga29/4pga29 strain was tested for SDS-sensitvity as well, which did not reveal an altered phenotype of the Apga29/4pga29 strain. These data suggest that Pga29p is not involved in the fundamental maintenance of the cell wall integrity in C. albicans. In all microdilution spot assays the wild type SC5314 appeared more resistant than the mutant and revertant strains. As mentioned above in the cell wall composition analysis of Apga29/4pga29 mutants (see 3.6), we speculate that this could be explained by the ectopic expression of the auxotrophic markers in the mutant and revertant. 


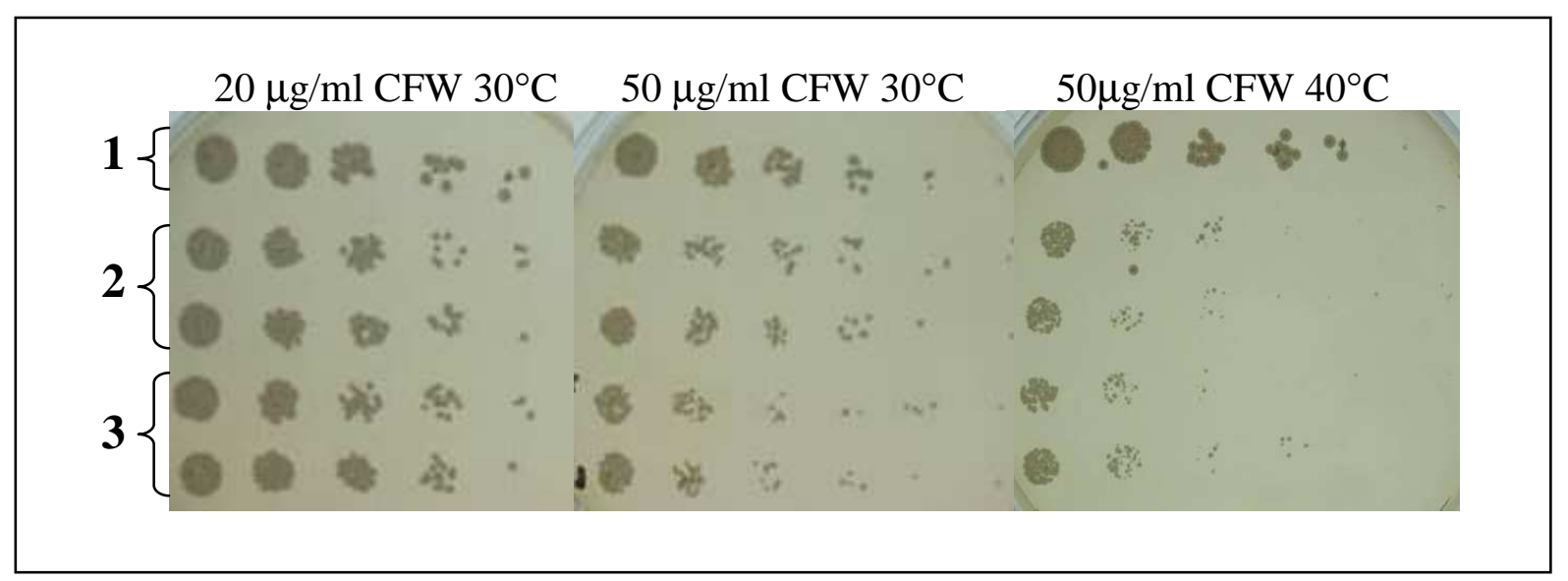

Figure 20. Microdilution spot assay screening for CFW sensitivity in 4pga29/4pga29 mutants. For each strain six different concentrations of stationary phase or mid-log phase cells were spotted on YPD or YNB agar supplemented with concentrations of CFW that were ranging between 0$75 \mu \mathrm{g} / \mathrm{ml}$. Cells were incubated at different temperatures $\left(25^{\circ} \mathrm{C}\right.$-not shown-, $30^{\circ} \mathrm{C}, 37^{\circ} \mathrm{C}$-not shownand $\left.40^{\circ} \mathrm{C}\right)$. Additional stress was induced by adding high concentrations $(0.7-1.0 \mathrm{M})$ of $\mathrm{NaCl}$ or by incubating at low $\left(25^{\circ} \mathrm{C}\right)$ or high $\left(40^{\circ} \mathrm{C}\right)$ temperatures. Two independent $\Delta p g a 29 / \Delta p g a 29$ strains and two independent $\triangle p g a 29 / \Delta p g a 29 / P G A 29$ strains were used in each experiment. (1) wild type SC5314. (2) Apga29/Apga29/PGA29 strain. (3) Apga29/4pga29 strain.

\subsection{3 $\beta-1,3$-glucanase sensitivity assay}

The mannoprotein layer can serve as a protective entity against foreign macromolecules and degrading enzymes. As Pga29p is abundantly present in yeast cells, we investigated the possibility whether this protein might serve as a protective shield for the inner glucan layer. Our strains were grown to the mid log-phase and were incubated in $50 \mathrm{mM}$ Tris- $\mathrm{HCl}$ with $\beta$ 1,3-glucanase (Quantazyme), a recombinant enzyme that degrades the polysaccharide backbone of the cell wall. Over time in a hypo-osomolaric solution this leads to cell lysis that can be monitored photospectrometrically. Lysis was determined and compared by measuring the $\mathrm{OD}_{600}$ over a time period of 60 minutes (Figure 21). The $4 p g a 29 / \Delta p g a 29$ mutants did not show increased sensitivity to $\beta$-1,3-glucanase, suggesting that Pga29p does not play a role as a protective entity in the mannoprotein layer in this respect. 


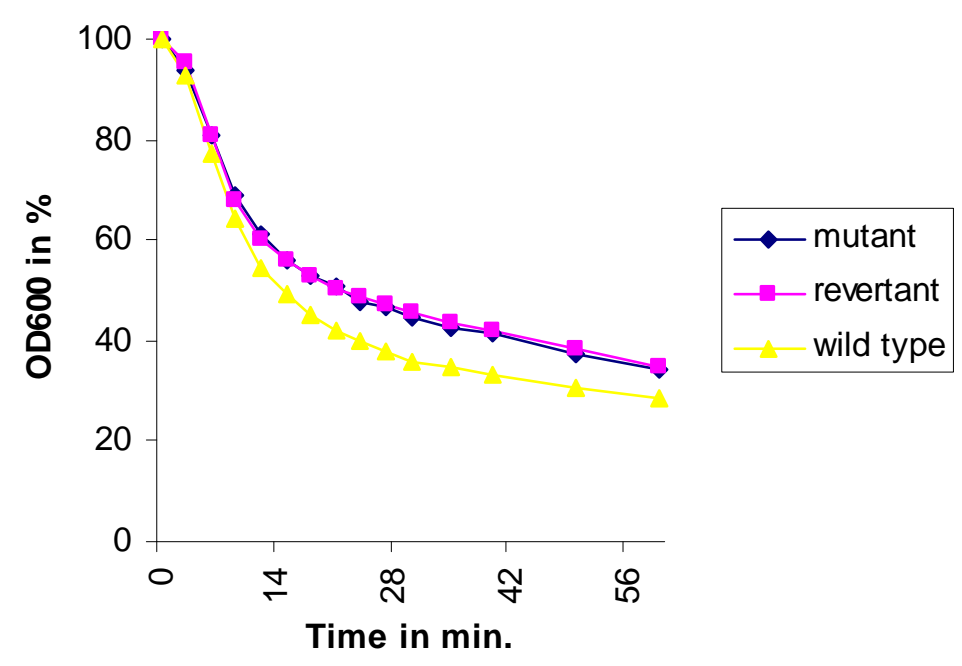

Figure 21. $\beta$-1,3-glucanase sensitivity assay

Strains were grown to the mid-log phase till an $\mathrm{OD}_{600}$ of 2.0 was reached. For the assay cells were adjusted to an $\mathrm{OD}_{600}$ of 0.7 , which is indicated as $100 \%$ in the graph. After adding Quantazym, the decrease in the $\mathrm{OD}_{600}$ was measured over a time period of $60 \mathrm{~min}$. The experiment was repeated two times and the mean values were used to generate the graph.

\subsubsection{Sensitivity against antimycotics}

We tested whether deletion of Pga29p affected the sensitivity against selected clinically relevant antimycotics using the E-test format: Fluconazole, Intraconazole, Voriconazole, , 5Fluocytosin and Amphotericin B and the cell wall active substance Caspofungin. The mutant strain showed similar sensitivity compared with the revertant strain (Table 17, Appendix).

\subsection{Is Pga29p redundant?}

\subsubsection{PGA30 and PGA31 expression in Apga29/4pga29 mutants}

In order to investigate whether the lack of obvious cell wall phenotypes in the Apga29/4pga29 mutants is based on the fact that PGA29 is a redundant gene, we examined the expression of $P G A 30$ and $P G A 31$ (two identified homologs of $P G A 29$ ) in the Apga29/4pga29 strain by using Northern analysis. PGA31 was shown to be highly upregulated in protoplasts that regenerate their cell wall and is therefore a potential candidate for taking over the function of PGA29. Increased expression of $P G A 30$ and $P G A 31$ was not observed in mutant cells grown in YPD medium at $30^{\circ} \mathrm{C}$ (Figure 22, 1a) as well as in cells grown under CFW stress (Figure 22, 1b). In case of CFW stress, PGA31 transcription was upregulated in both, the mutant and in the wild type strain, whereas PGA30 transcripts could not be detected in both conditions. 


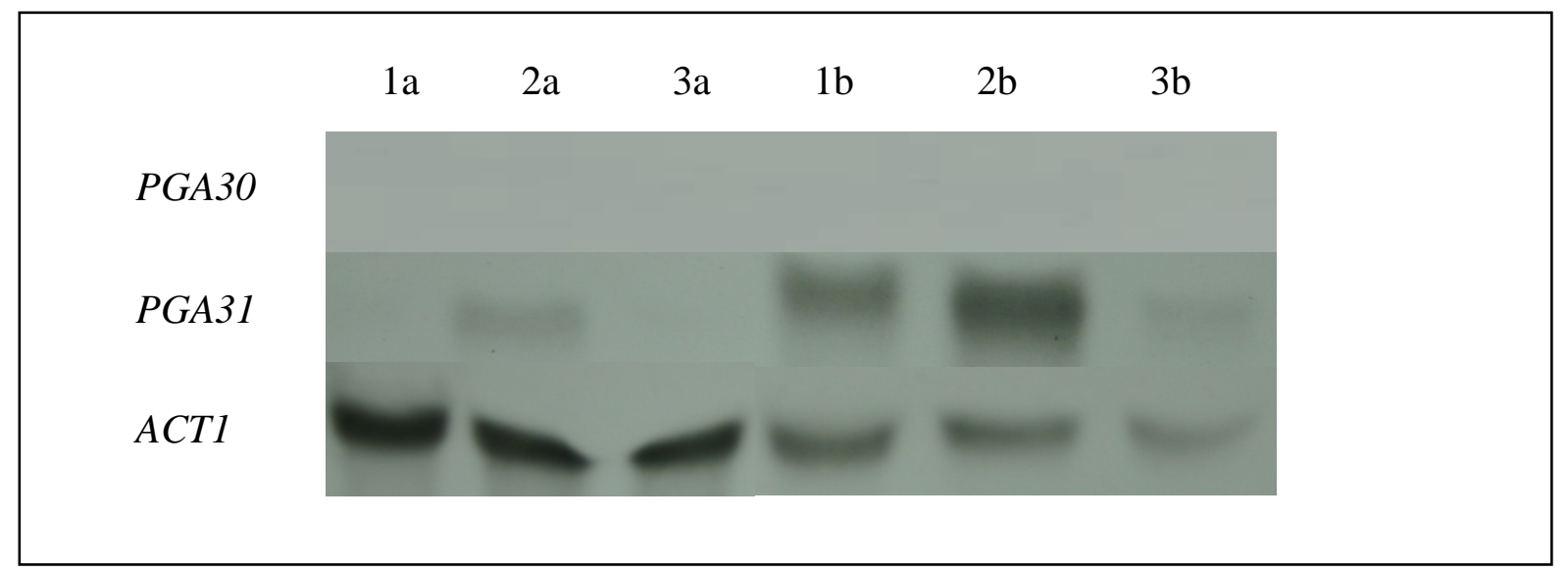

Figure 22. Comparison of $P G A 30$ and PGA31 expression between $4 p g a 29 / 4 p g a 29$ mutants and in wild type strains

C. albicans cells were grown to the mid-log phase $\left(\mathrm{OD}_{600}\right.$ of 2.0) and harvested or incubated with CFW for 15 min. Northern blot analysis was performed with PGA30, PGA31 and ACT1 digoxigenin probes. ACT1 was used as a loading control.

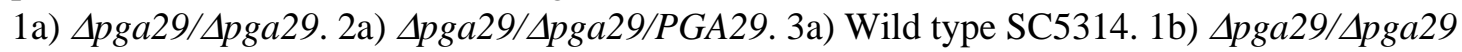
grown in $25 \mu \mathrm{g} / \mathrm{ml} \mathrm{CFW.} \mathrm{2b)} \Delta p g a 29 / \Delta p g a 29 / P G A 29$ grown in $25 \mu \mathrm{g} / \mathrm{ml} \mathrm{CFW.} \mathrm{3b)} \mathrm{Wild} \mathrm{type}$ SC5314 grown in $25 \mu \mathrm{g} / \mathrm{ml} \mathrm{CFW}$

\subsubsection{Cell wall proteome of the Apga29/4pga29 mutants}

To determine whether $C$. albicans attempts to compensate for PGA29 deletion by upregulating other CWPs or by incorporating a different set of CWPs into the cell wall, we analysed the full cell wall proteome of the Apga29/4pga29 mutant with the aid of liquid chromatography-tandem mass spectrometry (LC/MS/MS) (Table 14). We extracted cell walls from stationary phase-yeast cells that were cultured in YPD medium at $25^{\circ} \mathrm{C}$ or $37^{\circ} \mathrm{C}$. CWPs were released from the cel wall by using the 'cell wall shaving method', in which extracted cell walls are directly digested by trypsin (Yin et al., 2008).

In total 24 CWPs were identified, which included GPI-adhesins (Als1p, Als2p, Als3p and Als4p), proteins that are involved in cell wall integrity or assembly (Cht2p, Crh11p, Ecm33p, Pga4p, Phr1p, Phr2p, Pir1p, Sap9p, Scw1p, Ssr1p and Utr2p), proteins that are involved in iron aquisition (Rbt51p/Pga10p and Rbt5p), superoxide dismutases (Sod4p/Pga2p and Sod5p/Pga3p) and proteins with unknown functions (Csa1p, Hyr1p, Pga29p and Pga36p). The yeast form wall protein 1 (Ywp1p) seems to play a role in dispersal of $C$. albicans in the host (Granger et al., 2005). It should be noted that Csalp was identified with only one peptide sequence, 'IYDQLPECAK', which occurs seven times in this protein, but is also present one time in Rbt5p and Rbt51/Pga10p. In Csa1p, these peptide sequences are followed by a proline 
residue, which can prevent cleavage of trypsin, suggesting the identification of Csalp has not been fully proven.

Interestingly, several CWPs were shown to be specifically upregulated at $25^{\circ} \mathrm{C}$ or $37^{\circ} \mathrm{C}$, as indicated by the number of identified peptides. Als $2 p$ peptides were exclusively identified in cell walls from cells that were cultured at $25^{\circ} \mathrm{C}$, whereas the proteins Als $3 p$ and Hyr $1 p$ were only found at $37^{\circ} \mathrm{C}$.

Twenty tryptic peptides from Pga29p were identified, confirming that it is abundantly present in the cell wall of $C$. albicans. As expected, the MS results confirmed that the cell walls of the deletion mutant $4 p g a 29 / \Delta p g a 29$ did not contain Pga29p, whereas the control strains did. The family members Pga30p and Pga31p were not identified in any strain, which coincides with our data deduced from Northern blot analysis.

Although the performed LC/MS/MS analysis is a qualitative rather then a quantitative method, the data for the cell walls of the $\Delta p g a 29 / \Delta p g a 29$ strain that was grown at $25^{\circ} \mathrm{C}$ indicate that the mutant contains less Als4p and Pga4p. In Apga29/4pga29 cell walls, only three tryptic peptides from Als4p were identified, whereas nine and ten peptides from this protein were identified in the revertant and wild type strains, respectively. In addition, only one peptide from Pga4p was found in Apga29/4pga29 cell walls, compared to four peptides in the revertant and wild type strains. These data might indicate that Als4p and Pga4p are downregulated upon $P G A 29$ deletion. However, this has to be confirmed with a quantitative approach. Upregulation of other CWPs in the Apga29/4pga29 strain was not observed, suggesting C. albicans does not compensate for PGA29 deletion. 
Table 14. LC/MS/MS analysis of the cell wall proteome from $\Delta p g a 29 / \Delta p g a 29, \Delta p g a 29 / \Delta p g a 29 / P G A 29$ and SC5314 cell walls. Cell walls were extracted from yeast cells that were grown for 24 hours at $25^{\circ} \mathrm{C}$ or $37^{\circ} \mathrm{C}$. Cells wall samples were treated with trypsin and the supernatants containing the solubilised peptides were analysed with LC/MS/MS. Identified peptides are indicated a ' + '.

Protein Name Residues Peptide sequence

TLNMPCVFK

YTTSQTSVDLTADGVK

$\begin{array}{ll}77-92 & \text { YTTSQTSVDLTADGV } \\ 176-188 & \text { STVDPSGYLYASR }\end{array}$

237-254 GLNDWNYPVSSESFSYTK

265-279 YQNVPAGYRPFIDAY

303-311 SQSKPFTLR

Als2

18-34

$35-41$

$42-76$

$45-76$

77-92

93-111

$112-123$

153-166

$166-175$

291-305

291-310

Als3
$50-76$

$77-92$

$108-123$

$124-149$

133-149

$135-149$

$150-166$

166-175

$167-175$
KVITGVFNSFDSLTWTR

AGNYAYK

GPNRPTWNAVLGWSLDGTSANPGDTFTLNMPCVFK

RPTWNAVLGWSLDGTSANPGDTFTLNMPCVFK

FITDQTSVDLTAEGVK

YATCQFYSGEEFTTFSSLK

CTVSNTLTSSIK

AGTNTVTFNDGDKK

KISIDVDFEK

YTNDYACVGSSLQSK

YTNDYACVGSSLQSKPFNLR

AVLGWSLDGTSASPGDTFTLNMPCVFK

FTTSQTSVDLTAHGVK

STLTCTVSNTLTPSIK

ALGTVTLPLAFNVGGTGSSVDLEDSK

AFNVGGTGSSVDLEDSK

NVGGTGSSVDLEDSK

CFTAGTNTVTFNDGGKK

KISINVDFER

ISINVDFER
Dpga29/4pga29

$25^{\circ} \mathrm{C} \quad 37^{\circ} \mathrm{C}$

Dpga29/Apga29/PGA29

SC5314

$25^{\circ} \mathrm{C} \quad 37^{\circ} \mathrm{C}$

$25^{\circ} \mathrm{C} \quad 37^{\circ} \mathrm{C}$

$+$

$+$

+
+
+
+

+
+
+
+
+
+
+
+
+
+

$+$

$+$

$+$

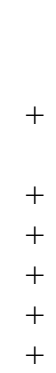

$+$

$+$ 
Table 14. Continued.

Protein Name Residue

Als4

237-254

289-305

291-305
Peptide sequence

\section{GYLTDSR}

VSTLFVAPQCANGYTSGTMGFANTYGDVQIDCSNIHVGITK

208-236

217-236

255-266

295-305

307-312

1344-1350

$18-38$
$55-76$
$77-91$
$92-107$
$113-123$
$157-175$
$217-254$
$237-254$
$255-273$
$255-275$
$255-279$
$255-284$
$260-284$
$266-284$
$268-284$
$274-284$
$285-291$

GYTSGTMGFANTYGDVQIDCSNIHVGITK

ANTYGDVQIDCSNIHVGITK

GLNDWNYPVSSESFSYTK

TCSSNGIFITYK

TLSYANEYTCAGGYWQR

SYANEYTCAGGYWQR

EYTCAGGYWQR

APFTLR

VIPSLNK

KVITGIFDSFNSLTWTNAASY

SLDGATASAGDTFTLDMPCVFK

FITDQTSIDLVADGR

TYATCNLNSAEEFTTF

TVTTTMTADTK

TVTFNDGDTSISTTVDFEK

STAGTGATIDCSTVHVGISNGLNDWNYPISSESFSYTK

GLNDWNYPISSESFSYTK

TCTSTSVLVTYQNVPAGYR

TCTSTSVLVTYQNVPAGYRPF

TCTSTSVLVTYQNVPAGYRPFVDAY

TCTSTSVLVTYQNVPAGYRPFVDAYVSATR

SVLVTYQNVPAGYRPFVDAYVSATR

QNVPAGYRPFVDAYVSATR

VPAGYRPFVDAYVSATR

PFVDAYVSATR

VSSYAMR
Dpga29/4pga29

Dpga29/Apga29/PGA29

$\operatorname{SC5314}$

$25^{\circ} \mathrm{C} \quad 37^{\circ} \mathrm{C}$

$25^{\circ} \mathrm{C} \quad 37^{\circ} \mathrm{C}$

$25^{\circ} \mathrm{C} \quad 37^{\circ} \mathrm{C}$

$+$

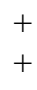

$+$

$+$

$+\quad+$

$+$
$+$

$+$

$+$

$+$ 
Table 14. Continued.

Peptide sequence

$\Delta p g a 29 / \Delta p g a 29$

Apga29/Apga29/PGA29

SC5314

$25^{\circ} \mathrm{C} \quad 37^{\circ} \mathrm{C}$

$25^{\circ} \mathrm{C} \quad 37^{\circ} \mathrm{C}$

$25^{\circ} \mathrm{C} \quad 37^{\circ} \mathrm{C}$

Cht2

$\begin{array}{ll}20-39 & \text { SASNQVALYWGQNGAGGQER } \\ 22-39 & \text { SNQVALYWGQNGAGGQER } \\ 75-91 & \text { TFESGLLHCSQIGADIK } \\ 99-121 & \text { TVLLSLGGGVGDYGFSDVASATK } \\ 122-129 & \text { FADTLWNK } \\ 185-200 & \text { PQCPYPDASLGDLLSK } \\ 229-236 & \text { FADSAPNK } \\ 240-258 & \text { LFVGVPATSNIAGYVDTSK } \\ 259-267 & \text { LSSAIEEIK } \\ 268-290 & \text { CDSHFAGVSLWDASGAWLNTDEK } \\ 268-299 & \text { CDSHFAGVSLWDASGAWLNTDEKGENFVVQVK } \\ 278-299 & \text { WDASGAWLNTDEKGENFVVQVK }\end{array}$

Crh11

$\begin{array}{ll}29-45 & \text { SSDCSPVPALGSSFLEK } \\ 45-58 & \text { KFDNGLGPHFESLK } \\ 46-58 & \text { FDNGLGPHFESLK } \\ 46-59 & \text { FDNGLGPHFESLKK } \\ 60-75 & \text { QGTIDSGSNGLSLTMK } \\ 77-84 & \text { RFDNPSFK } \\ 78-84 & \text { FDNPSFK } \\ 148-158 & \text { GGYHDIANPLK } \\ 159-169 & \text { DYHTYVIDWTK } \\ 170-182 & \text { DAVTWSVDGSVIR } \\ 236-246 & \text { SVLVADYSSGK } \\ 247-261 & \text { QYSYSDQSGSWESIK } \\ 271-279 & \text { YDQAQDDIK }\end{array}$


Table 14. Continued.

\begin{tabular}{|c|c|c|c|c|c|c|c|c|}
\hline \multirow[t]{2}{*}{ Protein Name } & \multirow[t]{2}{*}{ Residues } & \multirow[t]{2}{*}{ Peptide sequence } & \multicolumn{2}{|c|}{$\Delta p g a 29 / \Delta p g a 29$} & \multicolumn{2}{|c|}{$\Delta p g a 29 / \Delta p g a 29 / P G A 29$} & \multicolumn{2}{|c|}{ SC5314 } \\
\hline & & & $25^{\circ} \mathrm{C}$ & $37^{\circ} \mathrm{C}$ & $25^{\circ} \mathrm{C}$ & $37^{\circ} \mathrm{C}$ & $25^{\circ} \mathrm{C}$ & $37^{\circ} \mathrm{C}$ \\
\hline \multirow[t]{2}{*}{ (Csa1) } & $\begin{array}{l}53-62 \\
(244-253) \\
(576-585)\end{array}$ & IYDQLPECAK & + & + & + & & & \\
\hline & $\begin{array}{l}55-62 \\
(246-253) \\
(416-423) \\
(578-585)\end{array}$ & DQLPECAK & & & + & & & + \\
\hline \multirow[t]{7}{*}{ Ecm33 } & $139-168$ & TGLTAGITSAESVVISDTGLSSLTGINVFK & & & + & & & \\
\hline & $246-262$ & VELAELTSIGNSLTINK & & & + & & & \\
\hline & $246-273$ & VELAELTSIGNSLTINKNDDLTELDFPK & & & + & & + & \\
\hline & $276-290$ & TIGGALQISDNSELR & + & + & + & + & + & \\
\hline & 291-297 & SFSGFPK & + & + & + & & + & + \\
\hline & $321-329$ & RVSGGFILK & & + & & + & & + \\
\hline & $334-341$ & LSCSAFNK & + & + & + & + & + & + \\
\hline \multirow[t]{7}{*}{ Hyr1 } & $31-41$ & GGIQGFHGDVK & & + & & + & & + \\
\hline & $135-142$ & STAYLYAR & & + & & & & \\
\hline & $143-157$ & EWTNNGLIVAYQNQK & & + & & & & + \\
\hline & $181-189$ & HQDFVPATK & & + & & + & & + \\
\hline & $192-205$ & GTGCVTADEDTWIK & & & & & & + \\
\hline & $206-222$ & LGNTILSVEPTHNFYLK & & + & & + & & \\
\hline & $278-286$ & AAALPQYFK & & + & & + & & + \\
\hline \multirow[t]{8}{*}{ Pga4 } & $24-37$ & VEGNAFWDSESGDR & & & & & & + \\
\hline & $42-65$ & GVDYQPGGSSELEDPLADTNVCER & & & & & & + \\
\hline & $69-79$ & YFQELGINTIR & & + & + & + & + & + \\
\hline & $99-116$ & AGIYVILDVNTPHSSITR & & + & & + & & + \\
\hline & $199-214$ & LPSGLYFNCGDDDMAR & + & + & & & + & + \\
\hline & $215-241$ & IDMYGINDYSWCGDASMTTSQYSQQMK & & & & & & + \\
\hline & $302-315$ & GDSVTTNDDFDNLK & & & + & & + & + \\
\hline & $321-332$ & TKNPSGDGGYLK & & + & + & + & + & \\
\hline
\end{tabular}


Table 14. Continued.

\begin{tabular}{|c|c|c|c|c|c|c|c|c|}
\hline \multirow[t]{2}{*}{ Protein Name } & \multirow[t]{2}{*}{ Residues } & \multirow[t]{2}{*}{ Peptide sequence } & \multicolumn{2}{|c|}{$\Delta p g a 29 / \Delta p g a 29$} & \multicolumn{2}{|c|}{$\Delta p g a 29 / \Delta p g a 29 / P G A 29$} & \multicolumn{2}{|c|}{ SC5314 } \\
\hline & & & $25^{\circ} \mathrm{C}$ & $37^{\circ} \mathrm{C}$ & $25^{\circ} \mathrm{C}$ & $37^{\circ} \mathrm{C}$ & $25^{\circ} \mathrm{C}$ & $37^{\circ} \mathrm{C}$ \\
\hline \multirow[t]{2}{*}{ Pga4 } & $343-357$ & SNIWNVTEEIPDTPK & & & + & & & \\
\hline & $365-385$ & GLAEPTGHGFDAYVQGNCNAK & & & & & & + \\
\hline \multirow[t]{3}{*}{ Pga10/Rbt51 } & $47-56$ & IYDQLPECAK & + & + & & + & & \\
\hline & $50-56$ & QLPECAK & & & + & & & \\
\hline & $61-92$ & QSTSNTPCPYWDTGCLCVMPQFGGAIGDCVAK & & & + & + & + & + \\
\hline \multirow[t]{2}{*}{ Pga24/Ywp1 } & $331-339$ & TVVACDEHK & + & & + & & & \\
\hline & $329-339$ & VITVVACDEHK & + & & + & + & + & + \\
\hline \multirow[t]{20}{*}{ Pga29 } & $16-25$ & TISSIQLFAK & & & + & + & & + \\
\hline & $26-39$ & SDDSKVDGLGLYSK & & & & & & \\
\hline & $27-39$ & DDSKVDGLGLYSK & & & + & + & + & \\
\hline & $29-39$ & SKVDGLGLYSK & & & + & & & \\
\hline & $31-39$ & VDGLGLYSK & & & + & & + & \\
\hline & $40-58$ & HEGAAIDYLFLGKNGADLK & & & + & & & \\
\hline & $64-71$ & KQIFQELK & & & + & & & \\
\hline & $72-78$ & TSSITVR & & & + & & + & \\
\hline & $65-71$ & QIFQELK & & & & + & & \\
\hline & $72-78$ & TSSITVR & & & + & + & + & \\
\hline & $79-103$ & QSFTLGGDVYELGATDNFIPVTINK & & & + & & & + \\
\hline & $82-103$ & TLGGDVYELGATDNFIPVTINK & & & + & & & \\
\hline & $104-114$ & DGTLSFTGDDK & & & + & & & \\
\hline & $104-119$ & DGTLSFTGDDKVYASK & & & & + & & \\
\hline & $106-119$ & TLSFTGDDKVYASK & & & + & & & \\
\hline & $120-126$ & NVNDPYR & & & + & + & + & \\
\hline & $127-137$ & YSESEYAVSNK & & & + & + & & + \\
\hline & $127-138$ & YSESEYAVSNKK & & & + & & + & \\
\hline & $138-150$ & KTDDSAPITIVAK & & & + & + & + & + \\
\hline & $144-150$ & PITIVAK & & & + & & & \\
\hline
\end{tabular}


Table 14. Continued.

\begin{tabular}{|c|c|c|c|c|c|c|c|c|}
\hline \multirow[t]{2}{*}{ Protein Name } & \multirow[t]{2}{*}{ Residues } & \multirow[t]{2}{*}{ Peptide sequence } & \multicolumn{2}{|c|}{$\Delta p g a 29 / \Delta p g a 29$} & \multicolumn{2}{|c|}{ Dpga29/Apga29/PGA29 } & \multicolumn{2}{|c|}{ SC5314 } \\
\hline & & & $25^{\circ} \mathrm{C}$ & $37^{\circ} \mathrm{C}$ & $25^{\circ} \mathrm{C}$ & $37^{\circ} \mathrm{C}$ & $25^{\circ} \mathrm{C}$ & $37^{\circ} \mathrm{C}$ \\
\hline \multirow[t]{2}{*}{ Pga36 } & $20-34$ & ADQICNDHCSNAYQK & & & & & & + \\
\hline & $35-52$ & QQSCGGTDDVSSQSATLK & & + & & & & + \\
\hline \multirow[t]{11}{*}{ Phr1 } & $21-35$ & KFESSTPPVEVVGNK & & + & & + & & + \\
\hline & $49-70$ & GIAYQQDAAGSVSSGYDADPNR & & + & & + & & + \\
\hline & $99-113$ & VYAIDPDKDHEECMK & & & & & & + \\
\hline & $138-147$ & PEWNLDLYKR & & & & & & + \\
\hline & $175-184$ & SNTDASAFVK & & + & + & + & & + \\
\hline & $201-215$ & QIPVGYSSNDDEEIR & & + & & & & + \\
\hline & $280-291$ & LFQEIGTLYSDK & + & + & + & + & & \\
\hline & $387-423$ & SLECVVADDVDKEDYGDLFGQVCGYIDCSAISADGSK & & & & & & + \\
\hline & $424-437$ & GEYGVASFCSDKDR & & + & & + & & + \\
\hline & $438-452$ & LSYVLNQYYLDQDKK & & + & & + & & + \\
\hline & $439-452$ & SYVLNQYYLDQDKK & & & & & & + \\
\hline \multirow[t]{9}{*}{$\mathrm{Phr} 2$} & $23-34$ & EDLPAIEIVGNK & + & + & & + & & \\
\hline & $164-174$ & KSNTDASAFVK & & + & + & & & + \\
\hline & $165-174$ & SNTDASAFVK & + & & + & & + & \\
\hline & $191-205$ & SIPVGYSANDDSAIR & + & + & + & + & + & + \\
\hline & $193-205$ & PVGYSANDDSAIR & & & & & & + \\
\hline & $228-238$ & MYEWCGDSSYK & & & + & & & \\
\hline & $239-250$ & ASGYESATNDYK & & + & & + & & + \\
\hline & $270-292$ & KFTEVATLFGDQMTPVWSGGIVY & & & & & + & \\
\hline & $316-325$ & DYSYYSSEIK & & + & & + & & + \\
\hline \multirow[t]{4}{*}{ Pir1 } & $249-266$ & ACSSANNLEMTLHDSVLK & + & + & + & + & + & + \\
\hline & $251-266$ & SSANNLEMTLHDSVLK & + & + & + & + & & \\
\hline & $253-266$ & ANNLEMTLHDSVLK & & & + & & & \\
\hline & $255-266$ & NLEMTLHDSVLK & + & + & + & & & \\
\hline
\end{tabular}


Table 14. Continued.

\begin{tabular}{|c|c|c|c|c|c|c|c|c|}
\hline \multirow[t]{2}{*}{ Protein Name } & \multirow[t]{2}{*}{ Residues } & \multirow[t]{2}{*}{ Peptide sequence } & \multicolumn{2}{|c|}{$\Delta$ pga29/4pga29 } & \multicolumn{2}{|c|}{$\Delta p g a 29 / \Delta p g a 29 / P G A 29$} & \multicolumn{2}{|c|}{ SC5314 } \\
\hline & & & $25^{\circ} \mathrm{C}$ & $37^{\circ} \mathrm{C}$ & $25^{\circ} \mathrm{C}$ & $37^{\circ} \mathrm{C}$ & $25^{\circ} \mathrm{C}$ & $37^{\circ} \mathrm{C}$ \\
\hline \multirow[t]{7}{*}{ Pir1 } & $272-281$ & WGAIVANHQF & & & & & + & \\
\hline & $272-284$ & WGAIVANHQFQFD & & & & & + & \\
\hline & $272-294$ & WGAIVANHQFQFDGPIPQAGTIY & & & & & + & \\
\hline & $272-301$ & WGAIVANHQFQFDGPIPQAGTIYSAGWSIK & + & & & & & + \\
\hline & $295-301$ & SAGWSIK & + & & + & & + & \\
\hline & $316-331$ & CLSGDFYNLYDENVAK & + & & + & & + & \\
\hline & $317-331$ & LSGDFYNLYDENVAK & + & & & & & + \\
\hline \multirow[t]{6}{*}{ Rbt5 } & $47-56$ & IYDQLPECAK & + & + & & + & & \\
\hline & $49-56$ & DQLPECAK & & & & + & & + \\
\hline & $61-92$ & QSTSSTPCPYWDTGCLCVMPQFAGAVGNCVAK & & + & + & + & & + \\
\hline & $71-92$ & WDTGCLCVMPQFAGAVGNCVAK & & + & + & + & & + \\
\hline & $78-92$ & VMPQFAGAVGNCVAK & & + & & + & & + \\
\hline & $82-92$ & FAGAVGNCVAK & & + & & + & + & + \\
\hline Sap9 & $307-319$ & AGSILFGAIDHAK & & & & & + & \\
\hline \multirow[t]{4}{*}{ Scw1/MP65 } & $128-141$ & GITYSPYSDNGGCK & & + & + & + & & + \\
\hline & $142-160$ & SESQIASEIAQLSGFDVIR & & & & & & + \\
\hline & $311-322$ & NVLITETGWPSR & & & & & & + \\
\hline & $334-344$ & SNQQAAISSIK & + & & + & & & \\
\hline Sod4/Pga2 & $105-117$ & TPAALELGDLSGR & & & & & + & + \\
\hline \multirow[t]{2}{*}{ Sod5/Pga3 } & $118-127$ & HGNIMGESYK & & + & & + & & + \\
\hline & $118-140$ & HGNIMGESYKTEYDDSYISLNEK & & & & & & + \\
\hline \multirow[t]{4}{*}{ Srr1 } & $23-31$ & APPACLLAC & & + & + & + & + & + \\
\hline & $24-34$ & PPACLLACVAK & + & + & & & & \\
\hline & $25-34$ & PACLLACVAK & & & & & + & \\
\hline & $41-51$ & CSGLNDLSCICTTK & + & + & + & + & + & + \\
\hline
\end{tabular}


Table 14. Continued.

\begin{tabular}{|c|c|c|c|c|c|c|c|c|}
\hline \multirow[t]{2}{*}{ Protein Name } & \multirow[t]{2}{*}{ Residues } & \multirow[t]{2}{*}{ Peptide sequence } & \multicolumn{2}{|c|}{$\Delta p g a 29 / \Delta p g a 29$} & \multicolumn{2}{|c|}{ Apga29/Apga29/PGA29 } & \multicolumn{2}{|c|}{ SC5314 } \\
\hline & & & $25^{\circ} \mathrm{C}$ & $37^{\circ} \mathrm{C}$ & $25^{\circ} \mathrm{C}$ & $37^{\circ} \mathrm{C}$ & $25^{\circ} \mathrm{C}$ & $37^{\circ} \mathrm{C}$ \\
\hline Srr1 & $64-79$ & EICPNGDADTAISAFK & + & + & + & + & & + \\
\hline \multirow[t]{8}{*}{ Utr2 } & $34-61$ & HCPEDKPCCSQFGICGTGAYCLGGCDIR & & & & & & + \\
\hline & $75-85$ & MSTFQESFDSK & & & & & + & \\
\hline & $245-253$ & YDYPQTPSR & & + & + & + & + & + \\
\hline & $254-268$ & IQFSLWPGGDSSNAK & & & + & & & \\
\hline & $269-286$ & GTIEWAGGLINWDSEDIK & & & & & & \\
\hline & $269-287$ & GTIEWAGGLINWDSEDIKK & & & + & & & + \\
\hline & $273-287$ & WAGGLINWDSEDIKK & & & & & & + \\
\hline & 288-296 & YGYYYAHIK & + & + & + & + & + & \\
\hline
\end{tabular}




\subsection{Pga29p is involved in systemic candidosis}

Our phenotypic screens do not support the hypothesis that Pga29p plays a major role in maintaining the cell wall integrity of $C$. albicans. However, we experimentally confirmed that Pga29p is one of the most abundant GPI-dependent CWP in the yeast form of C. albicans and, as shown above, we found homologs of Pga29p in other pathogenic Candida spp. To investigate whether Pga29p might be required for establishing C. albicans infections, we examined the Apga29/Apga29 strain in a mouse model of systemic candidosis. As systemic candidosis starts with Candida entering into the bloodstream, BALB/c mice were intravenously infected with the Apga29/4pga29 strain and control strains. Standard death curves were obtained after the infection (Figure 23), which showed that the virulence of the Apga29/4pga29 strain is slightly but significantly reduced compared with the control strains, indicating that Pga29p does play a role in the establishment of $C$. albicans infections.

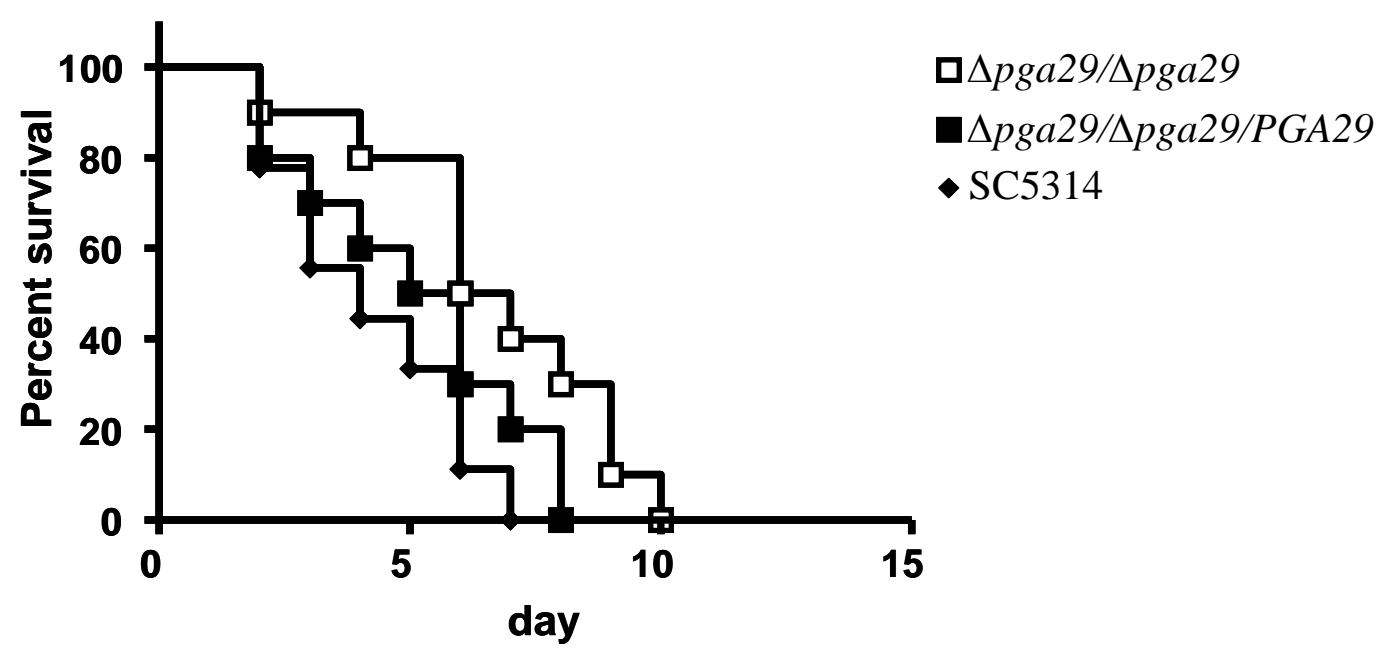

Figure 23. Systemic infection model.

Ten BALB/c mice were intravenously infected via the lateral tale vein with $1.0 * 10^{6}$ C. albicans cells. The median survival times were 6.5, 5.5 and 4.5 days for the $\Delta p g a 29 / \Delta p g a 29$ strain, Apga29/Apga29/PGA29 and SC5314 strains, respectively.

\subsection{PGA29 deletion does not affect morphology or adhesion of $C$. albicans}

Our next objective was to better elucidate the role of Pga29p in the infection process. The ability of $C$. albicans to transit between different morphological forms and to adhere to host cells is essential for establishing a systemic infection. We investigated whether the reduced virulence of the $\Delta p g a 29 / \Delta p g a 29$ strain was caused by a deficiency in morphological transition or by a reduced ability to adhere to different plastic surfaces and host cells. 
C. albicans is a polymorphic fungus that is able to grow as yeast, pseudohyphae, true hyphae or chlamydospores. This ability for morphological transition has been related to the virulence of $C$. albicans. To study a possible role of Pga29p in the morphological transition and morphological plasticity of C. albicans, we tested the ability of the $4 p g a 29 / \Delta p g a 29$ strain to grow in the above mentioned growth forms in various liquid and agar media. Different inducers of hyphal growth were used to test the yeast-to-hyphae transition: serum (YPD medium with $10 \%$ serum), neutral $\mathrm{pH}$ (Lee medium), $\mathrm{N}$-acetylglucosamine (SB medium), nutrient deprivation (Spider medium) and low concentrations of farnesol, which is a quorum sensing molecule that is excreted by $C$. albicans and prevents mycelium development (Hornby et al., 2001.). The formation of yeast cells from hyphae was tested by incubating serum-induced hyphae in YPD medium at $30^{\circ} \mathrm{C}$ for several hours. The ability to form chlamydospores was tested on rice-Tween agar medium. The Apga29/4pga29 strain showed normal development for all growth forms in these assays. An example is shown in figure 24, which depicts our C. albicans strains that were grown on Spider agar.
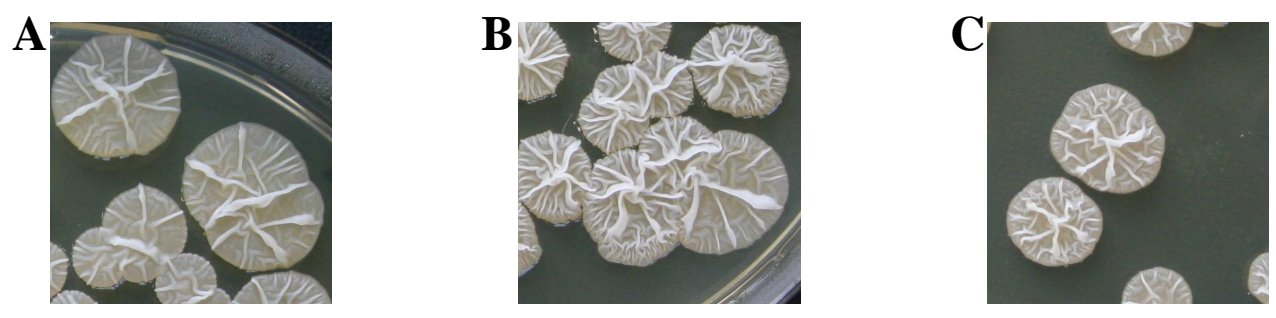

Figure 24. Morphology assay to screen for the ability of the Apga29/4pga29 mutants to develop hyphae.

From an overnight culture $C$. albicans cells were plated out on Spider agar, in order to induce nutrient-deprived hyphal development. The cells were incubated at $30^{\circ} \mathrm{C}$ or $37^{\circ} \mathrm{C}$ for $5-7$ days. (A) Apga29/4pga29 strain. (B) Apga29/_pga29/PGA29 strain. (C) wild type SC5314.

The ability of the mutants to adhere to several surfaces, which included plastic and epithelial cells, was tested in three different assays. In the first assay, we incubated $C$. albicans yeast cells with Caco- 2 cells and quantified number of non-adherent and adherent cells (Dieterich et al, 2002). After 15, 30, 45, 60 and 120 minutes, non-adherent cells were aspirated and adherent cells were scraped off the bottom of the ELISA wells. To determine the adherence ability of the strains, non-adherent and adherent cells were plated out on YPD agar and after 24 hours the colony forming units were counted. No significant differences were observed between the strains (not shown). 
C. albicans can adhere to a variety of plastic materials, including polystyrene, which is a model system to study the adhesion of this fungal pathogen to medical devices. It has been shown that the adherence ability of $C$. albicans germ tubes to polystyrene is correlated with the presence of a fibrillar layer which contained adhesins (Tronchin et al., 1988). The adherence ability of $\Delta p g a 29 / \Delta p g a 29$ stationary-phase yeast cells to plastic was tested with tissue culture-treated and non-treated polystyrene Petri dishes (Granger et al., 2005). The cells were incubated at $30^{\circ} \mathrm{C}$ or $37^{\circ} \mathrm{C}$ for $3,4,6$ and 24 hours and were stained with the dye crystal violet (CV) (Figure 25). In the assays no significant differences were observed between the Apga29/4pga29 and control strains.

To study the adhesion of hyphae to polystyrene, stationary phase yeast cells were diluted in modified RPMI medium and were distributed in tissue culture treated 24-well plates. During an incubation period of 3 days, the adhesion of hyphal colonies was checked by gently shaking the plates, thereby distinguishing the number of non-adherent colonies from the adherent ones. No significant differences in this assay were observed (data not shown). Taken together, the data obtained by the adhesion assays suggest that the adherence is not altered by the deletion of PGA29 in C. albicans.

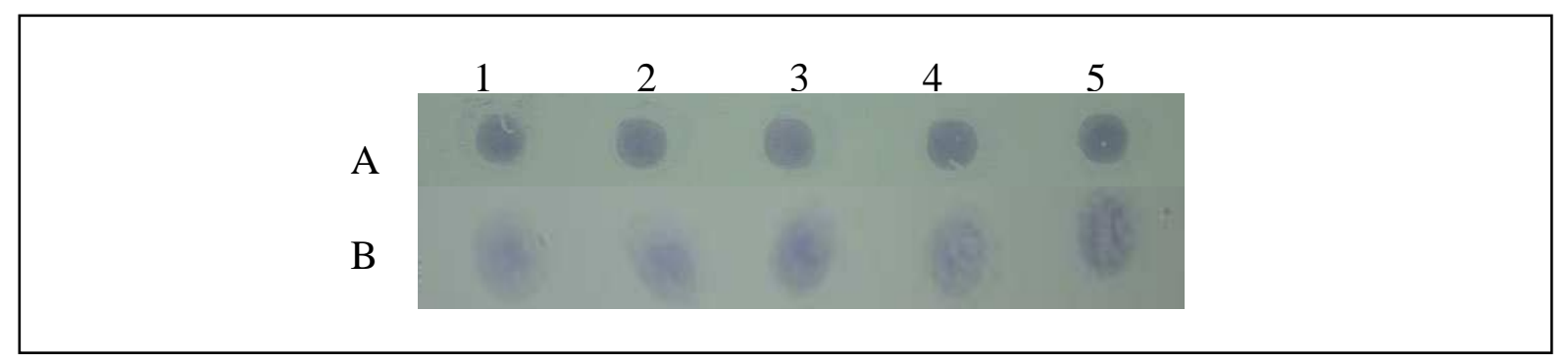

Figure 25. Adhesion assay, CV staining of $\boldsymbol{C}$.albicans on polystyrene. Stationary phase cells were spotted on non-treated (A) or tissue culture treated (B) polystyrene Petri dishes and incubated for different time periods at $30^{\circ} \mathrm{C}$ or $37^{\circ} \mathrm{C}$. Cells were stained with $0.1 \% \mathrm{CV} .1+2$.) Apga29/_pga29 3+4.) Apga29/_pga29/PGA29. 5) wild type SC5314

\subsection{Reconstituted Human Epithelial as model for oral candidosis.}

We used the Reconstituted Human Epithelium (RHE) as an infection model, to study more in detail the interaction of the $4 p g a 29 / 4 p g a 29$ strain with host cells. The model is developed by culturing transformed human keratinocytes of the cell line TR146 derived from a carcinoma of the oral epithelium (Rupniak et al., 1985). This three-dimensional epithelial tissue simulates very well the oral mucosa in vivo and can be supplemented with polymorphonuclear leukocytes (PMNs), which enhance the upregulation of TH1-cytokines and protect the 
epithelium by inhibiting C. albicans growth (Schaller et al., 2004). After 12 hours of infection, light microscopic pictures showed that the $\Delta p g a 29 / \Delta p g a 29$ strain caused a reduced tissue damage to the epithelium (Figure 26B) compared with the Apga29/4pga29/PGA29 strain (Figure 26C) and the wild type strain SC5314 (Figure 26D). To more accurately quantify and compare the degree of epithelial damage, an assay was performed in which the release of lactate dehydrogenase (LDH) from damaged epithelial cells measured. These analyses revealed a statistical discrepancy in the LDH release between $4 p g a 29 /$ Apga29 strain and the control strains (Table 15 and Figure 27). The quantitative difference between Apga29/Apga29 strain and the control strains, although statistically significant, is moderate, which is in accordance with the data obtained from the mouse model. The LDH activity from RHE supplemented with PMNs was overall lower than RHE without PMNs, which confirms the protective effect of these immune cells against $C$. albicans (Table 15 and Figure 27). Taken together, these data from the RHE-model confirm that Pga29p plays a role in the establishment of $C$. albicans infection.

A

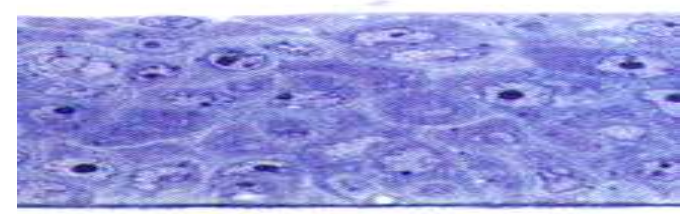

$\mathrm{C}$

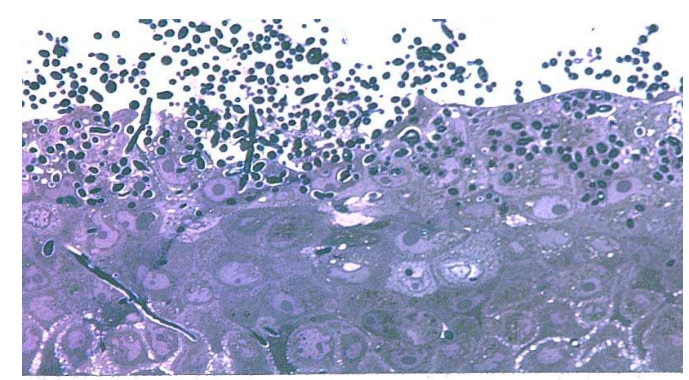

B

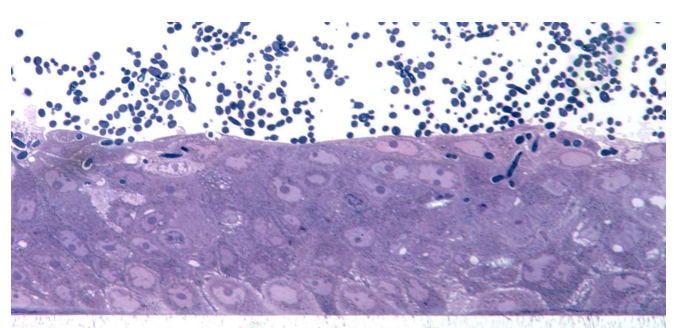

$\mathrm{D}$

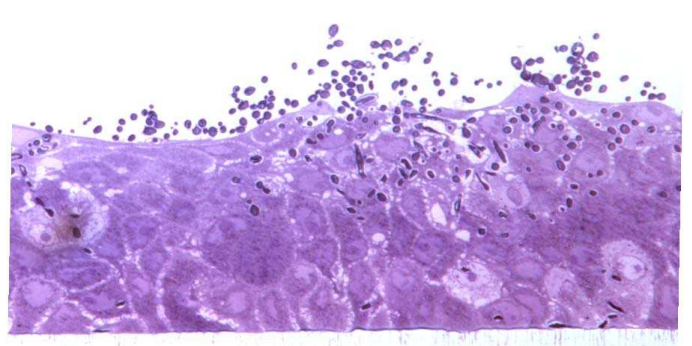

Figure 26. Apga29/4pga29 mutants show an attenuated virulence in a RHE model of oral candidosis.

RHE was infected with $2.0 \times 10^{6}$ C. albicans cells and was examined by light microscopy after 12 hours. (A) Non-infected (B) Apga29/Apga29 strain. (C) Apga29/Apga29/PGA29 strain. (D) SC5314 wild type. The experiment was three times performed with two independent $\Delta$ pga29/Apga29 strains and two independent $\Delta p g a 29 / \Delta p g a 29 / P G A 29$ strains. RHE infected with the mutant showed a reduced damage. In case of the revertant and wild type strain tissue damage was severe, showing clear oedema and vacuolisation of the epithelium. 


\section{Table 15. Determination of LDH activity in the RHE model.}

The activity of LDH that is liberated from the damaged epithelial cells was measured for RHE infected 24 hours with $\Delta p g a 29 / \Delta p g a 29$, Apga29/Apga29/PGA29 and wild type SC5314. Experiments were three times performed, from which the mean values and sample standard deviations (SD) were determined

\begin{tabular}{l|cccc} 
& \multicolumn{2}{|c}{$\begin{array}{l}\text { LDH (U/l) } \\
\text { without PMNs }\end{array}$} & \multicolumn{2}{c}{$\begin{array}{l}\text { LDH }(\mathrm{U} / \mathrm{l}) \\
\text { with PMNs }\end{array}$} \\
& mean & SD & mean & SD \\
\hline Control (PBS) & 18 & 2.65 & 19 & 4.24 \\
Apga29/4pga29 & 134 & 8.14 & 97 & 8.89 \\
Apga29/4pga29/PGA29 & 190 & 7.02 & 142 & 8.96 \\
SC5314 & 197 & 9.45 & 152 & 4.95
\end{tabular}

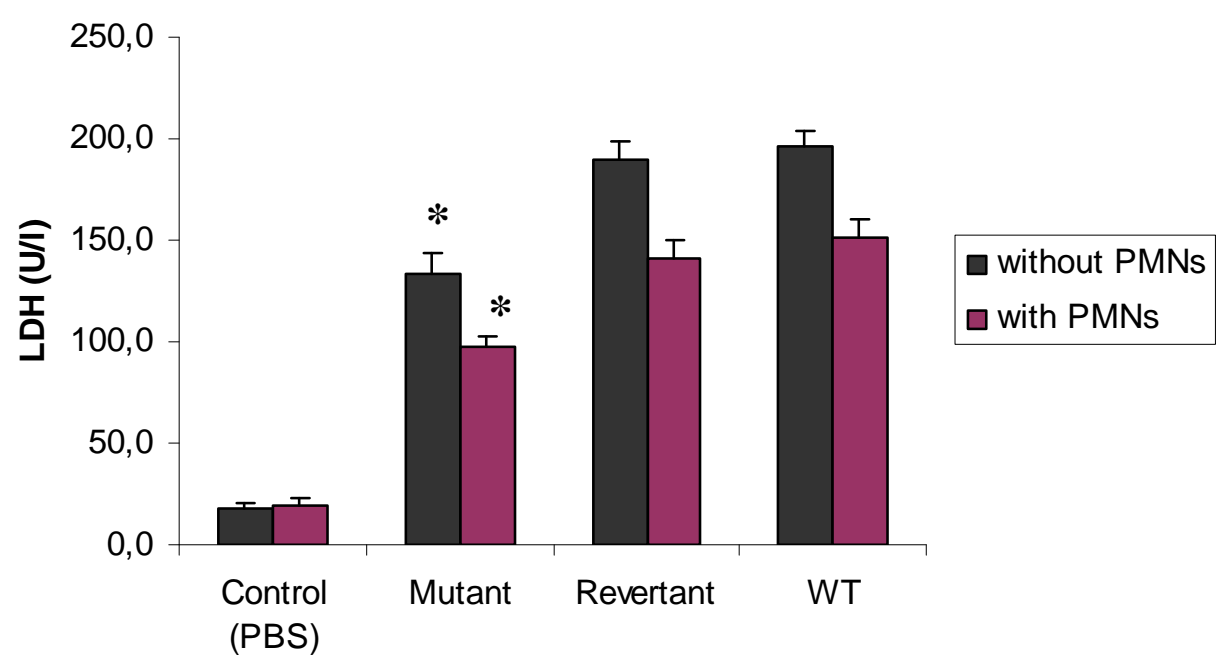

Figure 27. Determination of LDH activity in the RHE model.

The activity of LDH that is liberated from the damaged epithelial cells was measured for RHE infected with Apga29/Apga29, Apga29/Apga29/PGA29 and wild type SC5314. RHE that was supplemented with PMNs after 12 hours of infection, showed an overall lower LDH activity. The asterisks indicate significant lower LDH activity compared with the control strains $(T$-test, $P<0.05)$ 


\subsubsection{PGA29 expression in C. albicans infected RHE}

The observed reduced virulence of the Apga29/4pga29 strain is clearly caused by the deletion of the PGA29 gene. In order to obtain insight whether PGA29 is directly or indirectly involved in virulence, the expression of PGA29 in the RHE model was examined by isolating mRNA from 24 hours infected tissue and subsequently generating cDNA with reverse transcriptase PCR. Using this cDNA as a template, a PCR with specific primers for the open reading frame of PGA29 was performed. Analysis of the PCR by agarose gel electrophoresis did not show any signal (not shown), corroborating the data of Zakikhany et al. (2007) who performed genome wide transcript profiling of $C$. albicans RHE infection, which showed the lack of $P G A 29$ gene expression. As $C$. albicans yeast cells rapidly develop germ tubes during the incubation with RHE, it is not surprising that expression of the yeast-specific PGA29 was decreased in this model. This result indicates that Pga29p might be important during a short period of time in the initial stage of infection, prior to the yeast-to-hyphae transition.

\subsection{Pga29p is a potential PAMP}

Important structural features by which GPI-proteins can be identified are serine and threonine rich domains that are heavily O-glycosylated with mannan (Richard and Plaine, 2007). Olinked mannan is an important PAMP that is recognised by the host via the TLR4 receptor, which in turn induces the release of TH1-cytokines (Netea et al., 2008). The Pga29p amino acid sequence consists of $18 \%$ serine and threonine residues, which could serve as $\mathrm{O}-$ glycosylation sites. Pga29p does not contain the sequence N-X-S (X is any amino acid except proline), excluding that it is N-glycosylated. The fact that Pga29p (expected size of the mature protein is $18 \mathrm{kDa}$ ) migrates with SDS-PAGE at approximately $30 \mathrm{kDa}$ and that cell walls of Apga29/4pga29 mutants show a reduced mannose/glucose ratio (Figure 14), suggests that several serine/threonine residues are indeed mannosylated. In order to investigate whether Pga29p is O-mannosylated and therefore could be a potential PAMP, we analysed $\beta-1,6-$ glucanase CWP extracts of defined mutants that are deficient in O-glycosylation (Figure 28). The selected mutants have deletions in PMT1, PMT2, PMT4, PMT5 or PMT6, which encode protein mannosyltransferases that are responsible for adding the first mannose to a serine or threonine residue. Immunoblot analysis of the $\beta$-1,6-glucanase-released CWPs showed a downward shift of the Pga29p band (lane 2), which confirms O-mannosylation by Pmt1p. No downward shift was observed in case of the other Pmt mutants (lane 3-6), which indicates that Pmt2p, Pmt4p, Pmt5p and Pmt6p do not target Pga29p. 


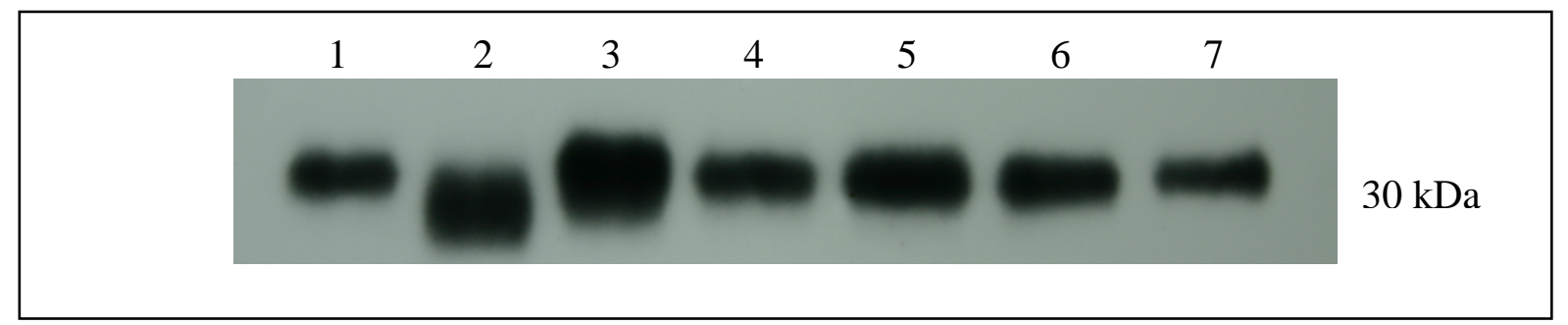

Figure 28. O-glycosylation of Pga29p in C. albicans Pmt deletion mutants.

$\beta$-1,6-glucanase cell wall protein extracts were separated by SDS-PAGE $(11 \%)$ and analysed by immuno-blotting using anti-Pga29p polyclonal antibodies. Lane 1 and 7) wild type strain SC5314. Lane 2) $\Delta p m t 1 / \Delta p m t 1$. Lane 3) $\Delta p m t 2 / P M T 2$. Lane 4) $\Delta p m t 4 / \Delta p m t 4$. Lane 5) $\Delta p m t 5 / \Delta p m t 5$. Lane 6) $\Delta p m t 6 / \Delta p m t 6$

\subsection{Immune response against the Apga29/4pga29 strain}

We showed that Pga29p is glycosylated with O-mannan (Figure 29), a sugar that was shown to be recognised by the host immune system with the PRR TLR4. Deletion of PGA29 probably results in a reduction of O-linked mannan (Figure 18B), that could cause an altered host-pathogen cross-talk, which may result in a diminished immune response. In addition to that, it seems also possible that $P G A 29$ deletion and consequent lack of the abundant Pga29p in the cells wall leads to the exposure of other PAMPs to the outside environment and therefore could be readily recognised by the immune system. This in turn could lead to an increased immune response. In order to study the role of Pga29p during host cell interactions in more detail, we examined the immune response of the RHE upon infection with the PGA29-deletion and the control strains. In addition, the Apga29/4pga29 strain was tested in interaction assays with different immune cells.

\subsubsection{Immune response of $C$. albicans infected RHE}

The immune response of human oral epithelia has been well studied in the past. Using the RHE as a model, it has been shown that $C$. albicans stimulates a strong expression of TH1cytokines at the mRNA and protein level. The expression of these cytokines is correlated with the degree of virulence (Schaller et al., 2002). Supplementing this model with polymorphonuclear leukocytes (PMNs) revealed that this immune response is associated with the chemoattraction of the PMNs, which protect the epithelial cells and enhance the TH1-type immune response (Schaller et al., 2004).

To more closely examine the interaction of the $\Delta p g a 29 / \Delta p g a 29$ mutant with the RHE, we studied the immune response of the epithelial cells against our strains by quantifying mRNA 
levels for the TH1 cytokines: granulocyte-monocyte colony stimulating factor (GM-CSF), tumor necrosis factor alpha (TNF $\alpha)$, interleukin-1 alpha (IL-1 $\alpha)$, interleukin-1 beta (IL-1 $\beta$ ), interleukin-6 (IL-6) and interleukin-8 (IL-8). As expected, epithelial cells that were infected with the reconstituted and wild type strains showed high expression levels of GM-CSF, TNF$\alpha, I L-8$ and moderate levels of $I L-1 \alpha, I L-1 \beta$ and $I L-6$ (Figure 29A). Challenging the RHE with the $\Delta p g a 29 / \Delta p g a 29$ mutant strains resulted in a significant reduced expression for these cytokines (Figure 29A). In order to investigate whether the cytokine mRNA levels coincide with their translational level, we determined the levels of GM-CSF, IL-6, IL-8 (Figure 29B) and TNF $\alpha$ (Figure 29C) with ELISA. RHE infected with the mutant strain released significant reduced levels for these cytokines, which coincides with the mRNA levels. In addition, we studied the expression and cytokine levels of infected RHE supplemented with PMNs. In both experiments only minor discrepancies were observed between the Apga29/Apga29 and control strains, which suggests a protective effect of the PMNs (Figure 30). 


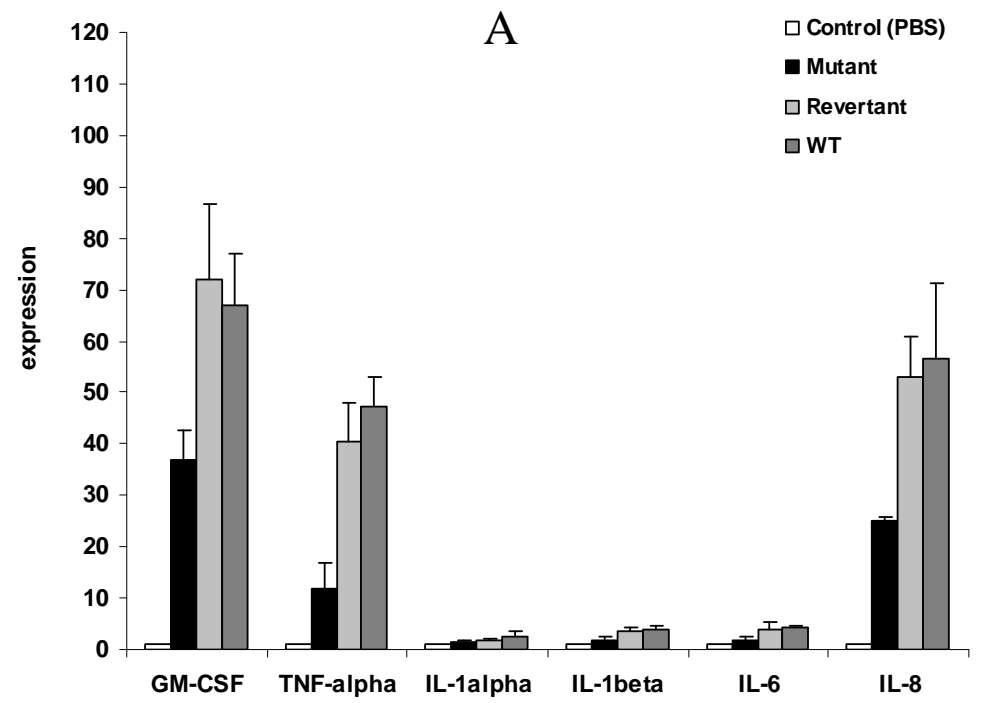

Figure 29. Cytokine expression in RHE. (A) RNA was isolated from RHE that was infected with $C$. albicans for 24 hours. Gene expression was examined for several cytokines that are known to be expressed in keratinocytes upon Candida infection.

(B) GM-CSF, IL-6, IL-8 and $(\mathrm{C}) \mathrm{TNF} \alpha$ protein release was quantified from 24 hours infected RHE.
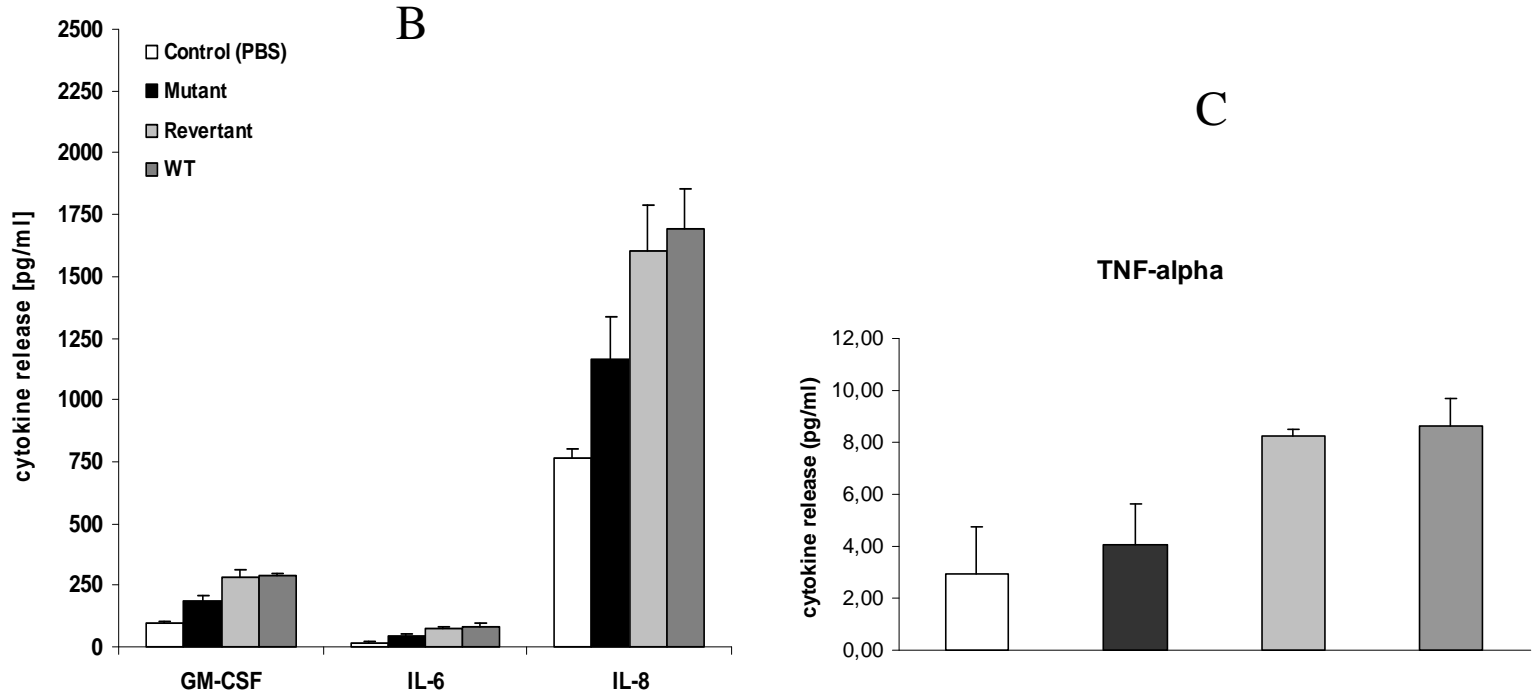


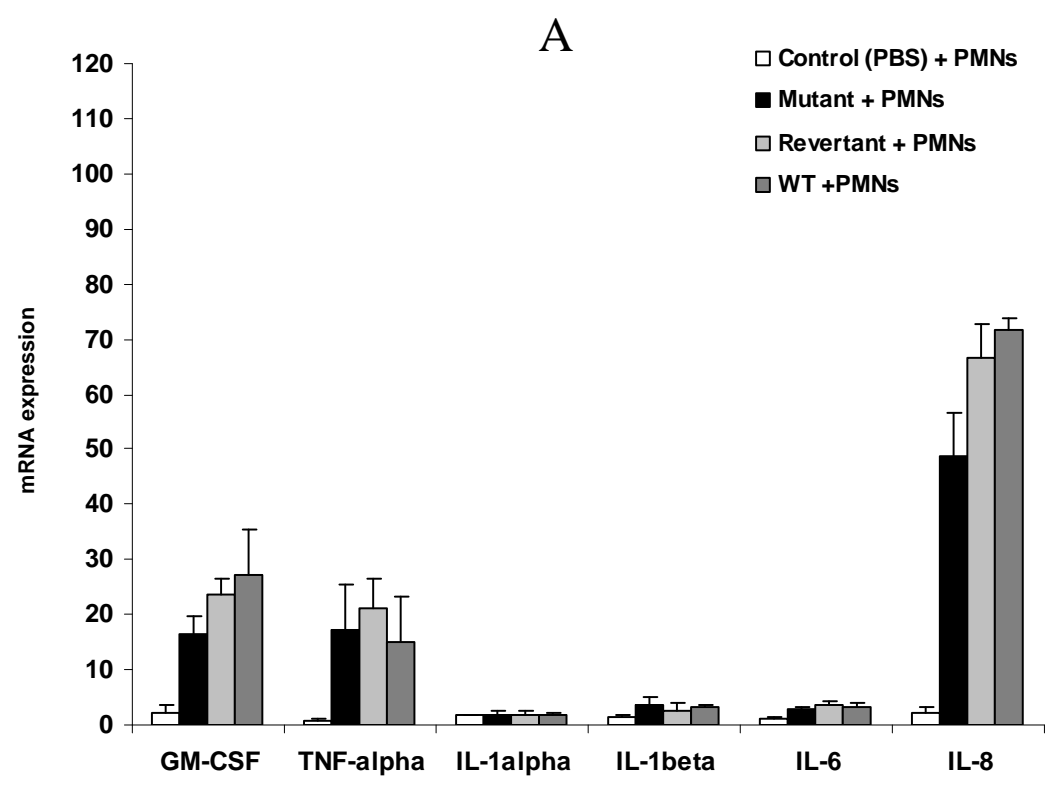

B
Figure 30. Cytokine expression in RHE supplemented with PMNs.

A) After 24 hours of infection, RNA was isolated from RHE that was supplemented with PMNs. Gene expression was examined for several cytokines that are known to be expressed in keratinocytes upon Candida infection .(B) GM-CSF, IL-6, IL-8 and (C) TNF $\alpha$ protein release was quantified from 24 hours infected RHE that was supplemented with PMNs.
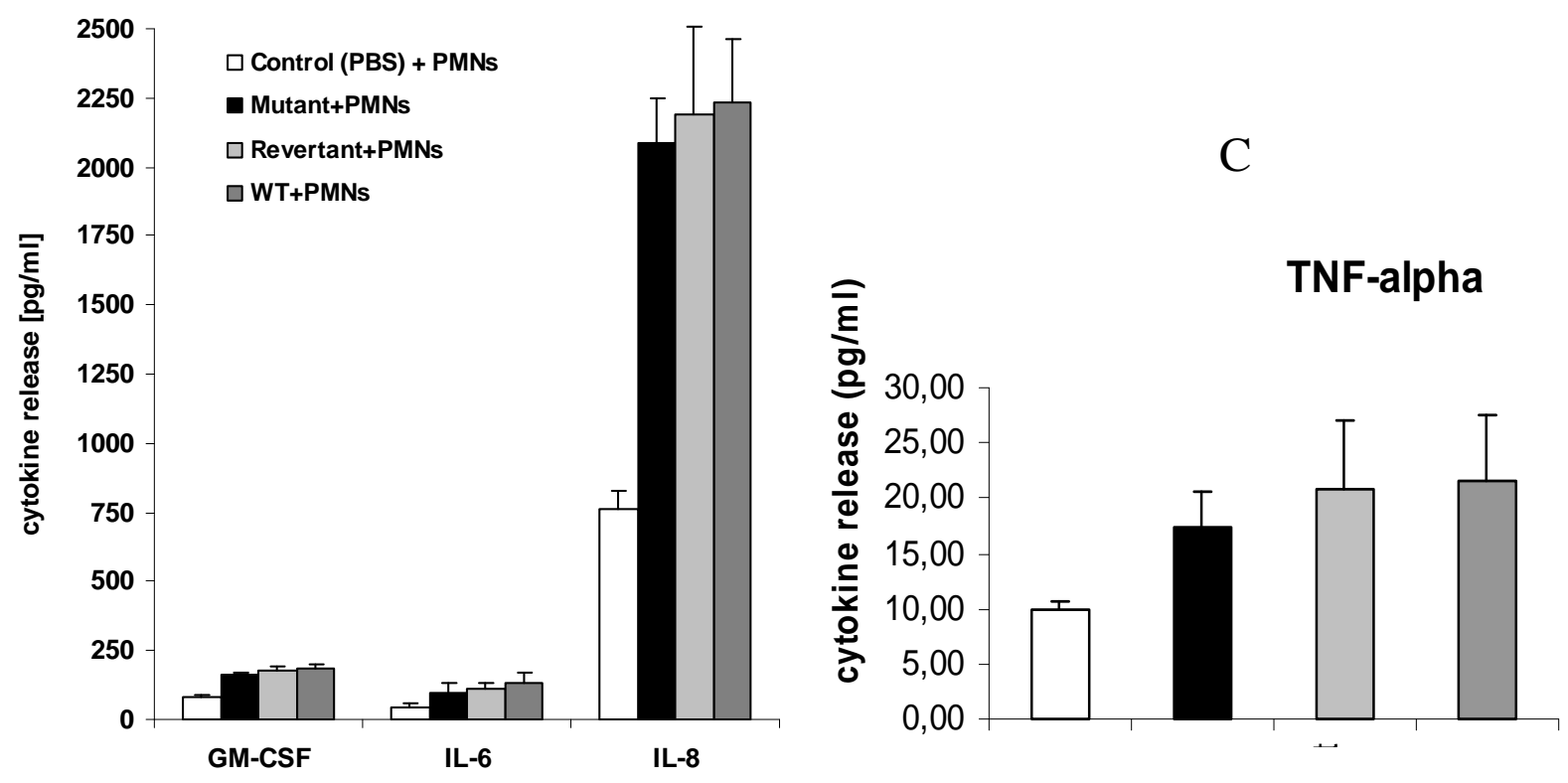


\subsubsection{Interaction of $C$. albicans with PMNs and primary dendritic cells}

We further investigated whether the $\Delta p g a 29 / \Delta p g a 29$ strain induced a different immune response in interaction assays with two different types of immune cells: murine primary dendritic cells and human PMNs. Dendritic cells (DCs) are antigen presenting cells that are able to promote the initiation of T-cell-dependent immunity and can stimulate the immune response by the secretion of cytokines (Netea et al., 2008) Due to their location at sites where C. albicans invasion frequently occurs, such as mucosal surfaces and in the skin, it is believed that dendritic cells play an important role in immunity against $C$. albicans.

Primary DCs were obtained by isolating DC presursors from mice bone marrow that were cultured for 7 days in mDC medium. We determined cytokine expression of murine primary dendritic cells stimulated with $\Delta p g a 29 / \Delta p g a 29$ mutants. The cytokine expression was examined by quantifying mRNA levels of TH1 cytokines IFN- $\beta$, TNF- $\alpha$, IL-12, IFN- $\gamma$ and the TH2 cytokine IL-10 of primary dendritic cells that were incubated with our strains for 20 or 110 minutes. No significant differences were observed between the strains (example given for IFN- $\beta$, Figure 31).

IFN-beta expression

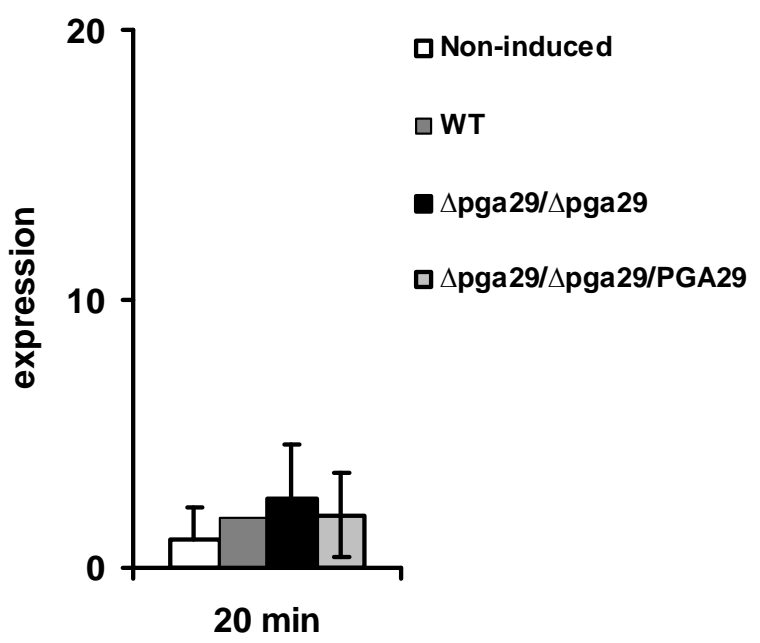

Figure 31. Cytokine expression of primary DCs upon interaction with the 4pga29/4pga29 strain.

Primary DCs were stimulated for 20 minutes with the Apga29/Apga29, Apga29/Apga29/PGA29 and wild type strain. The Candida- DCs interaction was performed at a 2:1 MOI in a $2 \mathrm{ml}$ volume in $6 \mathrm{~cm}$ dishes. RNA was isolated and cytokine expression was examined by RT-PCR. 
The oxidative burst is an important mechanism of host immune cells to kill C. albicans (Netea et al., 2008). Consequently, we measured the oxidative burst of human PMNs upon interaction with the Apga29/4pga29 and Apga29/Apga29/PGA29 strains (Figure 32), that were grown at $28^{\circ} \mathrm{C}$ or $37^{\circ} \mathrm{C}$. C. albicans grown at $37^{\circ} \mathrm{C}$ were stimulating the PMNs more than cells grown at $28^{\circ} \mathrm{C}$, however no significant difference was observed between the Apga29/4pga29 and Apga29/_pga29/PGA29 strains. Our data indicate that the reduced virulence may not be related to an altered pathogen host cross-talk via the mannans.

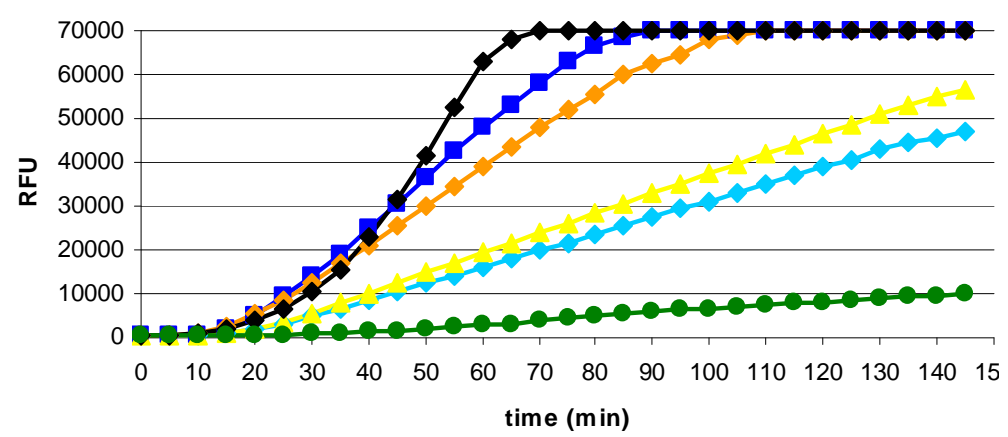

Mutant $28^{\circ} \mathrm{C}$

- Revertant $28^{\circ} \mathrm{C}$

Mutant $37^{\circ} \mathrm{C}$

Revertant $37^{\circ} \mathrm{C}$

$50 \mathrm{ng} / \mathrm{ml}$ PMA

medium

Figure 32. Determination of oxidative burst in interaction assay between PMNs and the Apga29/4pga29 mutant strain.

C. albicans strains that were grown at $28^{\circ} \mathrm{C}$ or $37^{\circ} \mathrm{C}$ were incubated with human PMNs and the oxidative burst was measured at $37^{\circ} \mathrm{C}$ over a time period of 145 minutes. As a postive control 50 $\mathrm{ng} / \mathrm{ml}$ phorbol 12-myristate 13-acetate (PMA) was used. Relative fluorescence units (RFU) were measured every 5 minutes. 


\section{Discussion}

C. albicans is a human pathogenic fungus that normally exists in the host as a commensal organism, but can cause severe infections when the immune system is weakened.

Infections can occur superficially on the skin or mucosa, but can emerge systemically as well, causing damage to organs, which can lead to the decease of the patient.

Since the completion of the C. albicans Sequencing Project at the Stanford Genome Technology Center in 1998, molecular analyses of this pathogen have been considerably facilitated. As a consequence of this, the generation of gene deletion mutants and development of DNA-microarray and proteome projects rapidly increased, which resulted in a ampleness of data that already have started to give answers to several questions regarding the function of particular genes.

C. albicans research has been mainly focussing on the identification of virulence factors and their role in host-pathogen interactions. Cell wall proteins (CWPs) are known to be involved in virulence and several of them are necessary for establishing an infection. In this study, we characterised the GPI-CWP Pga29p, an abundant protein that is covalently linked in the cell wall of the yeast form of $C$. albicans, with the aid of different molecular techniques.

\subsection{Pga29p incorporation into the cell wall}

There are two types of CWPs that are covalently linked to the cell wall of C. albicans: ASLCWPs and GPI-CWPs. ASL-CWPs are directly attached to the $\beta$-1,3-glucan framework, presumably via an alkali sensitive ester-linkage (Ecker et al., 2006). GPI-proteins contain at their C-terminal part a hydrophobic domain, which is cleaved off and replaced by a glycolipid, the GPI-anchor. After being processed through the secretory pathway, GPIproteins finally arrive in the extracellular space while they remain attached to the plasma membrane via their GPI-anchor. In C. albicans, GPI-proteins can be further processed to be linked to the cell wall via a $\beta$-1,6-glucan- $\beta$-1,3-glucan heteropolymer (Kapteyn et al., 1995, 2000).

De Groot et al. (2004) could identify Pga29p in extracts from cell walls treated with HFpyridine and $\beta-1,3$-glucanase, thereby proving that this protein is incorporated into the cell wall. In this study, we attempted to reveal to which polysaccharides in the cell wall Pga29p is covalently linked. First, a recombinant form of Pga29p was produced and isolated from $E$. coli, which was used to generate an anti-Pga29p polyclonal antibody that specifically recognised C. albicans Pga29p. To release CWP fractions from SDS-extracted cell walls of 
the wild type SC5314, the enzymes $\beta$-1,3-glucanase, $\beta$-1,6-glucanase and a $30 \mathrm{mM}$ solution of $\mathrm{NaOH}$ were used. The supernatants were analysed by immuno-blotting and showed that cell walls that were treated with $\beta$-1,6-glucanase released Pga29p, resulting in a single band on the membrane at $30 \mathrm{kDa}$. In contrast, supernatant from cell wall samples that were treated with $\beta$-1,3-glucanase resulted in a high molecular smear. This $\beta$-1,3-glucanase extract was additionally treated with $\beta$-1,6-glucanase, which resulted in a migration of the signal to a size of $30 \mathrm{kDa}$. This proved that Pga29p is linked to the $\beta$-1,3-glucan layer via $\beta$-1,6-glucan. Treatment of cell walls with $\mathrm{NaOH}$ did not release Pga29p, which showed that the protein is not linked via a mild alkali sensitive linkage. This result is in agreement with the lack of Pirlike sequences (QIGDGQVQ) in the amino acid sequence of Pga29p, through which presumably the GPI-CWP Cwp1p of S. cerevisiae and C. glabrata is linked to the $\beta-1,3-$ glucan (Kapteyn et al., 2001; Weig et al., unpublished data).

\subsection{Pga29p is a yeast-specific protein}

\subsection{PGA29 expression during the yeast-to-hyphal transition}

Under certain conditions, the yeast form of C. albicans is able to develop hyphae, a process that is regulated via several pathways and transcription factors (reviewed by Liu, 2001). The morphological transition from the yeast to the hyphal form strongly affects the composition of the cell wall proteome. For example, Sohn et al. (2003) showed with microarrays that the cell wall genes $Y W P 1$ and $H W P 2$ are specifically expressed in the yeast and hyphal form, respectively.

In this study, we were able to show that Pga29p is a yeast-specific protein in C. albicans, by monitoring the downregulation of the gene products in time during yeast-to-hyphal transition. Northern analysis showed that the PGA29 transcript rapidly decreased over a time period of 45 minutes, indicating that the expression of the gene is particularly related to the yeast form of $C$. albicans. In addition, we confirmed with immuno-blot analysis that this decrease occurs also on translational level, though over a much longer time period. After 2 hours of hyphal induction, Pga29p levels in the cell wall start to significantly decrease and could even be detected after 4 hours, which coincides with study of Ruiz-Herrera et al. (2002) who observed in a pulse-chase experiment that cell wall protein recycling did not occur within a time period of 4.5 hours. However, it should be noted that the Pga29p signal that is detected after 4 hours of hyphal growth might orginate from yeast cells that are still in a small number present in the 
culture. From these data, we conclude that Pga29p is a yeast-specific CWP and that its turnover is probably very slow upon hyphal induction.

\subsubsection{Expression in the $\Delta e f g 1 / \Delta e f g 1$ and $\Delta e f g 1 / \Delta e f g 1 \Delta c p h 1 / \Delta c p h 1$ mutants}

The transcription factors $E F G l$ and $C P H I$ encode transcription factors that play a major role in hyphal development and virulence in C. albicans (Lo et al., 1997). Transcription analysis revealed that $P G A 29$ expression is increased in $\Delta e f g 1 / \Delta e f g 1$ and $\Delta e f g 1 / \Delta e f g 1 \Delta c p h 1 / \Delta c p h 1$ mutants (Nantel et al., 2002). We proved that higher amounts of Pga29p are incorporated in the cell wall of these mutants in comparison with the wild type strain SC5314. This suggests that both transcription factors act as repressors of PGA29 transciption in yeast cells of $C$. albicans. Transcription profiling of putative cell wall genes in a $\Delta$ efg $1 / \Delta e f g l$ mutant revealed that Efg1 controls the expression of yeast as well as hyphae specific genes and acts as a strong repressor of cell wall genes, which particularly was shown for RBE1 (Sohn et al., 2003). It has been reported that Efg1 specifically binds to an E-box in vitro, which has the consensus sequence CANNTG (Leng et al., 2001). We determined the number of E-box sequences by searching in the regulatory region for the consensus sequence CANNTG $2 \mathrm{~kb}$ upstream after the start codon of PGA29. In our search we found 8 E-boxes, which suggests that Efg1 directly regulates $P G A 29$ via these sites. However, it should be noted that the E-box consensus sequence occurs frequently by chance (Argimon et al., 2007) and the in vivo transcriptional regulation of Efg1 via E-boxes has never been proven, which suggest that PGA29 may be indirectly repressed by Efg1.

Sohn et al. (2003) showed in the $\Delta$ efgl/Aefg1 $\Delta c p h 1 / \Delta c p h 1$ mutant that cell wall gene expression depends more on Efg1 and Cph1 plays only a minor role. However, in our study we show that Pga29p incorporation is two times more elevated in the $\Delta e f g 1 / \Delta e f g 1$ $\Delta c p h 1 / \Delta c p h 1$ than in the $\Delta e f g 1 / \Delta e f g 1$ strain, indicating Cph1 strongly influences the expression of this gene. Cph1 is the homologue of Ste12 from S. cerevisiae, which binds to the specific sequence TGAAACA (Dolan et al., 1989). These motifs could be putative binding sites for $\mathrm{Cph} 1$ in $C$. albcians. In order to determine the presence of potential binding sites for Cph1 in the promoter region PGA29, we searched for Ste12 binding motifs. Although we did not find any Ste12 motifs, we cannot exclude that Cph1 is able to directly affect $P G A 29$ expression by binding to other motifs. A recent study showed that overexpression of $C P H 1$ under the control of the $A D H 1$ promoter results in a increased expression of PGA29 under hyphal growth conditions (YPD with $10 \%$ serum at $37^{\circ} \mathrm{C}$ ), which refutes the idea that 
Cph1 solely acts as a repressor for PGA29 expression (Huang et al., 2008). Moreover this result shows that the transcriptional regulation of $P G A 29$ by $\mathrm{Cph} 1$ is rather complex.

\subsection{Expression under different conditions}

Transcription analysis of cell wall genes may give a strong indication about their function. For example when the cell wall is experimentally weakened in S. cerevisisae by incubating the cells with the enzyme $\beta$-1,3-glucanase or is genetically altered in deletion mutants, several cell wall genes that have a role in cell wall integrity or modelling were found to be upregulated (Jung and Levin, 1999; De Nobel et al., 2000; Lagorce et al., 2003; Boorsma et al., 2004; García et al., 2004). Another example is that under iron starvation C. albicans upregulates a number of genes that encode GPI-proteins, suggesting they may be involved in the uptake of iron (Lan et al., 2004). Cell wall gene expression can also be investigated on the translational level for example by studying protein incorporation using Western analysis. For example, Weissman and Kornitzer (2004) generated antibodies against Rbt5p, a GPI-protein that facilitates the uptake of haemin and haemoglobin, and subsequently showed with Western analysis that this protein is strongly induced by iron starvation.

\subsubsection{Expression under cell wall stress}

Pga29p is a small CWP and it does not consist of conserved domains that propose enzymatic or adhesive properties. Therefore, it is possible that this protein has a structural purpose by maintaining the cell wall integrity. Consequently, we investigated Pga29p incorporation in the cell wall of cells that underwent cell wall stress. Pga29p incorporation was increased in cells that were grown in YPD medium which was supplemented with CFW, a well-known cell wall perturbant that binds to chitin. Culturing $C$. albicans cells in YPD with the membrane perturbant SDS did not result in elevated levels of the protein in the cell wall. It has been shown for $C$. albicans and other fungi that a reduced cell wall porosity leads to a decrease in SDS sensitivity (Turchini et al., 2000; Coca et al., 2000; Rowbottom et al., 2004). Reducing the cell wall porosity can be established by increasing the concentration of cell wall components, such as mannoproteins (De Nobel et al., 1990). These data suggest that Pga29p upregulation is more related to cell wall stress that directly affects the cell wall organisation, as shown for CFW stress. It is likely that $C$. albicans attempts to compensate the disorganisation of the cell wall by increasing the Pga29p incorporation, which might indicate that this CWP plays a role in maintaining the stability of the cell wall. This suggestion is 
supported by the study of Castillo et al. (2006) who showed with micorarrays that PGA29 is among the seven highest expressed genes in protoplasts that regenerate their cell wall.

\subsection{Generation of PGA29 deletion mutants}

In order to generate a PGA29 deletion mutant and a reconsituted strain, we used PCR-based transformation, a technique that is based on the amplification of the knockout cassette by PCR. Gene deletion was performed in strain BWP17 (Wilson et al., 1999), a widely used derivative of the $C$. albicans wild type isolate SC5314 which has a triple auxothrophy due to the deletion of ARG4, HISI and URA3. We used the marker genes ARG4 and HIS1 for deleting both alleles of PGA29 and the subsequent deletion mutants were complemented with $U R A 3$ in order to restore the uracil auxotrophy. The revertant strain was generated by directing one copy of PGA29 together with URA3 in the RPS10 locus of Apga29/Apga29 mutants. Ectopic expression of URA3 can influence the virulence phenotypes and proteome of C. albicans deletion mutants (Staab and Sundstrom, 2003). This problem can be solved by targeting URA3 at the RPS10 locus, from which it is well expressed (Brand et al., 2004). Phenotype related problems have not been reported for ARG4 and HIS1 marker genes.

\subsection{Cell wall composition of the Apga29/4pga29 mutants}

As described above, Pga29p is abundantly present in the yeast cell wall where it can play a role maintaining the cell wall stability. Its absence in Apga29/4pga29 mutants could induce compensatory mechanisms that result in the increase or decrease of cell wall components. In order to unravel any possible differences in the cell wall structure, we analysed the Apga29/_pga29, Apga29/_pga29/PGA29 and wild type SC5314 strains with transmission electron microscopy. Prior to electron microscopic analysis, the yeast cells were fixed with the high pressure freezing technique (cryofixation), which is an essential fixation method to maintain the upper mannoprotein layer of the cell wall intact (Tokunaga et al., 1986). By measuring the thickness of the glucan and mannoprotein layer we observed no significant difference between the Apga29/Apga29 and Apga29/_pga29/PGA29 strain, suggesting PGA29 deletion does not lead to gross changes in the cell wall structure in C. albicans. A more detailed analysis of the cell wall composition was carried out by measuring the concentrations of cell wall components. It is known that deletion of cell wall genes that are involved in cell wall integrity or assembly can result in altered levels of chitin, glucan and cell wall proteins. For example, deletion of the glycosidases $P H R 1$ and $P H R 2$, which are part of 
the cell wall assembly in C. albicans, result in a 5-fold increase of chitin (Fonzi, 1999). In contrast, deletion of a family member of $P G A 29, P G A 31$, leads to a 2-fold decrease of the chitin concentration in the in the cell wall (Plaine et al., 2008). An increase in the amount of $\beta$-1,3-glucan was detected in deletion mutants lacking SSR1, which encodes a GPI-protein that has a structural purpose in the cell wall (Garcerá et al., 2003, 2005).

To determine the levels of chitin, glucan, mannan and protein in the Apga29/4pga29 strain, cell walls were treated with the chemicals $\mathrm{HCl}$ or $\mathrm{H}_{2} \mathrm{SO}_{4}$ and $\mathrm{NaOH}$ in order to hydrolyse glycosidic and amide bonds, respectively. The concentrations of monosaccharides and amino acids were measured in a colorometric assay or with HPLC. No changes in the concentration of chitin or protein were detected in the cell wall of $\Delta p g a 29 / \Delta p g a 29$ mutants, however, the mannose/glucose ratio was significantly reduced in Apga29/4pga29 strain, compared with the revertant and wild type strain. This suggests that either the mannan amount is decreased or the glucan amount is increased in the cell wall. It is more plausible that the mannan amount is decreased since Pga29p is O-mannosylated (see 4.9 Pga29p is a potential PAMP) and Apga29/4pga29 mutants did not show an increased sensitivity for the enzyme $\beta$-1,3glucanase. In case of a decrease in mannan, one could assume that the structure of the fibrillar mannoprotein layer should be strongly affected by the reduced mannan level. Indeed, the Nglycosylation mutants $\Delta o c h 1 \Delta o c h 1$ and $\Delta$ pmrl/Apmrl are almost lacking their fibrillar layer, however, a $\Delta m n t 1 / \Delta m n t 1 \Delta m n t 2 / \Delta m n t 2$ mutant that lacks the four terminal O-linked mannosyl residues, shows a normal fibrillar layer compared to the wild type strain (Netea et al., 2006). These data indicate that O-mannosylation is not responsible for the appearence of the fibrillar layer.

It should be noted that in our electron microscopic analysis of the cell wall structure, a significant difference was observed in the thickness of the cell wall layers between the wild type SC5314 and the generated mutant strains Apga29/4pga29 and Apga29/_pga29/PGA29. This discrepancy might be explained by the ectopic expression of the auxotrophic markers which might change the cell wall composition in the mutant and revertant. Although this phenomenon has never been directly shown, several indications are described in previous studies for the URA3 marker. For example, adherence to host cells, a factor that is dependent on the CWP composition, is affected by changing the location or by the absence of URA3 (Cheng et al., 2003; Bain et al., 2001). The increased awareness among scientists about the problem of misleading phenotypes (Lay et al, 1998; Bain et al.,2001; Sundstrom et al, 2002; Cheng et al., 2003; reviewed by Staab and Sundstrom, 2003), led to the development of a new 
gene knockout methodology (Brand et al., 2004). In this method the URA3 gene is solely used to select revertant strains, by directing the CIp10, that contains $U R A 3$ and the gene of interest, to the high-expression locus RP10. Although BWP17 has genetic differences (such as aneuploidy) compared to its parental strain SC5314 (Forche et al. 2004: Selmecki et al., 2005; Ahmad et al., 2008), this strain together with the CIp10 system is still considered as a valuable model system to knockout genes and study the respective mutants.

\subsection{Phenotypic analysis of PGA29 deletion mutants}

Deleting cell wall genes that are implicated in cell wall stability or organisation may lead to changes in cell wall composition (described above), cell morphology and increased sensitvity to cell wall stress. For instance, deletion of one single allele of PIRI results in elongated and abnormal formed cells that have a tendency to aggregate. This mutant was highly sensitive to CFW and transformants that lack both alleles could not be obtained, indicating that this cell wall protein is necessary for the viability of $C$. albicans (Martinez et al., 2004). Examples for GPI-proteins are the $C R H$ family (CRH11, CRH12 and UTR2) (Pardini et al., 2006), CHT2 (Dünkler et al., 2005) ECM33 (Martinez-Lopez et al., 2004) and SRR1 (Garcerá et al., 2003) of which the respective deletion mutants showed changes in cell morphology or increased hypersensitivity to agents that effect cell wall assembly.

The upregulation of Pga29p during growth in YPD supplemented with the cell wall perturbant CFW indicated that the protein might stabilise the cell wall upon cell wall stress. However, the Apga29/4pga29 strain did not induce compensatory mechanisms that lead to alterations of chitin or glucan levels in the cell wall, nor did it exhibit any cell wall defective phenotypes or changes in morphology . Furthermore the mutant did not show increased sensitivity to $\beta-1,3-$ glucanase, which excludes the possibility that Pga29p is needed to limit cell wall porosity in order to protect the $\beta$-1,3-glucan layer (Zlotnik et al., 1984; De Nobel et al., 1990). To determine whether Pga29p is redundant, the expression of two family members, PGA30 and $P G A 31$, was analysed under normal growth conditions and CFW stress. PGA31 seemed to be a potential candidate for taking over the function of $P G A 29$, since this homolog is the second highest upregulated gene (18.2 fold increase) in regenerating protoplasts (Castillo et al., 2006) and its deletion results in hypersensitivity to CFW and caspofungin, an antifungal drug that is inhibiting the synthesis of beta-1,3-glucan (Plaine et al., 2008). Northern analysis showed that $P G A 31$ was expressed under CFW stress and $P G A 30$ expression was undetectable under both conditions. However, we did not observe an increased $P G A 30$ or $P G A 31$ expression in our 
mutant strains, indicating these genes do not compensate for the PGA29 deletion. Moreover, Pga30p and Pga31p were not identified in our LC/MS/MS analysis of the Apga29/4pga29 cell wall proteome (see below), neither upregulation of other CWPs was detected.

Conclusively, our data show that Pga29p is not involved in maintaining the cell wall integrity in C. albicans.

\subsection{Pga29p is involved in the virulence of $C$. albicans}

C. albicans is a polymorphic fungus that is able to grow in a yeast as well as in a hyphal form. The formation of hyphae is strongly related to the virulence of the fungus, which has been shown by the reduction of virulence of mutants that are defective in hypha formation (reviewed by Kumamoto and Vinces, 2005). Co-regulation of numerous virulence factors during hyphal morphogenesis plays an important role in the establishment of a C. albicans infection. For example, Hwplp, a GPI-adhesin that has a major role in C. albicans infection (Tsuchimori et al., 2000), is expressed in germ tubes and hyphae, but not in yeast cells and pseudohyphae (Staab et al., 2003b). Although hyphal development has been shown to be crucial to cause tissue damage that leads to subsequent death (Bendel et al., 2003; Saville et al., 2003), little is known about the role of the yeast form of $C$. albicans in virulence. Indications about a significant contribution of the yeast form have been deduced experimentally by mutants that were unable to develop hyphae, that still could enter tissues via blood vessels (Bendel et al., 2003; Saville et al., 2003) and could cause death in severly immunocompromised mice (Saville et al., 2008). It has been proposed that yeast cells, because of their compact size and shape, may be adapted for free dissemination within the circulation (Gow et al., 2002).

PGA29 deletion mutants exhibited a moderate, but significant reduction in virulence in a mouse model for systemic candidosis, which suggests that Pga29p is involved in the virulence of $C$. albicans. To study more in detail the role of Pga29p in virulence, we selected the RHE model. This model is widely used (Schaller et al., 1998, 1999) to test $C$. albicans deletion mutants for their ability to establish oral candidosis. In this model, the virulence of $C$. albicans strain can be monitored microscopically and quantified accurately by measuring levels of LDH activity from damaged epithelial cells. Furthermore, RNA can be readily isolated from the RHE, thereby enabling to investigate gene transcription from the host or pathogen during infection (Schaller et al., 1998; Green et al., 2004; Schaller et al., 2002; Zhao et al., 2005; Zakikhany et al., 2007). Another advantage of using this model is that defective 
growth, such as diminished hyphae formation, can be studied with microscopy during infection.

Light microscopic pictures showed that after 12 hours of infection the Apga29/4pga29 mutants induced significantly less tissue damage than the revertant and wild type SC5314 strains. This reduction of tissue damage was accompanied by a moderate, but significant reduction of LDH activity, confirming that the Apga29/4pga29 strain is reduced in virulence. We propose that Pga29p is the first yeast-specific GPI-CWP that is directly involved in the virulence of $C$. albicans.

PGA29 transcript levels could not be detected in 24 hours infected epithelium, which is in agreement with the data of Zakikhany et al. (2007) who did not observe PGA29 expression in a genome wide transcript profiling of $C$. albicans RHE infection at different time points. During RHE infection most of the C. albicans cells germinate and produce hyphae, which coincides with a rapid downregulation of PGA29 transcript levels as we showed with Northern analysis. These data suggest that Pga29p is involved in the initial stage of infection, prior to germ tube development. In the literature mutants have been described that are not able to form hyphae while infecting RHE, for example the EEDl deletion mutant showed a superficial invasion of epithelial cells, but remained trapped intracellularly due to its inability to germinate (Zakikhany et al., 2007). We exclude such scenario for the PGA29 deletion; after several hours of infection the majority of the Apga29/4pga29 cells was able to develop normal hyphae, which is in accordance with the results from the yeast-to-hyphae transition assays. These results provide support to the hypothesis that the yeast form plays a significant role in the pathogenesis of $C$. albicans.

Another possible cause for the reduced virulence could be a change in the cell wall protein pool, which for example could alter the ability of the mutant to adhere to the epithelium. With the aid of LC/MS/MS analysis, we identified less peptides of the GPI-CWPs Als4p and Pga4p in 4 pga29/4pga29 cell walls that were extracted from stationary phase cells cultured at $25^{\circ} \mathrm{C}$, which might indicate $P G A 29$ deletion results in a downregulation of these proteins. Although ALS4 and PGA4 are transcribed in C. albicans during the RHE infection (Green et al., 2004; Eckert et al., 2007), deletion of these genes does not result in a reduced virulence in this oral model (Zhao et al., 2005; Eckert et al., 2007), which excludes a role for Als4p and Pga4p in the observed reduction in virulence. Moreover, at $37^{\circ} \mathrm{C}$, the temperature used during the RHE experiment, no significant differences were found in the CWP composition of our strains, which shows the diminished virulence of the Apga29/4pga29 strain is the result of the lack of 
Pga29p in the cell wall. We cannot exclude the possibility that the cell wall proteome of hyphal cell walls, however, since Pga29p is a yeast-specific protein this seems rather unlikely. In order to pinpoint the mechanism that is responsible for the reduced virulence, the ability of Apga29/4pga29 strain to adhere to Caco-2 epithelial cells and plastic was determined. In case of the adherence assay with Caco- 2 cells, short incubation periods (15, 30 and 45 minutes) were selected as well, in order to study the adhesion of yeast cells prior to their germ tube development. To study the adherence ability of yeast cells and hyphae to plastic, untreated and cell culture-treated polysytrene was used as a surface. These assays showed no differences in adherence between the $4 p g a 29 / 4 p g a 29$ strain and control strains, indicating that not altered adherence, but another factor is responsible for the reduced virulence.

\subsection{Pga29p is a potential PAMP}

The Pga29p amino acid sequence consists of $18 \%$ serine and threonine residues and migrates with SDS-PAGE at a higher molecular weight than its expected size. Furthermore, deletion of $P G A 29$ resulted in a reduced mannose/glucose ratio in the cell wall, which gave us a hint that Pga29p is mannosylated.

We investigated further whether the mannosylation of Pga29p could be the essential factor that determines the interaction with host cells and the virulence phenotype. In C. albicans, Pmt proteins are responsible for O-glycosylation by adding mannose to serine or threonine residues. The O-mannosylation of 7 C. albicans proteins have been studied previously by using PMT deletion mutants. These analyses showed that the cell surface proteins Als1, Pir2p, Kre9p and Hwp1p are mannosylated by the enzyme Pmt1 (Timpel et al., 1998; Prill et al., 2005; Staab et al., 2004), the ER membrane protein Sec20p by Pmt1 and Pmt4 (Weber et al., 2004) and the membrane protein Ax12p by Pmt4 (Prill et al., 2005). In S. cerevisiae, the yeast that originally was used as model for $C$. albicans, 14 proteins have been shown to be Omannosylated by different Pmt proteins. The majority of these proteins are targeted by Pmt1p and/or Pmt2p (reviewed by Lengler et al., 2008).

We studied the O-mannosylation of Pga29p by analysing CWP extracts of PMT1, PMT2, PMT4, PMT5 and PMT6 deletion mutants using immuno-blot analysis. These studies revealed that Pga29p is indeed O-mannosylated and targeted by Pmt1p. Previous studies reported that pmt1 and pmt 4 double mutants show a cell separation defect, an aggregation phenotype, a decreased hydrophobicity and an altered cell wall composition (Timpel et al., 1998; Prill et al., 2005; Kapteyn et al., 2000). Moreover, these mutants as well as the $\Delta p m t 2 / \mathrm{PMT} 2$ strain 
show an increased sensitivity against several antifungal drugs and cell wall-destabilising agents (Prill et al., 2005). These data suggest that Pmt1p, Pmt2p and Pmt4p are responsible for most of the O-glycosylation activity in C. albicans, while Pmt5p and Pmt6p play a less prominent role and may specifically target a small group of proteins (Lengler et al., 2008). Pmt1p accounts probably for most O-mannosylation of proteins that reside in the cell wall, which is supported by the fact that most cell wall proteins studied so far in C. albicans are mannosylated by Pmt1p (Timpel et al., 1998; Prill et al., 2005; Staab et al., 2004 and this study).

\subsection{Immune response against the $4 p g a 29 / \Delta p g a 29$ strain}

O-mannan is a major PAMP of C. albicans, which can induce cytokine production in immune cells upon TLR4 recognition (Tada et al., 2002; Netea et al., 2006). TLR4 activation results in the induction of two pathways that initiate transcription via the transcription factors NF-kB or IRF3, which leads to a strong stimulation of pro-inflammatory cytokines (Netea et al., 2008). TLR4 recognition is lost during the yeast to hyphae transition, which results in a TLR2 dependent anti-inflammatory response (Van der Graaf et al., 2005). This implies that TLR4 is involved in the recognition of yeast cells, the growth form in which Pga29p is abundantly present. As shown above, Pga29p is O-mannosylated by Pmt1, which designates this GPIprotein as a potential PAMP.

\subsubsection{Immune response of the RHE}

In order to protect itself against Candida infection, the RHE induces a TH1 type immune response by expressing proinflammatory cytokines such as GM-CSF and IL-8 (Schaller et al., 2002), which play a role in the recruitment of neutrophils in vivo. To examine the immune cross-talk between the epithelial cells and the Apga29/4pga29 strain, we determined the transcript and protein levels of TH1 cytokines that are usually expressed in RHE upon $C$. albicans infection (Schaller et al., 2002). Compared with the control strains, we observed a decrease of all studied cytokines in RHE that was infected with the PGA29 deletion mutant. There are two possible explanations for this reduction: (1) As a consequence of the reduced mannose level in the cell wall, the TLR4 receptors on the epithelia cells are less activated, which in turn leads to a decrease in pro-inflammatory cytokine production. (2) Another possibility is that the degree of virulence is related to the degree of cytokine expression; the Apga29/4pga29 strain causes a diminished epithelial damage, therefore a lower cytokine level 
is needed to protect the tissue. In view of the data of Schaller et al. (2002), who showed that a reduced cytokine expression in the RHE seem to correlate with the degree of virulence of different Candida species, the last explanation is very plausible. Moreover, it could be that cell wall components are not involved in inducing cytokine expression in epithelial cells, since heat-killed C. albicans failed to induce an immune response in RHE (Schaller et al., 2002). However, these C. albicans cells were heated at $90^{\circ} \mathrm{C}$ for 30 minutes, which could cause denaturation of CWPs and lead to an altered cell wall structure that fails to initiate an immune response in the epithelial cells.

The addition of PMNs to Candida-infected RHE results in an enhanced TH1 type immune response and a downregulation of the $\mathrm{TH} 2$ immune response. This is associated with a protective effect against Candida-induced tissue damage (Schaller et al., 2004). The addition of PMNs to RHE that was infected for 12 hours with the Apga29/4pga29 strain and control strains resulted in high cytokine levels of IL-8, which is known a chemoattractant and promotes degranulation and other antifungal activities of PMNs (Djeu et al., 1990; Kullberg et al., 1999). However, in this experiment the Apga29/4pga29 strain did not show great discrepancies between the cytokine expression or protein levels compared with the controls. This is might be the effect of the direct immunological crosstalk between the epithelium and PMNs (Schaller et al., 2004, Weindl et al., 2007).

\subsubsection{Immune response of immune cells}

The decreased cytokine expression in the RHE that was infected with the Apga29/4pga29 strain, urged us to investigate further the possibility of a link between PGA29 deletion and a reduction of TLR4 mediated cytokine expression. Moreover, the lack of Pga29p in the cell wall could lead to the exposure of other PAMPs, that are hidden in wild type strains and thereby stimulating the immune response. To investigate more in detail the immune response of the innate immune system against the Apga29/4pga29 strain, interaction assays were performed with two types of immune cells, DCs and PMNs. The expression of the cytokines IFN- $\beta$, TNF- $\alpha$, IL-12, IFN- and IL-10 were examined in DCs that were stimulated for 20 or 110 minutes with the Apga29/_pga29, Apga29/_pga29/PGA29 and SC5314 strain. No differences were observed in expression between the mutant and control strains, indicating Pga29p does not have influence on the immune response of DCs. At the time of writing, it has been reported that human DCs recognise N-linked mannan with the lectin receptors DC-SIGN and MR, which results in binding and internalisation of C. albicans (Cambi et al., 2008). In 
addition, interaction assays with $C$. albicans glycosylation mutants showed that only N-linked mannan stimulates the production of the pro-inflammatory IL-6 in human DCs (Cambi et al., 2008). Hence, it is likely that the lack of O-linked mannan in our mutant strain does not change the immune response of the DCs.

Upon $\beta$-glucan recognition, the PRR Dectin-1 induces the oxidative burst against fungi (Kennedy et al., 2007). To determine whether the glucan layer in cell walls of the Apga29/4pga29 strain are more exposed to the outside environment, we incubated Apga29/4pga29 mutants with human PMNs and measured the oxidative burst. No differences in this assay were observed, indicating Pga29p does not shield the $\beta$-1,3-glucan layer against Dectin-1 recognition. These data are in line with the $\beta$-1,3-glucanase sensitivity assay, in which was shown that the Apga29/4pga29 strain was equally sensitive to $\beta$-1,3-glucanase compared to the control strains. Our interaction assays suggest that the reduced virulence may not be related to an altered pathogen host cross-talk via the mannans. However we cannot fully exclude that Pga29p is recognised by other types of immune cells.

\subsection{Conclusion}

In this study the abundant GPI-CWP Pga29p of the human fungal pathogen C. albicans was characterised. Homologs of this protein are widespread among well-known virulent Candida species, but so far their functional characteristics have not been investigated. Pga29p was shown to be covalently linked in the cell wall to the $\beta$-1,3-glucan framework via $\beta$-1,6-glucan. During the yeast-to-hyphae transition this GPI-CWP is strongly downregulated, which proves that Pga29p is a yeast-specific protein. Although Pga29p was upregulated in cells that were grown in the presence of the cell wall perturbant $\mathrm{CFW}$, it is unlikely that this protein has a major role in maintaining the cell wall integrity of $C$. albicans. This was shown by the unchanged sensitivity of a $\Delta p g a 29 / \Delta p g a 29$ deletion strain against agents that induce cell wall stress, such as CFW, SDS and $\beta$-1,3-glucanase. In addition, the Apga29/4pga29 strain did not exhibit an altered thickness of the inner cell wall layer or a changed chitin concentrations, a phenomenon that is frequently observed after deletion of cell wall genes that play a role in cell wall integrity or assembly. Furthermore, Northern and LC/MS/MS analysis of the Apga29/Apga29 cell wall proteome showed that C. albicans did not compensate for PGA29 deletion by upregulating the homologs, $P G A 30$ and $P G A 31$, or other CWPs. By using two virulence models (systemic infection model and the RHE oral model), we could clearly show that the $\Delta p g a 29 / \Delta p g a 29$ strain exhibited a significant diminished virulence. The 
environmental conditions in these two virulence models stimulate filamentation of $C$.

albicans, a growth form in which Pga29p is downregulated. We have therefore reason to believe that Pga29p is involved in the initial stage of infection, prior to germ tube development from the yeast cells. To our knowledge Pga29p is the first yeast-specific CWP in C. albicans that directly plays a role in virulence. Additionally, this study supports the theory that the yeast cell of $C$. albicans is not merely a commensal growth from, but is also involved in pathogenesis. However, the role of Pga29p in virulence is not related to an altered adherence ability or a changed morphological plasticity, indicating another mechanism is responsible. For instance, Pga29p might facilitate the endocytosis of $C$. albicans yeast cells by endothelial or epithelial cells via host cell receptors that recognise particular amino acid sequences of Pga29p.

More research is needed in order to extend our insights into the exact function of Pga29p and to understand the role of the yeast form in C. albicans pathogenesis. In view of this, further characterisation of Pga29p homologs that are present in cell walls of other Candida species, might be helpful to answer the remaining questions about Pga29p and its role in virulence. 


\section{References}

Ahmad A., Kabir M.A., Kravets A., Andaluz E., Larriba G. and Rustchenko E. (2008) Chromosome instability and unusual features of some widely used strains of Candida albicans. Yeast. 25 (6): 433-48.

Alani E., Cao L. and Kleckner N. (1987) A method for gene disruption that allows repeated use of URA3 selection in the construction of multiply disrupted yeast strains. Genetics. 116 (4): 541-5.

Albrecht A., Felk A., Pichova I., Naglik J.R., Schaller M., de Groot P., Maccallum D., Odds F.C., Schäfer W., Klis F., Monod M. and Hube B. (2006) Glycosylphosphatidylinositol-anchored proteases of Candida albicans target proteins necessary for both cellular processes and host-pathogen interactions. J Biol Chem. 281 (2): 688-94.

Argimón S., Wishart J.A., Leng R., Macaskill S., Mavor A., Alexandris T., Nicholls S., Knight A.W., Enjalbert B., Walmsley R., Odds F.C., Gow N.A., Brown A.J. (2007) Developmental regulation of an adhesin gene during cellular morphogenesis in the fungal pathogen Candida albicans. Eukaryot Cell. 6 (4): 682-92.

Audrey C. (1887) Sur l'évolution du champignon du muguet. Rev. Méd. 7: 586-595.

Baba M., Baba N., Ohsumi Y., Kanaya K and Osumi M. (1989) Three-dimensional analysis of morphogenesis induced by mating pheromone alpha factor in Saccharomyces cerevisiae. J Cell Sci. 94 (Pt 2): 207-16.

Bailey D.A., Feldmann P.J., Bovey M., Gow N.A. and Brown A.J. (1996) The Candida albicans HYRl gene, which is activated in response to hyphal development, belongs to a gene family encoding yeast cell wall proteins. J Bacteriol. 178 (18): 5353-60

Bain J.M., Stubberfield C. and Gow N.A. (2001) Ura-status-dependent adhesion of Candida albicans mutants. FEMS Microbiol Lett. 204 (2): 323-8.

Bendel C.M., Hess D.J., Garni R.M., Henry-Stanley M. and Wells C.L. (2003) Comparative virulence of Candida albicans yeast and filamentous forms in orally and intravenously inoculated mice. Crit Care Med., (2): 501-7.

Beenhouwer D.O., Yoo E.M., Lai C.W., Rocha M.A. and Morrison SL. (2007) Human immunoglobulin G2 (IgG2) and IgG4, but not IgG1 or IgG3, protect mice against Cryptococcus neoformans infection Infect Immun. 75 (3): 1424-35. 
Beninati C., Oggioni M.R., Boccanera M., Spinosa M.R., Maggi T., Conti S., Magliani W., De Bernardis

F., Teti G., Cassone A., Pozzi G. and Polonelli L. (2000) Therapy of mucosal candidiasis by expression of an anti-idiotype in human commensal bacteria. Nat Biotechnol. 18 (10): 1060-4.

Bom I.J., Dielbandhoesing S.K., Harvey K.N., Oomes S.J., Klis F.M. and Brul S. (1998) A new tool for studying the molecular architecture of the fungal cell wall: one-step purification of recombinant trichoderma beta-(1-6)-glucanase expressed in Pichia pastoris. Biochim Biophys Acta. 1425 (2): 419-24.

Boorsma A., de Nobel H., ter Riet B., Bargmann B., Brul S., Hellingwerf K.J. and Klis F.M. (2004)

Characterization of the transcriptional response to cell wall stress in Saccharomyces cerevisiae. Yeast. 21 (5): 413-27.

Borg-von Zepelin M. and Wagner T. (1995) Fluorescence assay for the detection of adherent Candida yeasts to target cells in microtest plates. Mycoses. 38 (9-10): 339-47.

Brand A., MacCallum D.M., Brown A.J., Gow N.A. and Odds F.C. (2004) Ectopic expression of URA3 can influence the virulence phenotypes and proteome of Candida albicans but can be overcome by targeted reintegration of URA3 at the RPS10 locus. Eukaryot Cell. 3 (4): 900-9.

Brand A., Vacharaksa A., Bendel C., Norton J., Haynes P., Henry-Stanley M., Wells C., Ross K., Gow N.A. and Gale C.A. (2008) An internal polarity landmark is important for externally induced hyphal behaviors in Candida albicans. Eukaryot Cell. 7 (4): 712-20.

Braun B.R., Head W.S., Wang M.X. and Johnson A.D. (2000) Identification and characterization of TUP1regulated genes in Candida albicans. Genetics. 156 (1): 31-44.

Braun B.R., Kadosh D. and Johnson A.D. (2001) $N R G 1$, a repressor of filamentous growth in C.albicans, is down-regulated during filament induction. ЕMBO J. 20 (17): 4753-61

Braun BR and Johnson AD. (1997) Control of filament formation in Candida albicans by the transcriptional repressor TUP1. Science. 277 (5322): 105-9.

Bromuro C., Torosantucci A., Chiani P., Conti S., Polonelli L. and Cassone A. Interplay between protective and inhibitory antibodies dictates the outcome of experimentally disseminated Candidiasis in recipients of a Candida albicans vaccine. Infect Immun. 70 (10): 5462-70.

Buffo J., Herman M.A. and Soll D.R. (1984) A characterization of pH-regulated dimorphism in Candida albicans. Mycopathologia. 85 (1-2): 21-30. 
Cabib E., Roh D.H., Schmidt M., Crotti L.B. and Varma A. (2001) The yeast cell wall and septum as paradigms of cell growth and morphogenesis. J Biol Chem. 276 (23): 19679-82.

Cambi A., Netea M.G., Mora-Montes H.M., Gow N.A., Hato S.V., Lowman D.W., Cappellaro C., Mrsa V., and Tanner W. (1998) New potential cell wall glucanases of Saccharomyces cerevisiae and their involvement in mating. J. Bacteriol. 180: 5030-5037.

Cappelletty D. and Eiselstein-McKitrick K. (2007) The echinocandins. Pharmacotherapy. 27 (3): 369-88.

Caro L.H., Tettelin H., Vossen J.H., Ram A.F., van den Ende H. and Klis F.M. (1997) In silicio identification of glycosyl-phosphatidylinositol-anchored plasma-membrane and cell wall proteins of Saccharomyces cerevisiae. Yeast. 13 (15):1477-89.

Casadevall A., Dadachova E. and Pirofski L.A. (2004) Passive antibody therapy for infectious diseases. Nat Rev Microbiol., 2 (9): 695-703.

Casanova M., Cervera A.M., Gozalbo D. and Martínez JP. (1997) Hemin induces germ tube formation in Candida albicans. Infect Immun. 65 (10): 4360-4.

Cassone A and Torosantucci A. (2006) Opportunistic fungi and fungal infections: the challenge of a single, general antifungal vaccine. Expert Rev Vaccines. 5 (6): 859-67.

Castillo L., Calvo E., Martínez A.I., Ruiz-Herrera J., Valentín E., Lopez J.A. and Sentandreu R. (2008) A study of the Candida albicans cell wall proteome. Proteomics., 8 (18): 3871-81.

Castillo L., Martinez A.I., Garcerá A., Elorza M.V., Valentín E. and Sentandreu R. (2003) Functional analysis of the cysteine residues and the repetitive sequence of Saccharomyces cerevisiae Pir4/Cis3: the repetitive sequence is needed for binding to the cell wall beta-1,3-glucan. Yeast. 20 (11): 973-83.

Castillo L., Martínez A.I., Garcerá A., García-Martínez J., Ruiz-Herrera J., Valentín E., Sentandreu R. (2006) Genomic response programs of Candida albicans following protoplasting and regeneration. Fungal Genet Biol. 43 (2): 124-34.

Chaffin W.L., López-Ribot J.L., Casanova M., Gozalbo D. and Martínez J.P. (1998) Cell wall and secreted proteins of Candida albicans: identification, function, and expression. Microbiol Mol Biol Rev. 62 (1): 130-80

Cheng S., Nguyen M.H., Zhang Z., Jia H., Handfield M. and Clancy C.J. (2003) Evaluation of the roles of four Candida albicans genes in virulence by using gene disruption strains that express URA3 from the native locus. Infect Immun. 71 (10): 6101-3. 
Coca M.A., Damsz B., Yun D.J., Hasegawa P.M., Bressan R.A. and Narasimhan M.L. (2000)

Heterotrimeric G-proteins of a filamentous fungus regulate cell wall composition and susceptibility to a plant PR-5 protein. Plant J. 22 (1): 61-9.

Cutler J.E. (2001) N-glycosylation of yeast, with emphasis on Candida albicans. Med Mycol. 39 Suppl 1: 75 86.

Dallies N., François J. and Paquet V. (1998) A new method for quantitative determination of polysaccharides in the yeast cell wall. Application to the cell wall defective mutants of Saccharomyces cerevisiae. Yeast. 14 (14): 1297-306.

De Bernardis F., Lucciarini R., Boccanera M., Amantini C., Arancia S., Morrone S., Mosca M., Cassone A. and Santoni G. (2006) Phenotypic and functional characterization of vaginal dendritic cells in a rat model of Candida albicans vaginitis. Infect Immun. 74 (7): 4282-94.

De Groot P.W., de Boer A.D., Cunningham J., Dekker H.L., de Jong L., Hellingwerf K.J., de Koster C. and Klis FM. (2004) Proteomic analysis of Candida albicans cell walls reveals covalently bound carbohydrateactive enzymes and adhesins. Eukaryot Cell. 3 (4): 955-65

De Groot P.W., Hellingwerf K.J. and Klis F.M. (2003) Genome-wide identification of fungal GPI-proteins. Yeast. 20(9): 781-96.

De Groot P.W., Ram A.F. and Klis F.M. (2005) Features and functions of covalently linked proteins in fungal cell walls. Fungal Genet Biol. 42 (8): 657-75.

De Nobel H., Ruiz C., Martin H., Morris W., Brul S., Molina M. and Klis F.M. (2000) Cell wall perturbation in yeast results in dual phosphorylation of the Slt2/Mpk1 MAP kinase and in an Slt2-mediated increase in FKS2lacZ expression, glucanase resistance and thermotolerance. Microbiology. 146 ( Pt 9): 2121-32.

De Nobel J.G., Klis F.M., Munnik T., Priem J. and van den Ende H. (1990) An assay of relative cell wall porosity in Saccharomyces cerevisiae, Kluyveromyces lactis and Schizosaccharomyces pombe. Yeast. 6 (6): 48390.

Delgado M.L., Gil M.L. and Gozalbo D. (2003) Candida albicans TDH3 gene promotes secretion of internal invertase when expressed in Saccharomyces cerevisiae as a glyceraldehyde-3-phosphate dehydrogenaseinvertase fusion protein. Yeast. 20 (8): 713-22.

Dieterich C., Schandar M., Noll M., Johannes F.J., Brunner H., Graeve T. and Rupp S. (2002) In vitro reconstructed human epithelia reveal contributions of Candida albicans EFG1 and CPHI to adhesion and invasion. Microbiology. 148 (Pt 2): 497-506. 
Djeu J. Y., Matsushima K., Oppenheim J. J., Shiotsuki K., and Blanchard, D. K. (1990) Functional activation of human neutrophils by recombinant monocyte-derived neutrophil chemotactic factor/IL-8. $J$ Immunol, 144: 2205-2210.

Doedt T., Krishnamurthy S., Bockmühl D.P., Tebarth B., Stempel C., Russell C.L., Brown A.J. and Ernst J.F. (2004) APSES proteins regulate morphogenesis and metabolism in Candida albicans. Mol Biol Cell. 15 (7): 3167-80

Dolan J.W., Kirkman C. and Fields S. (1989) The yeast STE12 protein binds to the DNA sequence mediating pheromone induction. Proc Natl Acad Sci U S A. 86 (15): 5703-7.

Douglas L.J. (2002) Medical importance of biofilms in Candida infections. Rev Iberoam Micol. 19 (3): 139-43.

Ebanks R.O., Chisholm K., McKinnon S., Whiteway M. and Pinto D.M. (2006) Proteomic analysis of Candida albicans yeast and hyphal cell wall and associated proteins. Proteomics. 6 (7): 2147-56.

Ecker M., Deutzmann R., Lehle L., Mrsa V. and Tanner W. (2006) Pir proteins of Saccharomyces cerevisiae are attached to beta-1,3-glucan by a new protein-carbohydrate linkage. J Biol Chem. 281 (17): 11523-9.

Eckert S.E., Heinz W.J., Zakikhany K., Thewes S., Haynes K., Hube B. and Mühlschlegel F.A. (2007) PGA4, a GAS homologue from Candida albicans, is up-regulated early in infection processes. Fungal Genet. Biol., 44 (5): 368-77.

Edwards S.R., Braley R. and Chaffin W.L. (1999) Enolase is present in the cell wall of Saccharomyces cerevisiae. FEMS Microbiol Lett. 177 (2): 211-6.

Eisenhaber B., Bork P. and Eisenhaber F. (2001) Post-translational GPI lipid anchor modification of proteins in kingdoms of life: analysis of protein sequence data from complete genomes. Protein Eng. 14 (1): 17-25.

Eisenhaber B., Schneider G., Wildpaner M. and Eisenhaber F. (2004) A sensitive predictor for potential GPI lipid modification sites in fungal protein sequences and its application to genome-wide studies for Aspergillus nidulans, Candida albicans, Neurospora crassa, Saccharomyces cerevisiae and Schizosaccharomyces pombe. J Mol Biol. 337 (2): 243-53.

Enjalbert B and Whiteway M. (2005) Release from quorum-sensing molecules triggers hyphal formation during Candida albicans resumption of growth. Eukaryot Cell. 4 (7):1 203-10.

Ernst J.F. and Prill S.K. (2001) O-glycosylation. Med Mycol. 39 Suppl 1: 67-74. 
Fonzi W.A. (1999) PHRI and PHR2 of Candida albicans encode putative glycosidases required for proper cross-linking of beta-1,3- and beta-1,6-glucans. J Bacteriol. 181 (22): 7070-9.

Forche, A., Magee, B.B., Magee, P.T., and May, G. (2004) Genome-wide single-nucleotide polymorphism map for Candida albicans. Eukaryot Cell 3: 705-714

Fu Y., Ibrahim A.S., Sheppard D.C., Chen Y.C., French S.W., Cutler J.E., Filler S.G. and Edwards J.E. Jr. (2002) Candida albicans Als1p: an adhesin that is a downstream effector of the EFGl filamentation pathway. Mol Microbiol. 44 (1): 61-72.

Garcerá A., Castillo L., Martínez A.I., Elorza M.V., Valentín E. and Sentandreu R. (2005) Anchorage of Candida albicans Ssr1 to the cell wall, and transcript profiling of the null mutant. Res Microbiol. 156 (9): 91120.

Garcerá A., Martínez A.I., Castillo L., Elorza M.V., Sentandreu R. and Valentín E. (2003) Identification and study of a Candida albicans protein homologous to Saccharomyces cerevisiae Ssr1p, an internal cell-wall protein. Microbiology. 149 (Pt 8): 2137-45.

Garcerá A., Martínez A.I., Castillo L., Elorza M.V., Sentandreu R. and Valentín E. (2003) Identification and study of a Candida albicans protein homologous to Saccharomyces cerevisiae Ssr1p, an internal cell-wall protein. Microbiology. 149 (Pt 8): 2137-45.

García R., Bermejo C., Grau C., Pérez R., Rodríguez-Peña J.M., Francois J., Nombela C. and Arroyo J. (2004) The global transcriptional response to transient cell wall damage in Saccharomyces cerevisiae and its regulation by the cell integrity signaling pathway. J Biol Chem. 279 (15): 15183-95.

Gaur N.K., Klotz S.A. and Henderson R.L. (1999) Overexpression of the Candida albicans ALAl gene in Saccharomyces cerevisiae results in aggregation following attachment of yeast cells to extracellular matrix proteins, adherence properties similar to those of Candida albicans. Infect Immun. 67 (11): 6040-7.

Gaur N.K., Smith R.L. and Klotz S.A. (2002) Candida albicans and Saccharomyces cerevisiae expressing ALA1/ALS5 adhere to accessible threonine, serine, or alanine patches. Cell Commun Adhes. 9(1): 45-57.

Ghannoum M.A., Spellberg B., Saporito-Irwin S.M. and Fonzi W.A. (1995) Reduced virulence of Candida albicans PHR1 mutants. Infect Immun. 63 (11): 4528-30.

Gigliotti F., Harmsen A.G., Wright T.W. (2003) Characterization of transmission of Pneumocystis carinii f. sp. muris through immunocompetent BALB/c mice. Infect Immun. 71 (7): 3852-6. 
Gillum A.M., Tsay E.Y. and Kirsch D.R. (1984) Isolation of the Candida albicans gene for orotidine-5'phosphate decarboxylase by complementation of $S$. cerevisiae ura3 and E. coli pyrF mutations. Mol Gen Genet. 198 (1): 179-82.

Gow N.A., Robbins P.W., Lester J.W., Brown A.J., Fonzi W.A., Chapman T. and Kinsman O.S. (1994) A hyphal-specific chitin synthase gene (CHS2) is not essential for growth, dimorphism, or virulence of Candida albicans. Proc Natl Acad Sci U S A. Jun 21;91 (13): 6216-20.

Gow, N.A., Brown, A.J., and Odds, F.C. (2002) Fungal morphogenesis and host invasion. Curr Opin Microbiol 5: 366-371.

Granger B.L., Flenniken M.L., Davis D.A., Mitchell A.P. and Cutler J.E. (2005) Yeast wall protein 1 of Candida albicans. Microbiology. 151 (Pt 5): 1631-44.

\section{Green C.B., Cheng G., Chandra J., Mukherjee P., Ghannoum M.A. and Hoyer LL. (2004) RT-PCR} detection of Candida albicans $A L S$ gene expression in the reconstituted human epithelium (RHE) model of oral candidiasis and in model biofilms. Microbiology. 150 (Pt 2): 267-75.

Green C.B., Marretta S.M., Cheng G., Faddoul F.F., Ehrhart E.J. and Hoyer L.L. (2006) RT-PCR analysis of Candida albicans $A L S$ gene expression in a hyposalivatory rat model of oral candidiasis and in HIV-positive human patients. Med Mycol., 44 (20): 103-11.

Green C.B., Zhao X., Yeater K.M. and Hoyer L.L. (2005) Construction and real-time RT-PCR validation of Candida albicans PALS-GFP reporter strains and their use in flow cytometry analysis of $A L S$ gene expression in budding and filamenting cells. Microbiology. 151: 1051-60.

\section{Hagen I., Ecker M., Lagorce A., Francois J.M., Sestak S., Rachel R., Grossmann G., Hauser N.C.,} Hoheisel J.D., Tanner W. and Strahl S. (2004) Sed1p and Srl1p are required to compensate for cell wall instability in Saccharomyces cerevisiae mutants defective in multiple GPI-anchored mannoproteins. Mol Microbiol. 52 (5): 1413-25.

Halliwell B. and Gutteridge J.M. (1990) Role of free radicals and catalytic metal ions in human disease: an overview. Methods Enzymol. 186: 1-85

Hamada K., Terashima H., Arisawa M., Yabuki N. and Kitada K. (1999) Amino acid residues in the omegaminus region participate in cellular localization of yeast glycosylphosphatidylinositol-attached proteins. $J$ Bacteriol. 181 (13): 3886-9.

Harcus D., Nantel A., Marcil A., Rigby T. and Whiteway M. (2004) Transcription profiling of cyclic AMP signaling in Candida albicans. Mol Biol Cell. 15 (10): 4490-9. 
Hazen E.L. and Brown R. Two antifungal agents produced by a soil actinomycete. Science. 112 (2911): 423.

Hazen K. C. (1995). New and emerging yeast pathogens. Clin. Microbiol. Rev. 8: 462-478

Hogan D.A., Vik A. and Kolter R. (2004) A Pseudomonas aeruginosa quorum-sensing molecule influences Candida albicans morphology. Mol Microbiol. 54 (5): 1212-23.

Hornby J.M., Jensen E.C., Lisec A.D., Tasto J.J., Jahnke B., Shoemaker R., Dussault P. and Nickerson K.W. (2001) Quorum sensing in the dimorphic fungus Candida albicans is mediated by farnesol. Appl Environ Microbiol., 67 (7):2982-92.

Hoyer L.L. (2001) The ALS gene family of Candida albicans. Trends Microbiol. 9 (4): 176-80.

Hoyer L.L., Payne T.L., Bell M., Myers A.M. and Scherer S. (1998) Candida albicans ALS3 and insights into the nature of the ALS gene family. Curr Genet. 33 (6): 451-9.

Hoyer L.L., Scherer S., Shatzman A.R. and Livi G.P. (1995) Candida albicans ALS1: domains related to a Saccharomyces cerevisiae sexual agglutinin separated by a repeating motif. Mol Microbiol. 15 (1): 39-54.

Huang H., Harcus D. and Whiteway M. (2008) Transcript profiling of a MAP kinase pathway in C. albicans. Microbiol Res. 163 (4): 380-93.

Hubbard M.J., Markie D. and Poulter R.T. (1986) Isolation and morphological characterization of a mycelial mutant of Candida albicans. J Bacteriol. 165 (1): 61-65.

Hull C.M., Raisner R.M. and Johnson A.D. (2000) Evidence for mating of the "asexual" yeast Candida albicans in a mammalian host. Science., 289 (5477): 307-10.

Inaba K., Inaba M., Romani N., Aya H., Deguchi M., Ikehara S., Muramatsu S and Steinman R.M. (1992) Generation of large numbers of dendritic cells from mouse bone marrow cultures supplemented with granulocyte/macrophage colony-stimulating factor. J Exp Med. 176 (6): 1693-702.

Insenser M., Nombela C., Molero G. and Gil C. (2006) Proteomic analysis of detergent-resistant membranes from Candida albicans. Proteomics. 6 Suppl 1: S 74-81.

Iralu, V. (1971) Formation of aerial hyphae in Candida albicans. Appl Microbiol. 22 (3): 482-488. 
Jones T., Federspiel N.A., Chibana H., Dungan J., Kalman S., Magee B.B., Newport G., Thorstenson Y.R., Agabian N., Magee P.T., Davis R.W. and Scherer S. (2004) The diploid genome sequence of Candida albicans. Proc Natl Acad Sci U S A. 101 (19): 7329-34.

Jung U.S. and Levin D.E. (1999) Genome-wide analysis of gene expression regulated by the yeast cell wall integrity signalling pathway. Mol Microbiol. 34 (5): 1049-57.

Kadosh D and Johnson AD. (2001) Rfg1, a protein related to the Saccharomyces cerevisiae hypoxic regulator Rox1, controls filamentous growth and virulence in Candida albicans. Mol Cell Biol. 21 (7): 2496-505.

Kapteyn J.C., Hoyer L.L., Hecht J.E., Müller W.H., Andel A., Verkleij A.J., Makarow M., Van Den Ende H. and Klis F.M. (2000) The cell wall architecture of Candida albicans wild-type cells and cell wall-defective mutants. Mol Microbiol. 35 (3): 601-11

Kapteyn J.C., Montijn R.C., Dijkgraaf G.J., Van den Ende H., Klis F.M. (1995) Covalent association of beta-1,3-glucan with beta-1,6-glucosylated mannoproteins in cell walls of Candida albicans. J Bacteriol., 177 (13): 3788-92.

Kapteyn J.C., Ram A.F., Groos E.M., Kollar R., Montijn R.C., Van Den Ende H., Llobell A., Cabib E. and Klis F.M. (1997) Altered extent of cross-linking of beta1,6-glucosylated mannoproteins to chitin in Saccharomyces cerevisiae mutants with reduced cell wall beta1,3-glucan content. J Bacteriol. 179 (20): 6279-84.

Kapteyn J.C., ter Riet B., Vink E., Blad S., De Nobel H., Van Den Ende H. and Klis F.M. (2001) Low external pH induces HOG1-dependent changes in the organization of the Saccharomyces cerevisiae cell wall. Mol Microbiol., 39 (2):469-79.

Kelly S.L., Lamb D.C., Baldwin B.C., Corran A.J. and Kelly D.E. (1997) Characterization of Saccharomyces cerevisiae CYP61, sterol delta22-desaturase, and inhibition by azole antifungal agents. J Biol Chem. 272 (15): 9986-8.

Kennedy A.D., Willment J.A., Dorward D.W., Williams D.L., Brown G.D. and DeLeo F.R. (2007) Dectin-1 promotes fungicidal activity of human neutrophils. Eur J Immunol. 37 (2): 467-78.

Khalaf RA and Zitomer RS. (2001) The DNA binding protein Rfg1 is a repressor of filamentation in Candida albicans. Genetics. 157 (4): 1503-12.

Klis F.M., Boorsma A. and De Groot P.W. (2006) Cell wall construction in Saccharomyces cerevisiae. Yeast. 23 (3): 185-202 
Klis F.M., de Groot P. and Hellingwerf K. (2001) Molecular organization of the cell wall of Candida albicans. Med Mycol. 39 Suppl 1: 1-8.

Klis F.M., Mol P., Hellingwerf K. and Brul S. (2002) Dynamics of cell wall structure in Saccharomyces cerevisiae. FEMS Microbiol Rev. 26 (3): 239-56.

Klotz S.A., Gaur N.K., Lake D.F., Chan V., Rauceo J. and Lipke P.N. (2004) Degenerate peptide recognition by Candida albicans adhesins Als5p and Als1p. Infect Immun. 72 (4): 2029-34

Kopecká M., Phaff H.J. and Fleet G.H. (1974) Demonstration of a fibrillar component in the cell wall of the yeast Saccharomyces cerevisiae and its chemical nature. J Cell Biol. 62 (1): 66-76.

Kullberg B. J., Netea M. G., Vonk A. G. and Van der Meer J. W. (1999) Modulation of neutrophil function in host defense against disseminated Candida albicans infection in mice. FEMS Immunol Med Microbiol 26: 299-307.

Kullberg B.J., Torensma R., Williams D.L. and Figdor CG. (2008) Dendritic cell interaction with Candida albicans critically depends on N-linked mannan. J Biol Chem. 283 (29): 20590-9.

Kumamoto C.A. and Vinces M.D. (2005) Contributions of hyphae and hypha-co-regulated genes to Candida albicans virulence. Cell Microbiol. 7 (11): 1546-54.

Laboratory Press: Cold Spring Harbor, NY: 229-362.

Lagorce A., Hauser N.C., Labourdette D., Rodriguez C., Martin-Yken H., Arroyo J., Hoheisel J.D. and François J. (2003) Genome-wide analysis of the response to cell wall mutations in the yeast Saccharomyces cerevisiae. J Biol Chem. 278 (22): 20345-57.

Lan C.Y., Rodarte G., Murillo L.A., Jones T., Davis R.W., Dungan J., Newport G., Agabian N. (2004) Regulatory networks affected by iron availability in Candida albicans. Mol Microbiol. 53 (5): 1451-69.

Lane S., Birse C., Zhou S., Matson R. and Liu H. (2001) DNA array studies demonstrate convergent regulation of virulence factors by Cph1, Cph2, and Efg1 in Candida albicans. J Biol Chem. 276 (52): $48988-96$.

Lay J., Henry L.K., Clifford J., Koltin Y., Bulawa C.E. and Becker JM. (1998) Altered expression of selectable marker URA3 in gene-disrupted Candida albicans strains complicates interpretation of virulence studies. Infect Immun. 66 (11): 5301-6

Leng P., Lee P.R., Wu H. and Brown A.J. Efg1, a morphogenetic regulator in Candida albicans, is a sequencespecific DNA binding protein. J Bacteriol. 183 (13): 4090-3. 
Lengeler K.B., Tielker D. and Ernst J.F. (2008) Protein-O-mannosyltransferases in virulence and development. Cell Mol Life Sci. 65 (4): 528-44.

Lesage G. and Bussey H. (2006) Cell wall assembly in Saccharomyces cerevisiae. Microbiol Mol Biol Rev. 70 (2): $317-43$

Lipke P.N. and Ovalle R. (1998) Cell wall architecture in yeast: new structure and new challenges. J Bacteriol 180: $3735-3740$.

Liu H. (2001) Transcriptional control of dimorphism in Candida albicans. Curr Opin Microbiol. 4 (6): 728-35.

Liu H., Köhler J., Fink G.R. (1994) Suppression of hyphal formation in Candida albicans by mutation of a STE12 homolog. Science. 266 (5191):1723-6.

Lo H.J., Köhler J.R., DiDomenico B., Loebenberg D., Cacciapuoti A. and Fink G.R. (1997) Nonfilamentous C. albicans mutants are avirulent. Cell. 90 (5): 939-49.

Marichal P., Gorrens J. and Vanden Bossche H. (1985) The action of itraconazole and ketoconazole on growth and sterol synthesis in Aspergillus fumigatus and Aspergillus niger. Sabouraudia. 23 (1): 13-21.

Martchenko M., Alarco A.M., Harcus D. and Whiteway M. (2004) Superoxide dismutases in Candida albicans: transcriptional regulation and functional characterization of the hyphal-induced SOD5 gene. Mol Biol Cell. 15 (2): 456-67.

Martínez A.I., Castillo L., Garcerá A., Elorza M.V., Valentín E. and Sentandreu R. (2004) Role of Pir1 in the construction of the Candida albicans cell wall. Microbiology. 150 (Pt 10): 3151-61.

Martinez-Lopez R., Monteoliva L., Diez-Orejas R., Nombela C. and Gil C. (2004) The GPI-anchored protein CaEcm33p is required for cell wall integrity, morphogenesis and virulence in Candida albicans. Microbiology. 150 (Pt 10): 3341-54.

Martinez-Lopez R., Park H., Myers C.L., Gil C. and Filler S.G. (2006) Candida albicans Ecm33p is important for normal cell wall architecture and interactions with host cells. Eukaryot Cell. 5 (1): 140-7.

Masuoka J. (2004) Surface glycans of Candida albicans and other pathogenic fungi: physiological roles, clinical uses, and experimental challenges. Clin Microbiol Rev. 17 (2): 281-310.

Matthews R.C., Rigg G., Hodgetts S., Carter T., Chapman C., Gregory C., Illidge C., Burnie J. (2003) Preclinical assessment of the efficacy of mycograb, a human recombinant antibody against fungal HSP90. Antimicrob Agents Chemother. 47 (7): 2208-16 
McAlester G., O'Gara F. and Morrissey J.P. (2008) Signal-mediated interactions between Pseudomonas aeruginosa and Candida albicans. J Med Microbiol. 57 (Pt 5): 563-9.

Mencacci A., Torosantucci A., Spaccapelo R., Romani L., Bistoni F. and Cassone A. (1994) A mannoprotein constituent of Candida albicans that elicits different levels of delayed-type hypersensitivity, cytokine production, and anticandidal protection in mice. Infect Immun. 62 (12): 5353-60

Morschhäuser J., Michel S. and Staib P. (1999) Sequential gene disruption in Candida albicans by FLPmediated site-specific recombination. Mol Microbiol. 32 (3): 547-56.

Morschhäuser J., Staib P. and Köhler G. (2005) Targeted gene deletion in Candida albicans wild-type strains by MPAR flipping. Methods Mol Med. 118: 35-44.

Motshwene P., Brandt W. and Lindsey G. (2003) Significant quantities of the glycolytic enzyme phosphoglycerate mutase are present in the cell wall of yeast Saccharomyces cerevisiae. Biochem J. 369 (Pt 2): 357-62.

Moye-Rowley W.S. (2003) Regulation of the transcriptional response to oxidative stress in fungi: similarities and differences. Eukaryot Cell. 2 (3): 381-9.

Mrsa V. and Tanner W. (1999) Role of NaOH-extractable cell wall proteins Ccw5p, Ccw6p, Ccw7p and Ccw8p (members of the Pir protein family) in stability of the Saccharomyces cerevisiae cell wall. Yeast. 15 (10A): 813-20.

Mrsa V., Ecker M., Strahl-Bolsinger S., Nimtz M., Lehle L. and Tanner W. (1999) Deletion of new covalently linked cell wall glycoproteins alters the electrophoretic mobility of phosphorylated wall components of Saccharomyces cerevisiae. J Bacteriol. 181 (10): 3076-86.

Mrsă V., Seidl T., Gentzsch M. and Tanner W. (1997) Specific labelling of cell wall proteins by biotinylation. Identification of four covalently linked O-mannosylated proteins of Saccharomyces cerevisiae. Yeast. 13 (12): 1145-54.

Mühlschlegel F.A. and Fonzi W.A. (1997) PHR2 of Candida albicans encodes a functional homolog of the pH-regulated gene PHRl with an inverted pattern of pH-dependent expression. Mol Cell Biol. 17 (10): 5960-7

Murad A.M., Leng P., Straffon M., Wishart J., Macaskill S., MacCallum D., Schnell N., Talibi D., Marechal D., Tekaia F., d'Enfert C., Gaillardin C., Odds F.C. and Brown A.J.. (2001) NRG1 represses yeast-hypha morphogenesis and hypha-specific gene expression in Candida albicans. EMBO J. 20 (17): $4742-52$. 
Naglik J.R., Challacombe S.J. and Hube B. (2003) Candida albicans secreted aspartyl proteinases in virulence and pathogenesis. Microbiol Mol Biol Rev. 67 (3): 400-28

Nantel A., Dignard D., Bachewich C., Harcus D., Marcil A., Bouin A.P., Sensen C.W., Hogues H., van het

Hoog M., Gordon P., Rigby T., Benoit F., Tessier D.C. and Thomas D.Y. and Whiteway M. (2002)

Transcription profiling of Candida albicans cells undergoing the yeast-to-hyphal transition. Mol Biol Cell.13

(10): 3452-65.

Netea M.G., Brown G.D., Kullberg B.J. and Gow NA. (2008) An integrated model of the recognition of Candida albicans by the innate immune system. Nat Rev Microbiol. 6 (1): 67-78.

Netea M.G., Gow N.A., Munro C.A., Bates S., Collins C., Ferwerda G., Hobson R.P., Bertram G., Hughes H.B., Jansen T., Jacobs L., Buurman E.T., Gijzen K., Williams D.L., Torensma R., McKinnon A., MacCallum D.M., Odds F.C., Van der Meer J.W., Brown A.J. and Kullberg B.J. (2006) Immune sensing of Candida albicans requires cooperative recognition of mannans and glucans by lectin and Toll-like receptors. $J$ Clin Invest. 116 (6): 1642-50.

Nobile C.J. and Mitchell A.P. (2005) Regulation of cell-surface genes and biofilm formation by the C. albicans transcription factor Bcr1p. Curr Biol. 15 (12): 1150-5.

Nobile C.J., Andes D.R., Nett J.E., Smith F.J., Yue F., Phan Q.T., Edwards J.E., Filler S.G. and Mitchell A.P. (2006) Critical role of Bcr1-dependent adhesins in C. albicans biofilm formation in vitro and in vivo. PLoS Pathog. 2 (7)

Nobile C.J., Bruno V.M., Richard M.L., Davis D.A. and Mitchell AP. (2003) Genetic control of chlamydospore formation in Candida albicans. Microbiology. 149 (Pt 12): 629-37

Nucci M. and Marr K.A. (2005) Emerging fungal diseases. Clin Infect Dis. 41 (4): 521-6.

Odds F.C., Brown A.J. and Gow N.A. (2003) Antifungal agents: mechanisms of action. Trends Microbiol. 11 (6): $272-9$.

Odds, F.C. (1988) Candida and Candidosis. A review and bibliography. Baillière Tindall, 24-28 Oval Road, London, NW1 7DX, England.

Orlean P. (1997) Biogenesis of yeast wall and surface components. In: Cell Cycle and Cell Biology, vol 3, Pringle JR, Broach JR, Jones EW (eds). Cold Spring Harbor

Osumi M. (1998) The ultrastructure of yeast: cell wall structure and formation. Micron. 29 (2-3): 207-33. 
Pappas P.G., Rex J.H., Sobel J.D., Filler S.G., Dismukes W.E., Walsh T.J., and Edwards J.E. for the Infectious Diseases Society of America. (2004) Guidelines for treatment of candidiasis. Clin. Infect. Dis. 38:161-189.

Pardini G., De Groot P.W., Coste A.T., Karababa M., Klis F.M., de Koster C.G. and Sanglard D. (2006) The $C R H$ family coding for cell wall glycosylphosphatidylinositol proteins with a predicted transglycosidase domain affects cell wall organization and virulence of Candida albicans. J Biol Chem. 281 (52): 40399-411.

Pfaller M.A. and Diekema D.J. (2004) Rare and emerging opportunistic fungal pathogens: concern for resistance beyond Candida albicans and Aspergillus fumigatus. J Clin Microbiol. 42 (10): 4419-31

Pfaller M.A. and Diekema D.J. (2007) Epidemiology of invasive candidiasis: a persistent public health problem. Clin Microbiol Rev. 20 (1): 133-63.

Pfaller, M.A. (1998) The epidemiology of invasive mycoses—narrowing the gap. Clin. Infect. Dis. 27: 11481150 .

Phan Q.T., Myers C.L., Fu Y., Sheppard D.C., Yeaman M.R., Welch W.H., Ibrahim A.S., Edwards J.E. Jr and Filler S.G. (2007) Als3 is a Candida albicans invasin that binds to cadherins and induces endocytosis by host cells. PLoS Biol. 5 (3): e64

Plaine A., Walker L., Da Costa G., Mora-Montes H.M., McKinnon A., Gow N.A., Gaillardin C., Munro C.A. and Richard M.L. (2008) Functional analysis of Candida albicans GPI-anchored proteins: roles in cell wall integrity and caspofungin sensitivity. Fungal Genet Biol., 45 (10): 1404-14.

Prill S.K., Klinkert B., Timpel C., Gale C.A., Schröppel K. and Ernst JF. (2005) PMT family of Candida albicans: five protein mannosyltransferase isoforms affect growth, morphogenesis and antifungal resistance. Mol Microbiol. 55 (2): 546-60.

Rauceo J.M., De Armond R., Otoo H., Kahn P.C., Klotz S.A., Gaur N.K. and Lipke P.N. (2006) Threoninerich repeats increase fibronectin binding in the Candida albicans adhesin Als5p. Eukaryot Cell. 5 (10): $1664-73$.

Rentz, A.M., Halpern M.T., and Bowden R. (1998) The impact of candidemia on length of hospital stay, outcome, and overall cost of illness. Clin. Infect. Dis. 27: 781-788.

Reuss O., Vik A., Kolter R. and Morschhäuser J. (2004) The SATl flipper, an optimized tool for gene disruption in Candida albicans. Gene. 341: 119-27.

Rex J.H. and Pfaller M.A. (2002) Has antifungal susceptibility testing come of age? Clin Infect Dis. 35 (8): 982-9. 
Richard M.L. and Plaine A. (2007) Comprehensive analysis of glycosylphosphatidylinositol-anchored proteins in Candida albicans. Eukaryot Cell. 6 (2): 119-33.

Rikkerink E.H., Magee B.B. and Magee P.T. (1988) Opaque-white phenotype transition: a programmed morphological transition in Candida albicans. J Bacteriol. 170 (2): 895-9.

Rouabhia M., Schaller M., Corbucci C., Vecchiarelli A., Prill S.K., Giasson L. and Ernst J.F. (2005) Virulence of the fungal pathogen Candida albicans requires the five isoforms of protein mannosyltransferases. Infect Immun. 73 (8): 4571-80.

Rowbottom L., Munro C.A. and Gow N.A. (2004) Candida albicans mutants in the BNI4 gene have reduced cell-wall chitin and alterations in morphogenesis. Microbiology. 150 (Pt 10): 3243-52.

Ruiz-Herrera J., Martínez A.I. and Sentandreu R. (2002) Determination of the stability of protein pools from the cell wall of fungi. Res Microbiol. 153 (6): 373-8.

Rupniak H.T., Rowlatt C., Lane E.B., Steele J.G., Trejdosiewicz L.K., Laskiewicz B., Povey S. and Hill B.T. (1985) Characteristics of four new human cell lines derived from squamous cell carcinomas of the head and neck. J Natl Cancer Inst. 75 (4): 621-35.

Rustchenko E.P., Howard D.H. and Sherman F. (1994) Chromosomal alterations of Candida albicans are associated with the gain and loss of assimilating functions. J Bacteriol. 176 (11): 3231-41.

Santos M.A., Keith G. and Tuite M.F. (1993) Non-standard translational events in Candida albicans mediated by an unusual seryl-tRNA with a 5'-CAG-3' (leucine) anticodon. EMBO J. 12 (2): 607-16.

Santos R., Buisson N., Knight S., Dancis A., Camadro J.M. and Lesuisse E. (2003) Haemin uptake and use as an iron source by Candida albicans: role of CaHMX1-encoded haem oxygenase Microbiology. 149 (Pt 3): $579-88$.

Saporito-Irwin S.M., Birse C.E., Sypherd P.S. and Fonzi W.A. (1995) PHRl, a pH-regulated gene of Candida albicans, is required for morphogenesis. Mol Cell Biol. 15 (2): 601-13.

Saville S.P., Lazzell A.L., Monteagudo C. and Lopez-Ribot J.L. (2003) Engineered control of cell morphology in vivo reveals distinct roles for yeast and filamentous forms of Candida albicans during infection. Eukaryot Cell., 2 (5): 1053-60.

Saville S.P., Lazzell A.L., Chaturvedi A.K., Monteagudo C. and Lopez-Ribot J.L. (2008) Use of a genetically engineered strain to evaluate the pathogenic potential of yeast cell and filamentous forms during Candida albicans systemic infection in immunodeficient mice. Infect Immun., 76 (1): 97-102. 
Schaller M., Boeld U., Oberbauer S., Hamm G., Hube B. and Korting H.C. (2004) Polymorphonuclear leukocytes (PMNs) induce protective Th1-type cytokine epithelial responses in an in vitro model of oral candidosis. Microbiology. 150 (Pt 9): 2807-13.

Schaller M., Korting H.C., Schäfer W., Bastert J., Chen W. and Hube B. (1999) Secreted aspartic proteinase (Sap) activity contributes to tissue damage in a model of human oral candidosis. Mol Microbiol. 34 (1): 169-80.

Schaller M., Mailhammer R., Grassl G., Sander C.A., Hube B. and Korting H.C. (2002) Infection of human oral epithelia with Candida species induces cytokine expression correlated to the degree of virulence. $J$ Invest Dermatol. 118 (4): 652-7.

Schaller M., Schäfer W., Korting H.C. and Hube B. (1998) Differential expression of secreted aspartyl proteinases in a model of human oral candidosis and in patient samples from the oral cavity. Mol Microbiol. 29 (2): 605-15.

Segal B.H., Kwon-Chung J., Walsh T.J., Klein B.S., Battiwalla M., Almyroudis N.G., Holland S.M., Romani L. (2006) Immunotherapy for fungal infections. Clin Infect Dis. 42 (4): 507-15.

Selmecki A., Bergmann S. and Berman J. (2005) Comparative genome hybridization reveals widespread aneuploidy in Candida albicans laboratory strains. Mol Microbiol. 55 (5): 1553-65.

Selvakumar D., Miyamoto M., Furuichi Y. and Komiyama T. (2006) Inhibition of fungal beta-1,3-glucan synthase and cell growth by HM-1 killer toxin single-chain anti-idiotypic antibodies. Antimicrob Agents Chemother. 50 (9): 3090-7.

Sharkey L.L., McNemar M.D., Saporito-Irwin S.M., Sypherd P.S. and Fonzi W.A. (1999) HWPl functions in the morphological development of Candida albicans downstream of EFG1, TUP1, and RBF1. J Bacteriol. 181 (17): 5273-9.

Sharom F.J. and Lehto M.T. (2002) Glycosylphosphatidylinositol-anchored proteins: structure, function, and cleavage by phosphatidylinositol-specific phospholipase C. Biochem Cell Biol. 80 (5): 535-49.

Sheppard D.C., Yeaman M.R., Welch W.H., Phan Q.T., Fu Y., Ibrahim A.S., Filler S.G., Zhang M., Waring A.J. and Edwards J.E. Jr. (2004) Functional and structural diversity in the Als protein family of Candida albicans. J Biol Chem. 279 (29): 30480-9.

Siafakas A.R., Wright L.C., Sorrell T.C. and Djordjevic J.T. (2006) Lipid rafts in Cryptococcus neoformans concentrate the virulence determinants phospholipase $\mathrm{B} 1$ and $\mathrm{Cu} / \mathrm{Zn}$ superoxide dismutase. Eukaryot Cell. 5 (3): 488-98. 
Slutsky B., Buffo J. and Soll D.R. (1985) High-frequency switching of colony morphology in Candida albicans. Science. 230 (4726): 666-9.

Slutsky B., Staebell M., Anderson J., Risen L., Pfaller M. and Soll D.R. (1987) "White-opaque transition": a second high-frequency switching system in Candida albicans. J Bacteriol. 169 (1): 189-97.

Sohn K., Urban C., Brunner H. and Rupp S. (2003) EFG1 is a major regulator of cell wall dynamics in Candida albicans as revealed by DNA microarrays. Mol Microbiol. 47 (1): 89-102.

Soll D.R. (1997) Gene regulation during high-frequency switching in Candida albicans. Microbiology. 143 (Pt 2): $279-88$.

Soll D.R., Morrow B. and Srikantha T (1993) High-frequency phenotypic switching in Candida albicans. Trends Genet. 9 (2): 61-5.

Spellberg, B.J., Filler S.G., and. Edwards J.E. (2006) Current treatment strategies for disseminated candidiasis. Clin. Infect. Dis. 42: 244-251.

Spreghini E., Davis D.A., Subaran R., Kim M. and Mitchell A.P. (2003) Roles of Candida albicans Dfg5p and Dcw1p cell surface proteins in growth and hypha formation. Eukaryot Cell. 2 (4): 746-55.

Staab J.F., Bradway S.D., Fidel P.L. and Sundstrom P. (1999) Adhesive and mammalian transglutaminase substrate properties of Candida albicans Hwp1. Science. 283 (5407): 1535-8

Staab JF and Sundstrom P. (2003) URA3 as a selectable marker for disruption and virulence assessment of Candida albicans genes. Trends Microbiol. 11 (2): 69-73.

Staab J.F., Bahn Y.S. and Sundstrom P. (2003b) Integrative, multifunctional plasmids for hypha-specific or constitutive expression of green fluorescent protein in Candida albicans. Microbiology., 149(Pt 10): $2977-86$.

Staib P. and Morschhäuser J. (2007) Chlamydospore formation in Candida albicans and Candida dubliniensis--an enigmatic developmental programme. Mycoses. 50 (1): 1-12.

Stoldt V.R., Sonneborn A., Leuker C.E. and Ernst J.F. (1997) Efg1p, an essential regulator of morphogenesis of the human pathogen Candida albicans, is a member of a conserved class of bHLH proteins regulating morphogenetic processes in fungi. EMBO J. 16 (8): 1982-91

Sudbery P., Gow N. and Berman J. (2004) The distinct morphogenic states of Candida albicans. Trends Microbiol. 12 (7): 317-324. 
Sundstrom P. (2002) Adhesion in Candida spp. Cell Microbiol. 4 (8): 461-9.

Sundstrom P., Cutler J.E. and Staab J.F. (2002) Reevaluation of the role of HWPl in systemic candidiasis by use of Candida albicans strains with selectable marker URA3 targeted to the ENO1 locus. Infect Immun. 70 (6): 3281-3

Sutak R., Lesuisse E., Tachezy J. and Richardson D.R. (2008) Crusade for iron: iron uptake in unicellular eukaryotes and its significance for virulence. Trends Microbiol. 16 (6): 261-8.

Tada H., Nemoto E., Shimauchi H., Watanabe T., Mikami T., Matsumoto T., Ohno N., Tamura H., Shibata K., Akashi S., Miyake K., Sugawara S. and Takada H. (2002) Saccharomyces cerevisiae- and Candida albicans-derived mannan induced production of tumor necrosis factor alpha by human monocytes in a CD14- and Toll-like receptor 4-dependent manner. Microbiol Immunol. 46 (7): 503-12.

Timpel C., Strahl-Bolsinger S., Ziegelbauer K. and Ernst J.F. (1998) Multiple functions of Pmt1p-mediated protein O-mannosylation in the fungal pathogen Candida albicans.

Tokunaga M., Kusamichi M. and Koike H. (1986) Ultrastructure of outermost layer of cell wall in Candida albicans observed by rapid-freezing technique. J Electron Microsc (Tokyo). 35 (3): 237-46.

Tokunaga M., Niimi M., Kusamichi M. and Koike H. (1990) Initial attachment of Candida albicans cells to buccal epithelial cells. Demonstration of ultrastructure with the rapid-freezing technique. Mycopathologia. 111 (1): 61-8.

Torosantucci A., Bromuro C., Chiani P., De Bernardis F., Berti F., Galli C., Norelli F., Bellucci C., Polonelli L., Costantino P., Rappuoli R. and Cassone A. (2005) A novel glyco-conjugate vaccine against fungal pathogens. J Exp Med. 202 (5): 597-606

Tronchin, G., Bouchara, J. F., Robert, R. and Senet, J. M. (1988) Adherence of Candida albicans germ tube to plastic: ultrastructural and molecular studies of fibrillar adhesins. Infect Immun., 56: 1987-1993.

Tsuchimori N., Sharkey L.L., Fonzi W.A., French S.W., Edwards J.E. Jr. and Filler S.G. (2000) Reduced virulence of HWP1-deficient mutants of Candida albicans and their interactions with host cells. Infect Immun., 68 (4): 1997-2002.

Turchini A., Ferrario L. and Popolo L. (2000) Increase of external osmolarity reduces morphogenetic defects and accumulation of chitin in a gas1 mutant of Saccharomyces cerevisiae. J Bacteriol. 182 (4): 1167-71. 
Udenfriend S. and Kodukula K. (1995) How glycosylphosphatidylinositol-anchored membrane proteins are made. Annu Rev Biochem. 64: 563-91.

Urban C., Sohn K., Lottspeich F., Brunner H. and Rupp S. (2003) Identification of cell surface determinants in Candida albicans reveals Tsa1p, a protein differentially localized in the cell. FEBS Lett. 544 (1-3): 228-35.

Van der Graaf C.A., Netea M.G., Verschueren I., van der Meer J.W. and Kullberg B.J. (2005) Differential cytokine production and Toll-like receptor signaling pathways by Candida albicans blastoconidia and hyphae. Infect Immun. 73 (11): 7458-64.

Vanden Bossche H., Koymans L. and Moereels H. (1995) P450 inhibitors of use in medical treatment: focus on mechanisms of action. Pharmacol Ther. 67 (1): 79-100.

Vanden Bossche H., Marichal P., Gorrens J., Geerts H., Janssen P.A. (1988) Mode of action studies. Basis for the search of new antifungal drugs. Ann N Y Acad Sci. 544: 191-207.

Verstrepen K.J., Jansen A., Lewitter F. and Fink G.R. (2005) Intragenic tandem repeats generate functional variability. Nat Genet. 37 (9): 986-90.

Verstrepen K.J., Reynolds T.B. and Fink G.R. (2004) Origins of variation in the fungal cell surface. Nat Rev Microbiol. 2 (7): 533-40.

Vossen J.H., Müller W.H., Lipke P.N. and Klis F.M. (1997) Restrictive glycosylphosphatidylinositol anchor synthesis in cwh6/gpi3 yeast cells causes aberrant biogenesis of cell wall proteins. J Bacteriol. 179 (7): 2202-9

Walsh T.J., Groll A., Hiemenz J., Fleming R., Roilides E. and Anaissie E. (2004) Infections due to emerging and uncommon medically important fungal pathogens. Clin Microbiol Infect. 10 Suppl 1: 48-66.

Walther A. and Wendland J. (2003) An improved transformation protocol for the human fungal pathogen Candida albicans. Curr Genet. 42 (6): 339-43.

Weber Y., Prill S.K. and Ernst J.F. (2004) Pmt-mediated O mannosylation stabilizes an essential component of the secretory apparatus, Sec20p, in Candida albicans. Eukaryot Cell. 3 (5): 1164-8

Webster C.E. and Odds F.C. (1987) Growth of pathogenic Candida isolates anaerobically and under elevated concentrations of CO2 in air. J Med Vet Mycol. 25 (1): 47-53.

Weindl G., Naglik J.R., Kaesler S., Biedermann T., Hube B., Korting H.C. and Schaller M. (2007) Human epithelial cells establish direct antifungal defense through TLR4-mediated signaling. J Clin Invest., 117 (12): 3664-72. 
Weissman Z. and Kornitzer D. (2004) A family of Candida cell surface haem-binding proteins involved in haemin and haemoglobin-iron utilization. Mol Microbiol. 53 (4): 1209-20

Weissman Z., Shemer R. and Kornitzer D. (2002) Deletion of the copper transporter CaCCC2 reveals two distinct pathways for iron acquisition in Candida albicans. Mol Microbiol. 44 (6): 1551-60.

Wessling-Resnick M. (1999) Biochemistry of iron uptake. Crit Rev Biochem Mol Biol. 34 (5): 285-314.

White T. J., Bruns T., Lee S., and Taylor J.W. (1990) Amplification and direct sequencing of fungal ribosomal RNA genes for phylogenetics. Pages 315-322 . In: PCR Protocols: A Guide to Methods and Applications, Academic Press, Inc., New York

Wilson R.B., Davis D. and Mitchell A.P. (1999) Rapid hypothesis testing with Candida albicans through gene disruption with short homology regions. J Bacteriol. 181 (6): 1868-74

Wilson R.B., Davis D., Enloe B.M. and Mitchell A.P. (2000) A recyclable Candida albicans URA3 cassette for PCR product-directed gene disruptions. Yeast.16 (1): 65-70.

Wisplinghoff, H., Bischoff T., Tallent S.M., Seifert H., Wenzel R.P., and Edmond M.B. (2004) Nosocomial bloodstream infections in US hospitals: analysis of 24,179 cases from a prospective nationwide surveillance study. Clin. Infect. Dis. 39: 309-317.

Yin Q.Y., de Groot P.W., Dekker H.L., de Jong L., Klis F.M. and de Koster CG. (2005) Comprehensive proteomic analysis of Saccharomyces cerevisiae cell walls: identification of proteins covalently attached via glycosylphosphatidylinositol remnants or mild alkali-sensitive linkages. J Biol Chem. 280 (21): 20894-901.

Yin Q. Y., de Groot P.W.J., de Koster C.G. and Klis F. M. (2008) Mass spectrometry-based proteomics of fungal wall glycoproteins. Trends Microbiol., 16: 20-26.

Zakikhany K., Naglik J.R., Schmidt-Westhausen A., Holland G., Schaller M. and Hube B. (2007) In vivo transcript profiling of Candida albicans identifies a gene essential for interepithelial dissemination. Cell Microbiol. 9 (12): 2938-54.

Zhang N., Harrex A.L., Holland B.R., Fenton L.E., Cannon R.D. and Schmid J. (2003) Sixty alleles of the ALS7 open reading frame in Candida albicans: ALS7 is a hypermutable contingency locus. Genome Res. 13 (9): 2005-17

Zhao X, Oh S.H. and Hoyer L.L. (2007) Unequal contribution of ALS9 alleles to adhesion between Candida albicans and human vascular endothelial cells. Microbiology. 153 (Pt 7): 2342-50. 
Zhao X., Oh S.H., Cheng G., Green C.B., Nuessen J.A., Yeater K., Leng R.P., Brown A.J. and Hoyer L.L. (2004) $A L S 3$ and $A L S 8$ represent a single locus that encodes a Candida albicans adhesin; functional comparisons between Als3p and Als1p. Microbiology. 150 (Pt 7): 2415-28

Zhao X., Oh S.H., Yeater K.M. and Hoyer L.L. (2005) Analysis of the Candida albicans Als2p and Als4p adhesins suggests the potential for compensatory function within the Als family. Microbiology. 151 (Pt 5): 161930

Zhao X., Pujol C., Soll D.R. and Hoyer L.L. (2003) Allelic variation in the contiguous loci encoding Candida albicans ALS5, ALS1 and ALS9. Microbiology. 149 (Pt 10): 2947-60

Zheng M, Ramsay AJ, Robichaux MB, Norris KA, Kliment C, Crowe C, Rapaka RR, Steele C, McAllister F, Shellito JE, Marrero L, Schwarzenberger P, Zhong Q and Kolls JK. (2005) CD4+ T cell-independent DNA vaccination against opportunistic infections. J Clin Invest. 115 (12): 3536-44.

Zheng X., Wang Y. and Wang Y. (2004) Hgc1, a novel hypha-specific G1 cyclin-related protein regulates Candida albicans hyphal morphogenesis. EMBO J. 23 (8): 1845-56.

Zlotnik H., Fernandez M.P., Bowers B. and Cabib E. (1984) Saccharomyces cerevisiae mannoproteins form an external cell wall layer that determines wall porosity. J Bacteriol. 159 (3): 1018-26. 


\section{Appendix}

\section{Table 16. Homologs of Pga29p}

Species/proteins

Description

Identity in \%

E-value

\section{C. dubliniensis}

Cd36_43810
Cd36_43780
Cd36_43790
Cd36_24390
Cd36_72060
Cd36_46120
Cd36_72070
Cd36_46110
Cd36_62260
Cd36_05950

uncharacterized cell wall protein, putative

$2 \mathrm{e}-71$

uncharacterized cell wall protein, putative

uncharacterized cell wall protein, putative

$2 \mathrm{e}-30$

putative protein

$7 \mathrm{e}-22$

Candida conserved, putative

2e-21

conserved putative protein

3e-19

Candida conserved, putative

$4 \mathrm{e}-19$

conserved hypothetical protein

conserved hypothetical protein

putative

$1 \mathrm{e}-16$

$4 \mathrm{e}-13$

$3 e-05$

\section{C. guilliermondii}

PGUG_01942

predicted protein

6e-09

\section{C. tropicalis}

CTRG_00299.3

CTRG_00352.3

CTRG_00350.3

CTRG_00348.3

CTRG_03792.3

CTRG_00349.3

CTRG_02903.3

CTRG_03785.3

CTRG_03793.3

CTRG_04251.3

CTRG_02904.3

CTRG_04264.3

CTRG_04263.3

CTRG_04252.3

\section{C. lusitaniae}

CLUG_02844.1

\section{C. parapsilosis}

CPAG_04045.0

CPAG_04046.0

CPAG_00197.0

CPAG_00195.0

CPAG_00196.0

CPAG_00194.0

\section{D. hansenii}

\section{L. elongisporus}

LELG_04426

LELG_02548

LELG_05729

LELG_04428

LELG_ 04429 conserved hypothetical protein conserved hypothetical protein conserved hypothetical protein conserved hypothetical protein conserved hypothetical protein conserved hypothetical protein conserved hypothetical protein conserved hypothetical protein conserved hypothetical protein conserved hypothetical protein conserved hypothetical protein conserved hypothetical protein conserved hypothetical protein conserved hypothetical protein

conserved hypothetical protein

conserved hypothetical protein conserved hypothetical protein conserved hypothetical protein conserved hypothetical protein conserved hypothetical protein conserved hypothetical protein

hypothetical protein

conserved hypothetical protein conserved hypothetical protein conserved hypothetical protein conserved hypothetical protein predicted protein predicted protein 1e-31

$8 \mathrm{e}-27$

$1 \mathrm{e}-21$

$1 \mathrm{e}-14$

$1 \mathrm{e}-13$

$3 \mathrm{e}-13$

$8 \mathrm{e}-09$

$1 \mathrm{e}-13$

$4 \mathrm{e}-08$

2e-06

$1 \mathrm{e}-06$

$2 \mathrm{e}-05$

2e- 05

$7 \mathrm{e}-05$

1e-09

45

$4 \mathrm{e}-27$

$3 \mathrm{e}-28$

2e-16

$3 \mathrm{e}-15$

$7 \mathrm{e}-13$

$30 \quad 5 \mathrm{e}-09$ 2e-30

$4 \mathrm{e}-28$

9e-23

6e-20

2e-07

$4 \mathrm{e}-06$ 
Table 16. Continued.

\section{P. stipitis}

PICST_43383

hypothetical protein

\section{Table 17. Sensitivity against antimycotics.}

Sensitivity against antimycotics was tested by using the E-test format. The Apga29/4pga29 Apga29/Apga29/PGA29 cells were diluted to 0.5 McFarland units and were streaked out on RPMI agar medium supplemented with $0.05 \%$ methylene blue. E-test strips were laid on top of the agar medium and the plates were incubated for $24 \mathrm{hrs}$ at $35^{\circ} \mathrm{C}$. The minimal inhibitory concentrations were determined visually $(\mu \mathrm{g} / \mathrm{ml})$.

\begin{tabular}{l|cc} 
& Apga29/_pga29 & Apga29/_pga29/PGA29 \\
\hline Fluconazole & 0.5 & 0.5 \\
Intraconazole & 0.0275 & 0.023 \\
Voriconazole & 0.012 & 0.008 \\
5-Fluocytosin & 0.0275 & 0.032 \\
Amphotericin B & 0.047 & 0.0395 \\
Caspofungin & 0.125 & 0.125
\end{tabular}




\section{Curriculum vitae}

\section{Personal data}

Surname: de Boer

Names: Albert Daniël

Date of birth: February 16, 1979

Place of birth: Amsterdam, the Netherlands

E-mail: aboer@gwdg.de

\section{$\underline{\text { Scientific career and education }}$}

March 2004 - December 2008: Ph.D. Molecular Biology at the Georg-August-University

\section{Göttingen}

Dissertation title: Characterisation of the cell wall protein Pga29p in the human pathogenic fungus Candida albicans.

\section{Publications:}

de Boer A. D et al. (2008) In preparation .

Kaplanek P., de Boer A., Gross U., de Groot P., Hube B. and Weig M. (2006) FEMS Yeast Res., 6(8): 1290-4.

\section{September 1998 - February 2004: BSc and MSc at the University of Amsterdam}

\section{Publications:}

de Groot P.W., de Boer A.D., Cunningham J., Dekker H.L., de Jong L., Hellingwerf K.J., de Koster C. and Klis F.M. (2004) Eukaryot Cell., 3(4): 955-65.

Rep M., Dekker H.L., Vossen J.H., de Boer A.D., Houterman P.M., de Koster C.G. and Cornelissen B.J. (2003) FEBS Lett., 534(1-3): 82-6.

Rep M., Dekker H.L., Vossen J.H., de Boer A.D., Houterman P.M., Speijer D., Back J.W., de Koster C.G. and Cornelissen B.J. (2002) Plant Physiol., 130(2): 904-17. 